Ph.D. Thesis

Dynamic Force Measurement in Preformulation of Solid Dosage Forms

András Kelemen

Szeged

2012 


\author{
University of Szeged \\ Faculty of Pharmacy \\ Department of Pharmaceutical Technology
}

PhD Thesis

\title{
Dynamic Force Measurements in Preformulation of Solid Dosage Forms
}

\author{
By
}

András Kelemen

Supervisor:

Prof. Dr. Habil Klára Pintye-Hódi DSc

Szeged

2012 


\section{Publications related to the thesis:}

1. Kelemen, A., Szöllösi, A., Zsótér, A., Pintye-Hódi, K., Török, C., and Erős, I. (2002): Measurement of the swelling force of some sodium strach glycolate products with new software. Hung. J. Ind. Chem. Vol. 30 pp. 73-76 IF: 0,084

2. Muskó, ZS., Bajdik, J., Pintye-Hódi, K.,Szabó-Révész, P., Kelemen, A. and Erős, I. (2002).: Preparation of pellets containing theophylline. Pharm. Ind. 64. Nr.11. 1194-1198. IF:0,279

3. Bajdik, J., Pintye-Hódi, K., Novák, Cs., Kelemen, A.., Regdon Jr, G. and Erős, I. (2002): Indirect methods for determination of the protective effects of coating films on the surface of crystals. J. Therm. Anal. Calorim., Vol 68 613-627. IF:0,598

4. Kása Jr, P., Jójárt, I., Kelemen .A. and Pintye-Hódi, K. (2011): Formulation study of directly compressible chewable polymers containing ascorbic acid. Pharm. Dev. Tech. (DOI: 10.3109/10837450.2011.646426)

IF: 1,107

\section{Other publications}

5. Kelemen András, Pintye-Hódi Klára, Erős István (2004): Mérés-adatgyüjtő és jelfeldolgozó szoftverek fejlesztése a szilárd gyógyszerformák preformulációs vizsgálataiban. Acta Pharm. Hung. 74. 177-186.

6. Szalay, A., Kelemen, A., Kása Jr, P., Erős, I. and Pintye-Hódi, K. (2005): Effect of the particle size and shape parameters on the flow properties of sorbit. Eur. J. Pharm . Sci. 25; Suppl. 1., S192 - S194.

7. Bajdik, J., Bölcskei, É., Kelemen, A. and Pintye-Hódi, K. (2007): Rapid method to study the sedimentation of a pigment suspension prepared for coating fluids. J. Pharm. Biomed. Anal. 44. 1159-1162.

IF:2,76 
8. Bajdik, J., Baki, G., Kelemen,A. and Pintye-Hódi, K.: (2007): Formulation of longacting solid intravaginal matrix systems containing laxtic acid. Eur. J. Pharm. Sci. 32, Issue 1, Suppl. 1, 35.

9. Bajdik, J., Baki, G., Kelemen,A. and Pintye-Hódi, K.:(2008): The effect of wetting of powder mixture on the preparation of hydrophillic matrix granules with high-shear granulator. Chem. Eng. Res. Des. 86 1-7. IF:0,989

10. Baki, G., Bajdik, J. Kelemen, A. and Pintye-Hódi, K. (2009): Formulation of a solid intravaginal matrix system to prolong the $\mathrm{pH}$-decreasing effect of lactic acid. J. Drug. Del. Sci. Tech. 19 (2) 133-137.

IF:0,508

\section{Presentations}

1. J. Bajdik, É. Bölcskei, A. Kelemen, P. Szabó-Révész, K. Pintye-Hódi: Technological opportunities to improve the stability of a pigment suspension prepared for coating fluids. 5th World Meeting on Pharmaceutics Biopharmaceutics and Pharmaceutical Technology, Geneva, 27-30 March, 2006 PO 53 (March 30)

2. J. Bajdik, G. Baki, A. Kelemen, K. Pintye-Hódi: Formulation of longacting solid intravaginal matrix systems containing lactic acid. $2_{\text {nd }}$ BBBB Conference on Pharmaceutical Sciences, Tallin-Tartu, Estonia, 2007 


\section{Contents}

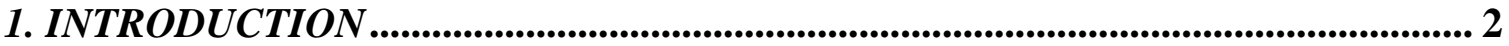

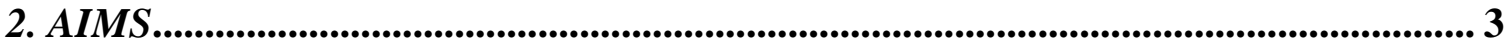

3. LITERATURE REVIEW OF BASIC CONCEPTS .............................................. 4

3.1. Computer-based data acquisition system ....................................................... 4

3.2. Characterization of tablet compaction data .................................................. 5

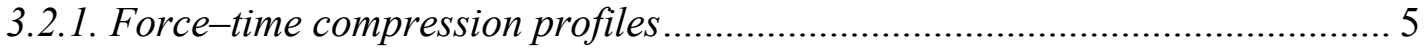

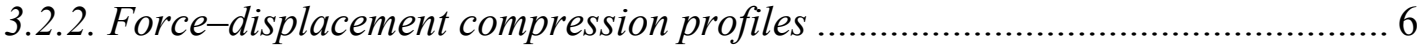

3.3. Characterization of tablet swelling.................................................................... 8

3.4. Deformation behaviour of solid dosage forms........................................... 9

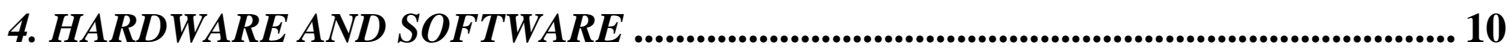

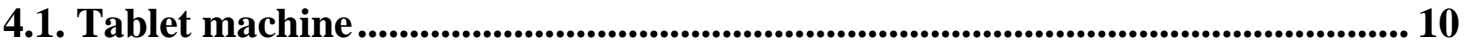

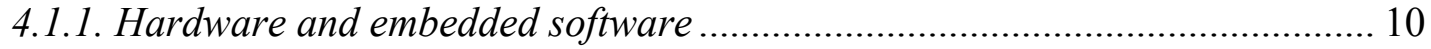

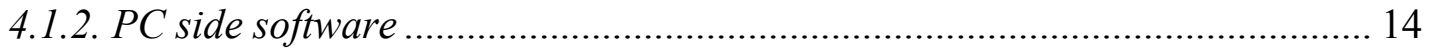

4.2. Swelling force tester ....................................................................................... 18

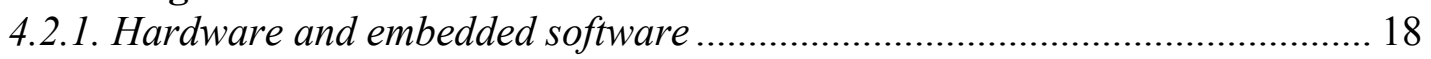

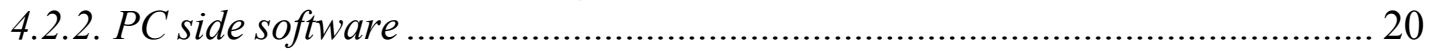

4.3. Hardness tester ......................................................................................................... 21

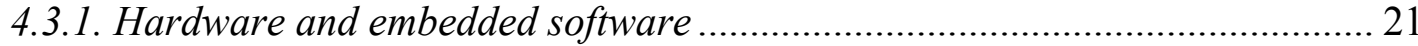

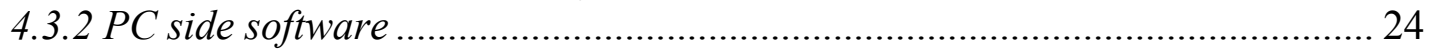

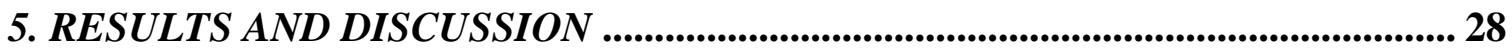

5.1. Study of the deformability process during loading............................................ 28

5.1.1. Deformability of medicated chewable polymers ......................................... 28

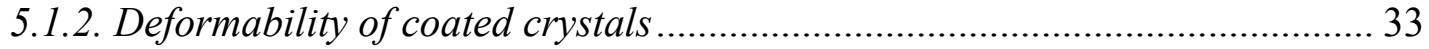

5.2. Study of swelling force profiles........................................................................ 36

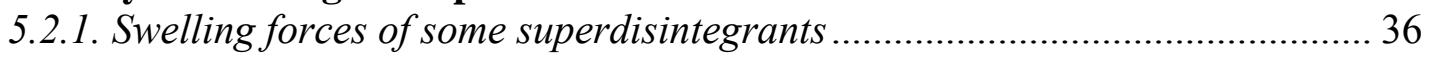

5.2.2. Swelling forces of swellable matrices ....................................................... 40

5.3. Measurement of breaking process of smaller particles ................................... 41

6. SUMMARY ................................................................................................................... 43

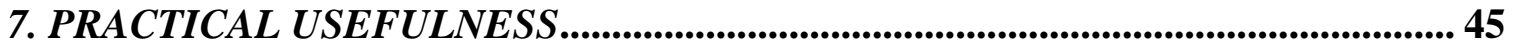

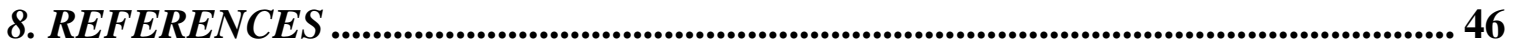




\section{INTRODUCTION}

Solid dosage forms, currently the most common dosage forms in pharmacy, contain not only the active pharmaceutical ingredient (API), but also various ingredients such as fillers, sweeteners, etc. During the manufacturing of tablets, application of the appropriate pressure is very important, as it influences the quality of the comprimates. Knowledge of the elasticity of polymer films used in the coating process and the deformability of granules and pellets is very important during tablet manufacturing. In the case of conventional tablets, the swelling behaviour influences the rate of disintegration, which determines the rate of dissolution of the API from the tablet. Knowledge of the swelling behaviour of swellable matrices is also important, for this plays a role in prediction of the dissolution profile.

Determination of the above mentioned physical parameters of solid dosage forms is based on the measurement of dynamic forces. In consequence of the nature of the task, computer-aided measurement and evaluation technology is required.

This dissertation focuses on force measurements involving the use of a digital computer. Such work demands the collaboration of a team consisting of a pharmacist, an electrical engineer, who prepares the equipment, and a software engineer, who connects the equipment to the computer and produces the appropriate software. 


\section{AIMS}

The overall aim of the work reported in this dissertation was the development of measurement and analysis systems with which to study the effects of forces during drug powder compaction, and also the deformation process and swelling behaviour of solid dosage forms, through use of a digital computer. The specific aims were:

- to develop a software system relating to the use of an instrumented tablet machine to measure punch forces and displacement during compression;

- to develop algorithms with which to evaluate compaction data profiles;

- to develop a software system to be used in conjuction with a swelling force tester in order to study the swelling behaviour of comprimates and tablets;

- to develop a software system with which to study the deformation behaviour of solid dosage forms during loading. 


\section{LITERATURE REVIEW OF BASIC CONCEPTS}

\subsection{Computer-based data acquisition system}

In this dissertation, computer-based data acquisition (DAQ) denotes the process in which physical signals (mechanical force, displacement, etc.) are transformed into digital electrical signals for processing by a digital computer. Figure.1. outlines the scheme of computer-based DAQ system

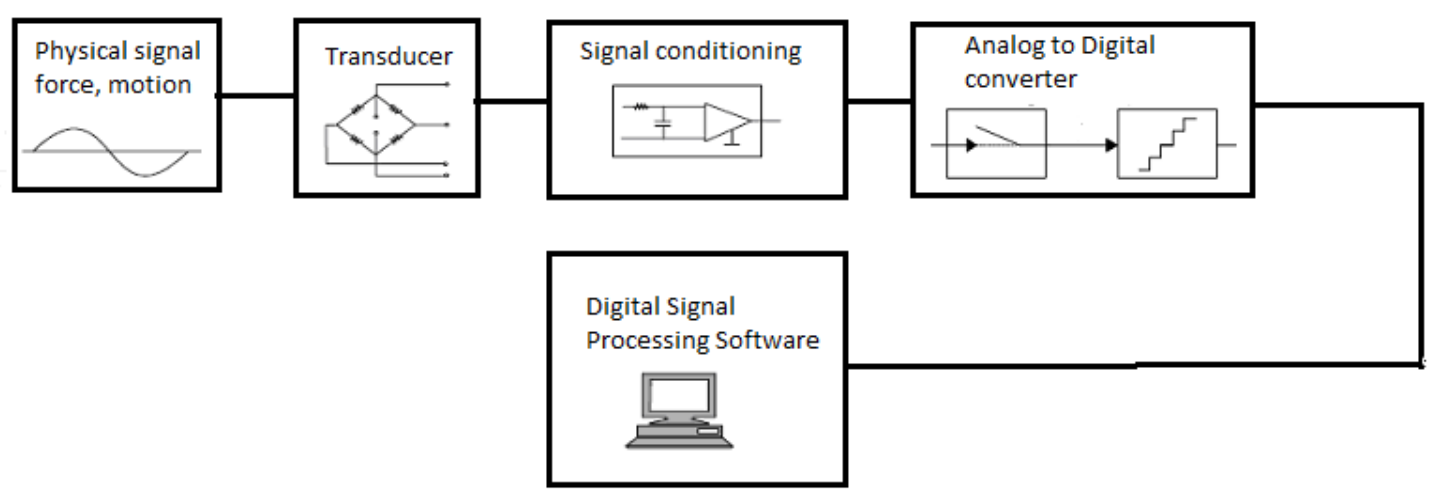

Figure 1. Outline of the DAQ system [1].

Brief explanations of the most important expressions will first be given. For more details of digital signal processing and the computer-based DAQ system, see [1-6].

A transducer converts the signal of one physical quantity into that of another. For the purpose of computer-based DAQ the transducer converts a physical signal into an electrical signal. A strain gauge is generally used as a transducer for the measurement of mechanical force or pressure. Linear variable differential transducers (LVDTs) are used to measure displacement.

Signal conditioning converts the electrical signals of transducers into an acceptable format for an analog to digital converter (ADC). This means amplification, linearization, and low pass filtering.

The $A D C$ unit converts band-limited electrical signals into a digital sequence. The conversion involves sampling and quantization processes as shown in Figure 2. 


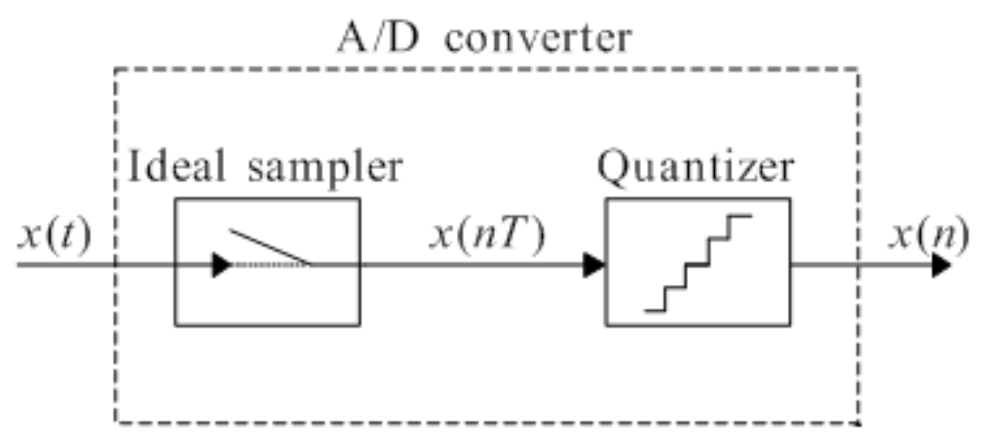

Figure 2. Block diagram for $\mathrm{AD}$ converter [2].

The sampling process produces a sequence of values from a continuously varying analog signal. The quantization process assigns a number to each sample from a sequence of values. The original analog signal is perfectly recoverable from the digital sequence if the Shannon sampling theory is satisfied $[1,2]$.

A digital signal processing unit stores and displays the digital sequence and applies signal-processing algorithms, which calculate the desired parameters from the digital sequence through different methods.

\subsection{Characterization of tablet compaction data}

Instrumented eccentric tablet machine is a suitable means of studying to the compression behaviour of various pharmaceutical powders. The main goal of such studies is to determine the plasticity of comprimates and the work or energy necessary for tableting. As concerns the instrumentation means the upper and lower punches are equipped with strain gauges and LVDTs. For details and a brief history of the instrumentation of tablet machines see $[7,8]$

\subsubsection{Force-time compression profiles}

Many parameters can be calculated from force-time profiles: the time when the punch impacts into the die, the maximum compression force, the residual force, the ejection force, the ejection time, the time for compression or decompression, the time to reach the maximum force, etc. For details, see Figure 11. 
Plasticity can be determined from the force-time profile through the following relationship (Emscherman and Müller [9]) (see Figure 3).

$$
P l_{E}=\frac{B}{A}
$$

where $A$ denotes the area of compression phase, and $B$ the area of the decompression phase.

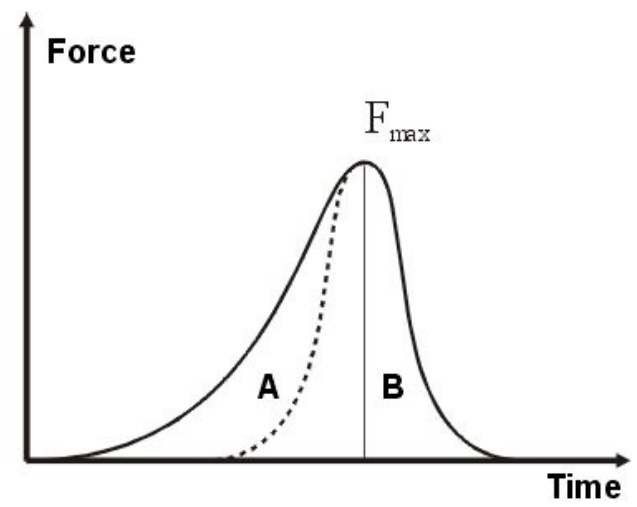

Figure 3. Illustrative schematic plot of upper punch force versus time during compression and decompression indicating the areas $A, B$ used in the characterization of the compression process.[34]

A low value of $P l_{E}$ is a sign of a more plastic deformation, while a high value points to elastic deformation.

\subsubsection{Force-displacement compression profiles}

Force-displacement diagrams (Figure 4.) are used to calculate the work or energy necessary for tableting from the areas enclosed. The force-displacement profile depicts the compression and postcompression of the powder to furnish the tablet. The area between the compression and postcompression curves is the area of the compaction energy, often called the energy of plastic deformation $\left(E_{2}\right)$. Area $E_{3}$ is the energy of elastic deformation, and area $E_{1}$ is the lost energy, which can be interpreted as the energy of friction between the particles. 


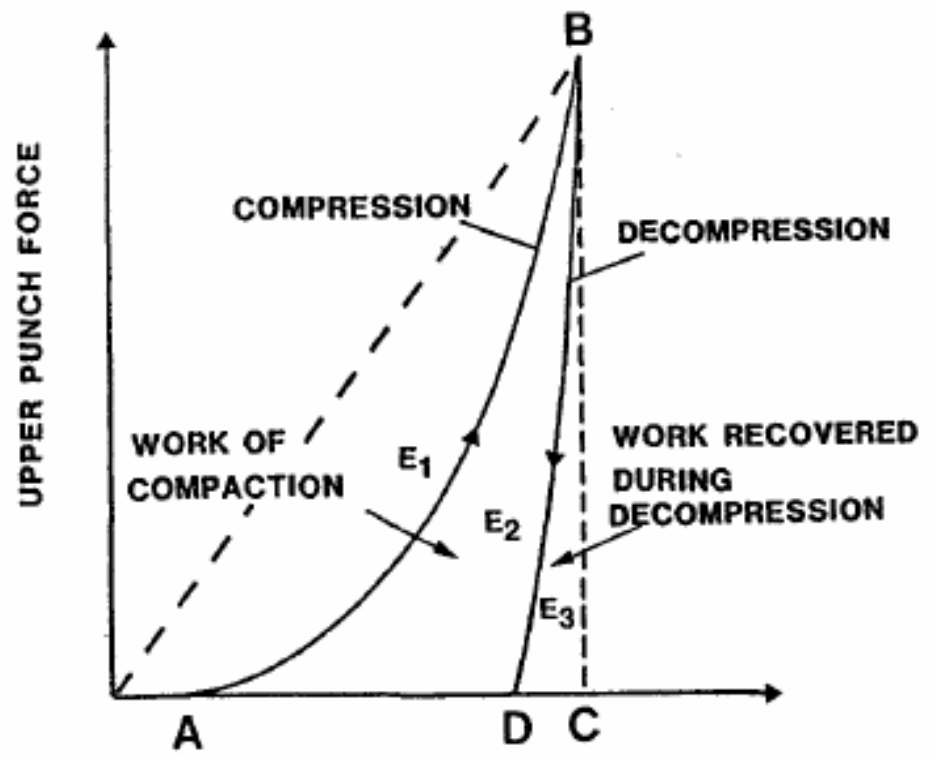

UPPER PUNCH DISPLACEMENT

Figure 4. Illustrative plot of upper punch force versus upper punch displacement during compression and decompression indicating the different areas $\left(\mathrm{E}_{1}-\mathrm{E}_{3}\right)$ used in the characterization of the compression process [10].

The sum of all three energies is the total energy of tableting. From these values the plasticity $P l_{\mathrm{SM}}($ Stamm-Mathis [11]) is calculated as

$$
P l_{S M}=\frac{E_{2}}{E_{2}+E_{3}} 100 \%
$$

The die wall friction influences the compaction of the powder. Since the frictional coefficient between the powder and the die wall is often not known, Järvinen and Juslin [12] developed Eq. 3 for determination of the work of friction.

$$
W_{f}=\int_{A}^{c}\left\{F_{u p}-\left(F_{u p}-F_{l p}\right) / \ln \left(F_{u p} / F_{l p}\right)\right\} d s
$$

where $F_{u p}$ is the upper punch force, and $F_{l p}$ is the lower punch force. 


\subsection{Characterization of tablet swelling}

When conventional tablets are applied, the rapid disintegration is very important. Various forces play roles in this process, the main one being the swelling force $F_{s}$ formed in the tablet during the uptake of water [13-17].

Conventional tablets always contain disintegrants which promote rapid disintegration of the tablets. The swelling kinetics of these disintegrants can most commonly be described with the RRSBW (Rosin-Rammler-Sperling-Bennett-Weibull) distribution (Eq. 4.) [18, 19].

$$
F(t)=F_{\infty}\left(1-e^{-\frac{(t-T)^{\beta}}{a}}\right)
$$

where $F(t)$ is the swelling force as a function of time $t, F_{\infty}$ is the maximum value of the swelling force, $T$ is the lag time, $a$ is a scale parameter that describes the time dependence, and $\beta$ describes the shape of the curve.

For $\beta=1$, the shape of the curve corresponds exactly to the shape of an exponential profile with constant $k=1 / a$. This implies first-order kinetics in the swelling process:

$$
F(t)=F_{\infty}\left(1-e^{-k(t-T)}\right)
$$

For $\beta=0$, the equation is

$$
F(t)=F_{\infty}\left(1-e^{-\frac{1}{a}}\right)
$$

For $\beta<1$, this fast swelling is observed at the beginning of the process, followed by a slower process.

For $(t-T)^{\beta}=a$, the equation is

$$
\frac{F(t)}{F_{\infty}}=1-e^{-\frac{a}{a}}=1-e^{-1}=0.632
$$

where $a=t_{63.2 \%}$ is a characteristic swelling time.

Another type of tablets, swelling matrix tablets, often exhibit swelling kinetics profiles that can not be described with the RRSBW distribution. 


\subsection{Deformation behaviour of solid dosage forms}

The hardness of a tablet is determined by the force required to break it in a diametrical compression test. The tensile strength $\sigma_{x}$ of a tablet is defined by the Newton-Fell equation [20]:

$$
\sigma_{x}=\frac{2 \cdot F}{\pi \cdot D \cdot t}
$$

where $D$ is the diameter, $F$ is the force and $t$ is the thickness of the tablet. 


\section{HARDWARE AND SOFTWARE}

\subsection{Tablet machine}

\subsubsection{Hardware and embedded software}

The equipment used to measure the compressibility of pharmaceutical powders was prepared on the basis of Fig 5.

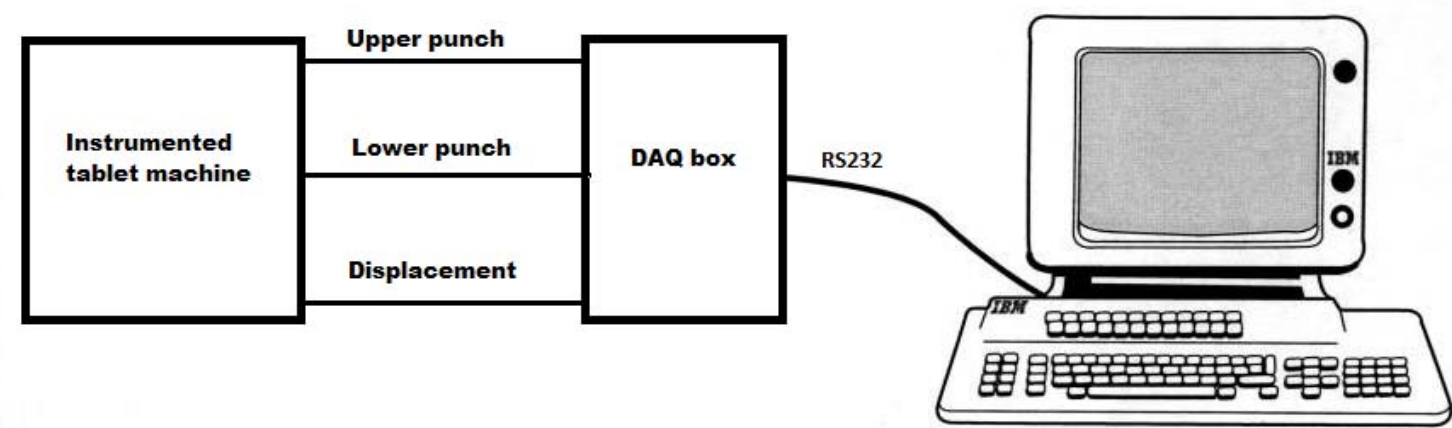

Figure 5. Setup for the instrumented tablet machine

The instrumented Korsch EK0 eccentric tablet machine (Emil Korsch Maschinenfabrik, Berlin, Germany) was used (Figure 6. ). 


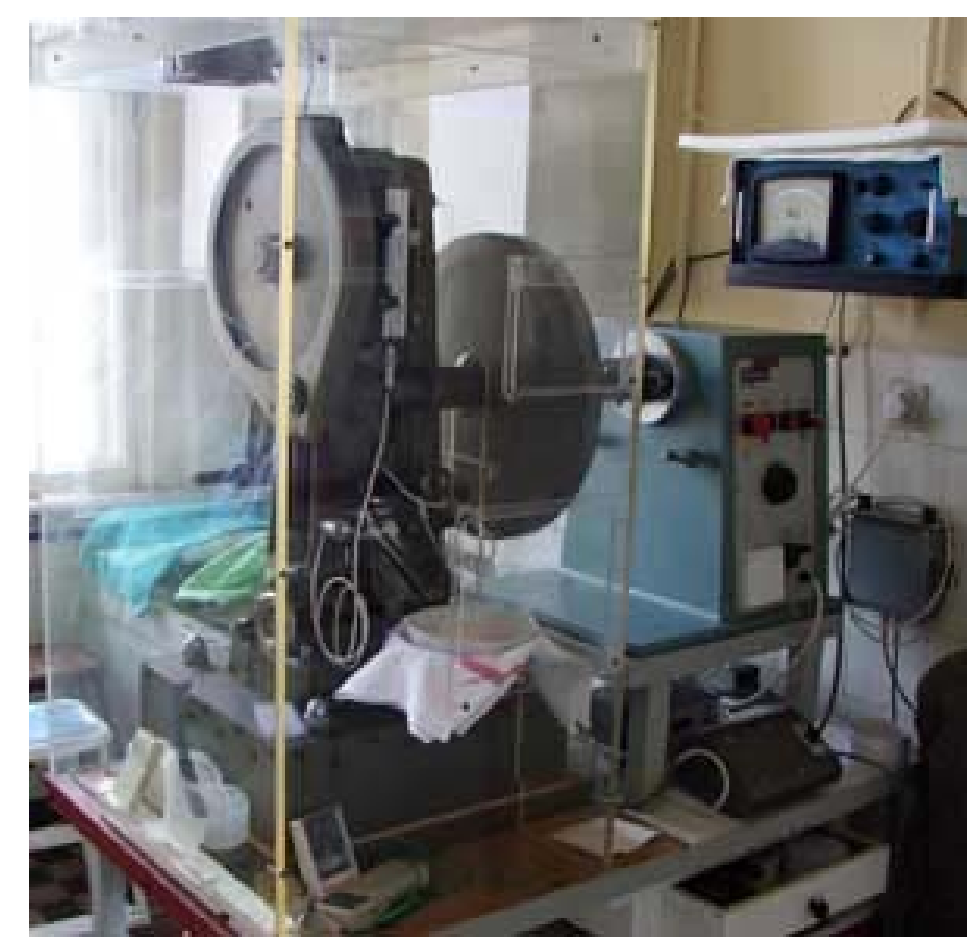

Figure 6. The instrumented Korsch EK0 eccentric tablet machine

The upper and lower punch compression forces were measured with strain gauges (Figure 7.) arranged in a full Wheatstone bridge. The upper punch displacement was measured through the use of LVDT. The strain gauges were calibrated with a Wazau HM-HN-30 kN-D cell (Kaliber Ltd., Budapest, Hungary).

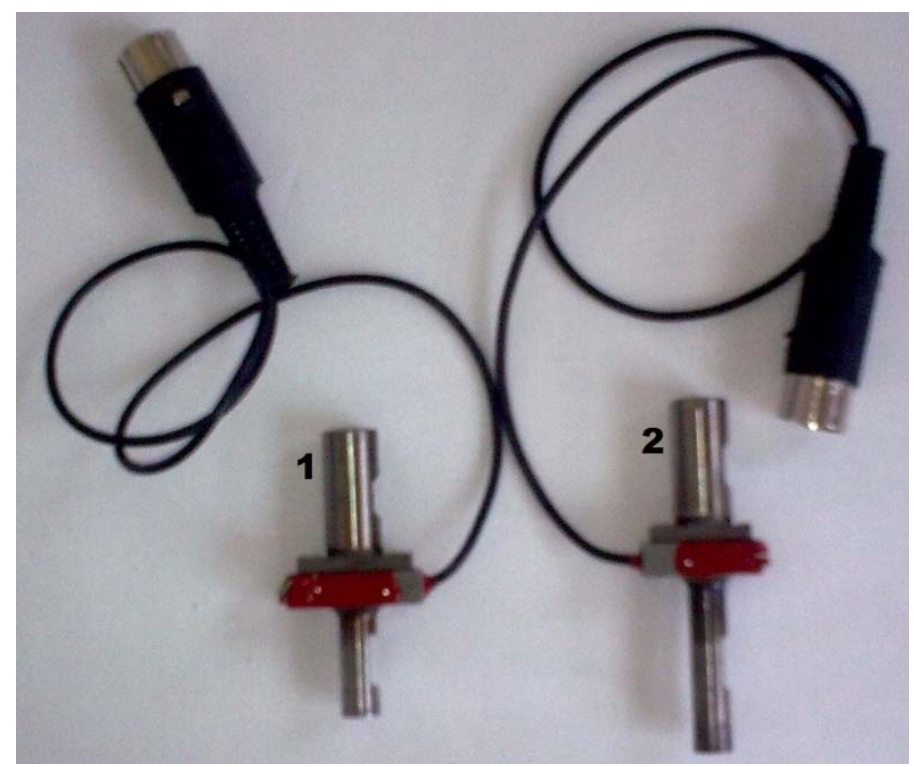

Figure 7. Upper (1) and lower (2) punches equipped with strain gauges. 
The displacement transducer was fitted over the upper punch (Figure 8). The transducer displacement accuracy was checked by using five measuring pieces (made of hardened steel) with different thicknesses $(2.0,5.0,7.5,10.0$ and $15.0 \mathrm{~mm})$ under a minimal measurable load (Mitutoyo, Tokyo, Japan).

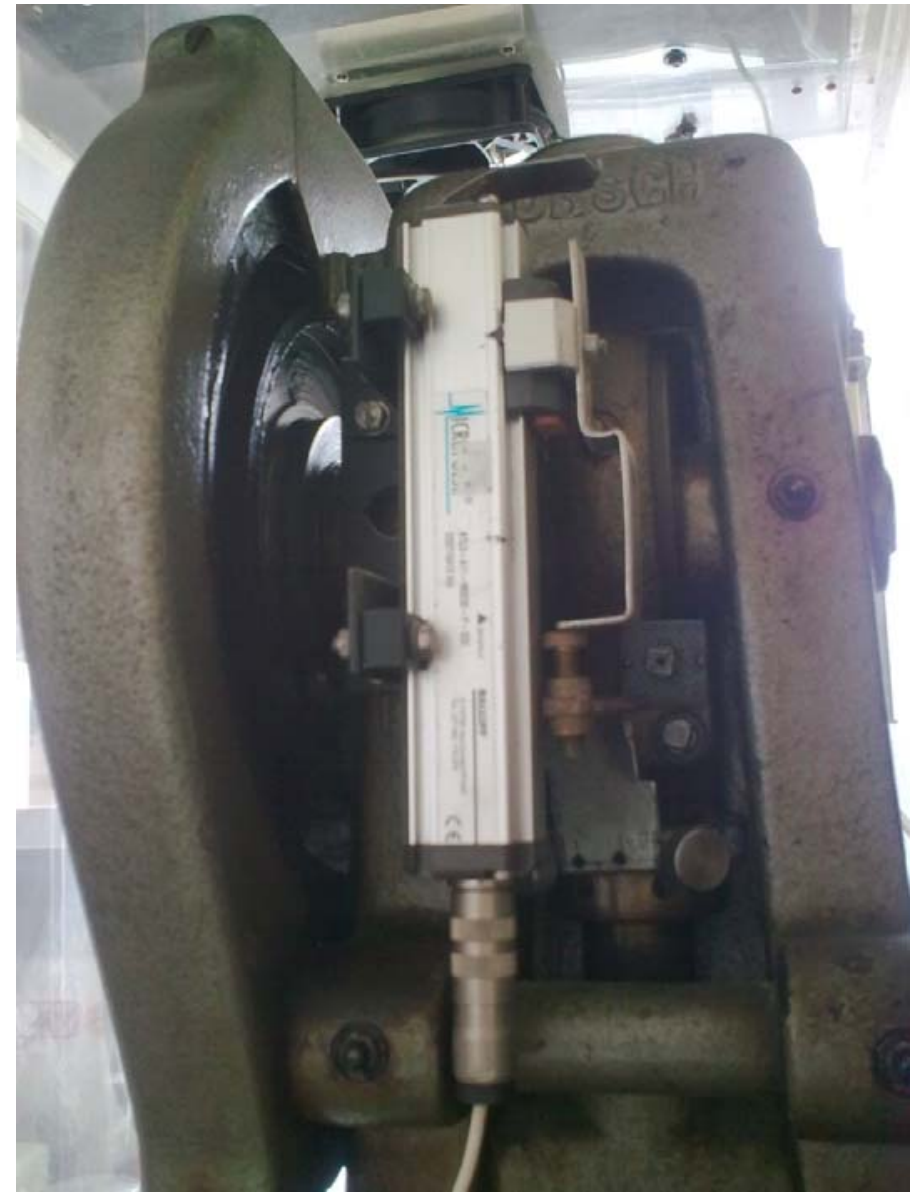

Figure 8. The built in displacement transducer

The strain gauges and the LVDT were connected to the DAQ box (Figure 9), based on a PIC16F871-I/P microcontroller [21]. The upper punch strain gauge, the lower punch strain gauge and the LVDT were connected to the ADC channel 0, channel 1 and channel 2, respectively. The resolution of the applied ADC was 13 bits. To filter the analog signals of the transducers, the DAQ box uses Butterworth filters [22-24]. The DAQ box is linked to a PC via an RS232 cable (connection parameters: 33600 baud, 8 data bits, 1 stop bit, no parity). The embedded software of the DAQ box was written in C language [25-27]. 


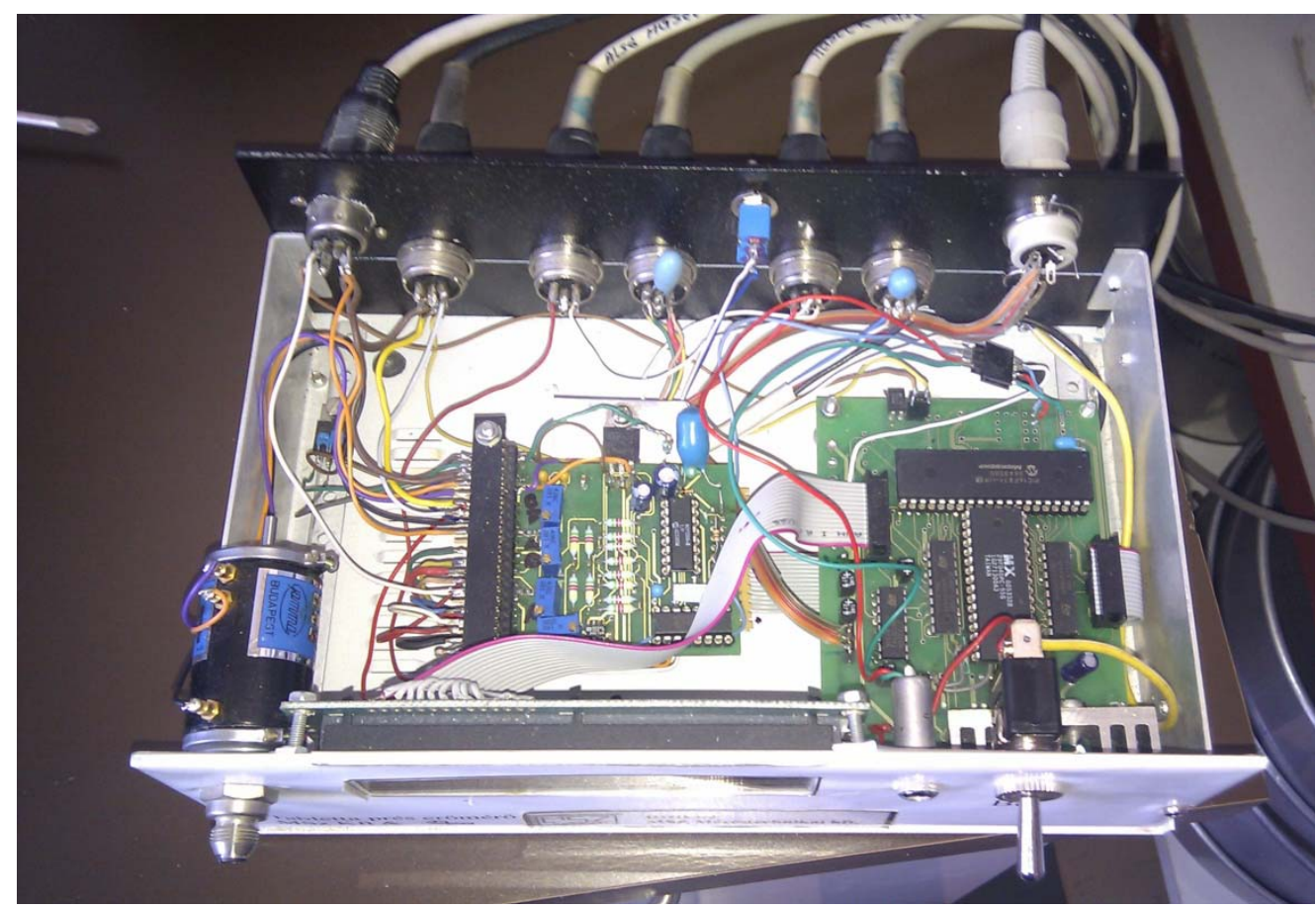

Figure 9. The DAQ box of the tablet machine.

When the tablet is ejected from the die the lower punch operates a switch, which generates a "cycle end" signal to the DAQ unit. The software of the DAQ box uses the timer interrupt routine to start the DAQ from the ADC channels. When the ADC has completed the conversion, its interrupt routine puts the data into the transmitter buffer and sets the serial transmitter flag, which activates the serial interrupt routine. The serial interrupt routine reads all of the available data from the transmitter buffer, sends them to the PC, and clears the serial transmitter flag. The communication protocol between the PC and DAQ box is as follows:

where

\begin{tabular}{|l|l|l|l|l|l|l|}
\hline STX & COM & LEN & DATA0,DATA1,DATA2 & ADD & XOR & ETX \\
\hline
\end{tabular}

- $\operatorname{STX}(1$ byte) is the start of the frame (its value is $03 \mathrm{~h}$ )

- $\operatorname{COM}(1$ byte) is the command (F0h or F1h). F0h denotes the data frame and F1h the control frame.

- $\operatorname{LEN}(2$ byte) is the length of the frame in bytes. 
- DATA0, DATA1 and DATA2 are the values of the upper punch, lower punch and displacement, respectively.

- $\operatorname{ADD}(2$ bytes) is the control summa.

- XOR (2byte) is the control xor (exclusive or) value.

- $\operatorname{ETX~(~} 1$ byte) is the end of the frame (its value is $02 \mathrm{~h}$ )

The structure of the control frame is as follows:

\begin{tabular}{|l|l|l|l|l|}
\hline STX & COM & ADD & XOR & ETX \\
\hline
\end{tabular}

When the DAQ box detects "cycle end" signal during the measurement process, it sends control frame to PC; otherwise, it sends data frames.

\subsubsection{PC side software}

The PC side software was written in $\mathrm{C}++$ [28]. During the DAQ, the PC side software displays and saves data. Its DAQ algorithm reads the frames from the serial port. If the frame is the control frame, the routine saves the data to disk, initializes the buffers and drawing controls; otherwise, it displays and adds the data to the storing buffer. Figure 10 displays upper punch displacement, upper punch force and lower punch force curves during the DAQ. 


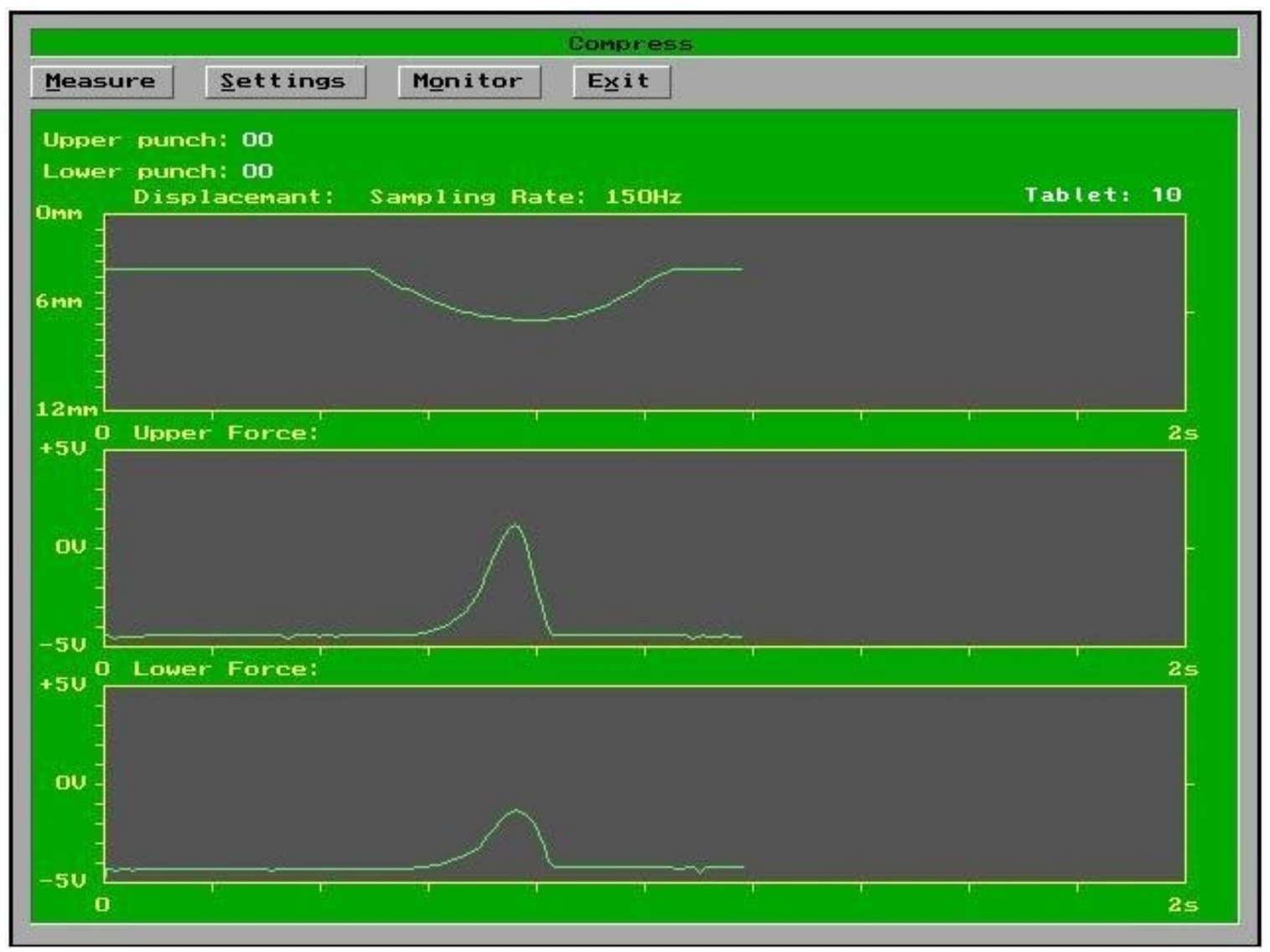

Figure 10. Screenshot of PC side software during the DAQ (AVICEL PH-101).

The software has a wide range of possibilities to show and evaluate the force and displacement signals, e.g. display force-time, displacement-time and force-displacement curves (Figs 11 and 12.), and it calculates the compression parameters in a manner dependent on the display profiles. 


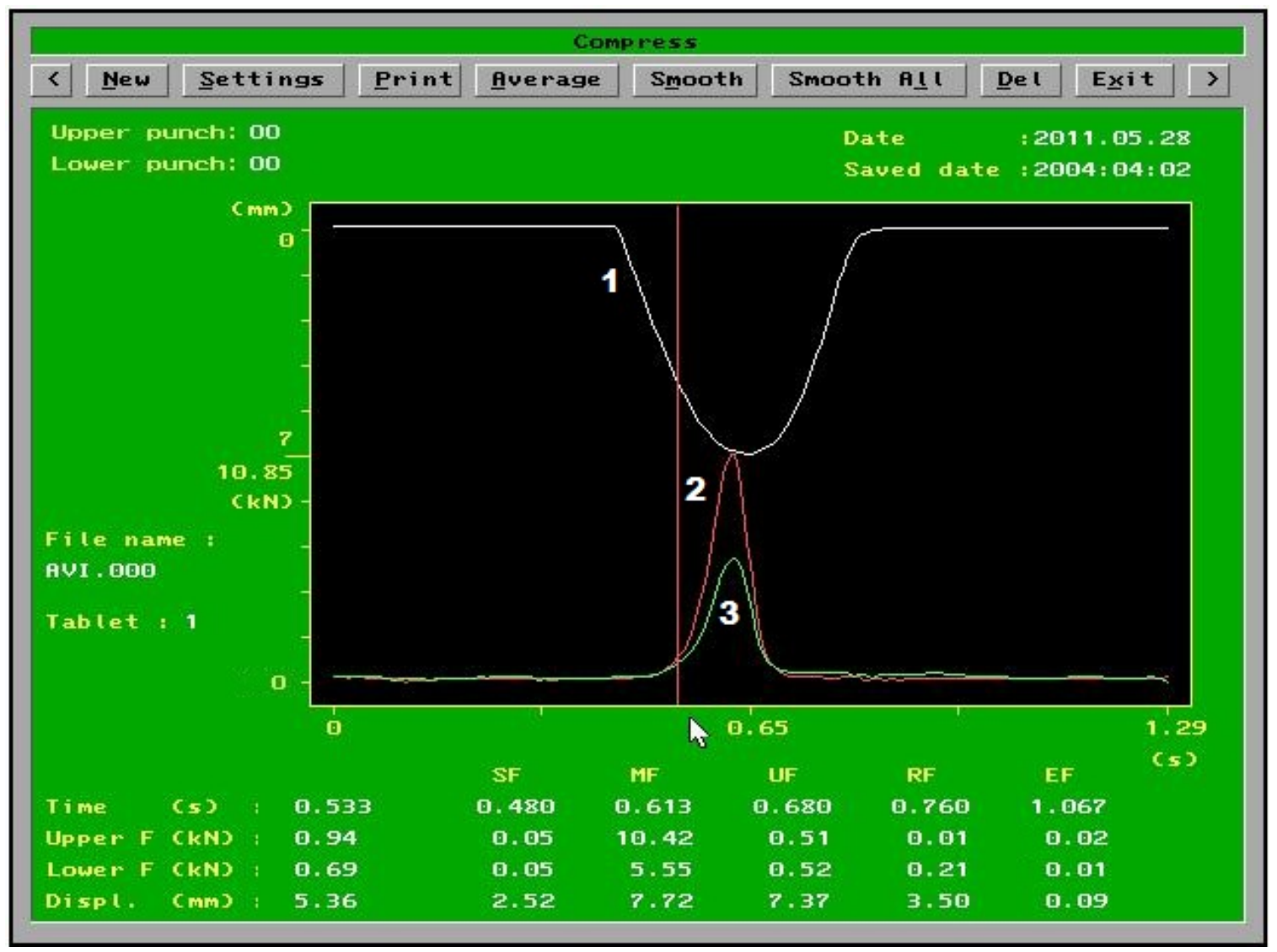

Figure 11. Screen shot of force-time, displacement-time curve analysis (AVICEL PH-101); 1. displacement-time, 2. upper punch force-time, 3. lower punch force-time diagrams. SF: the time in seconds when the upper punch impacts into the die, MF: the maximum upper punch force, UF: the time in seconds when the upper punch leaves the die. RF: the residual force, EF: the ejection force.

It is often seen that the compression force reaches its maximum value before the upper punch reaches its maximum distance, as shown in Figure 11. This effect occurs in consequence of the stress relaxation of the powder. This is a characteristic feature of solids that exhibit plastic deformation behaviour during compression. 


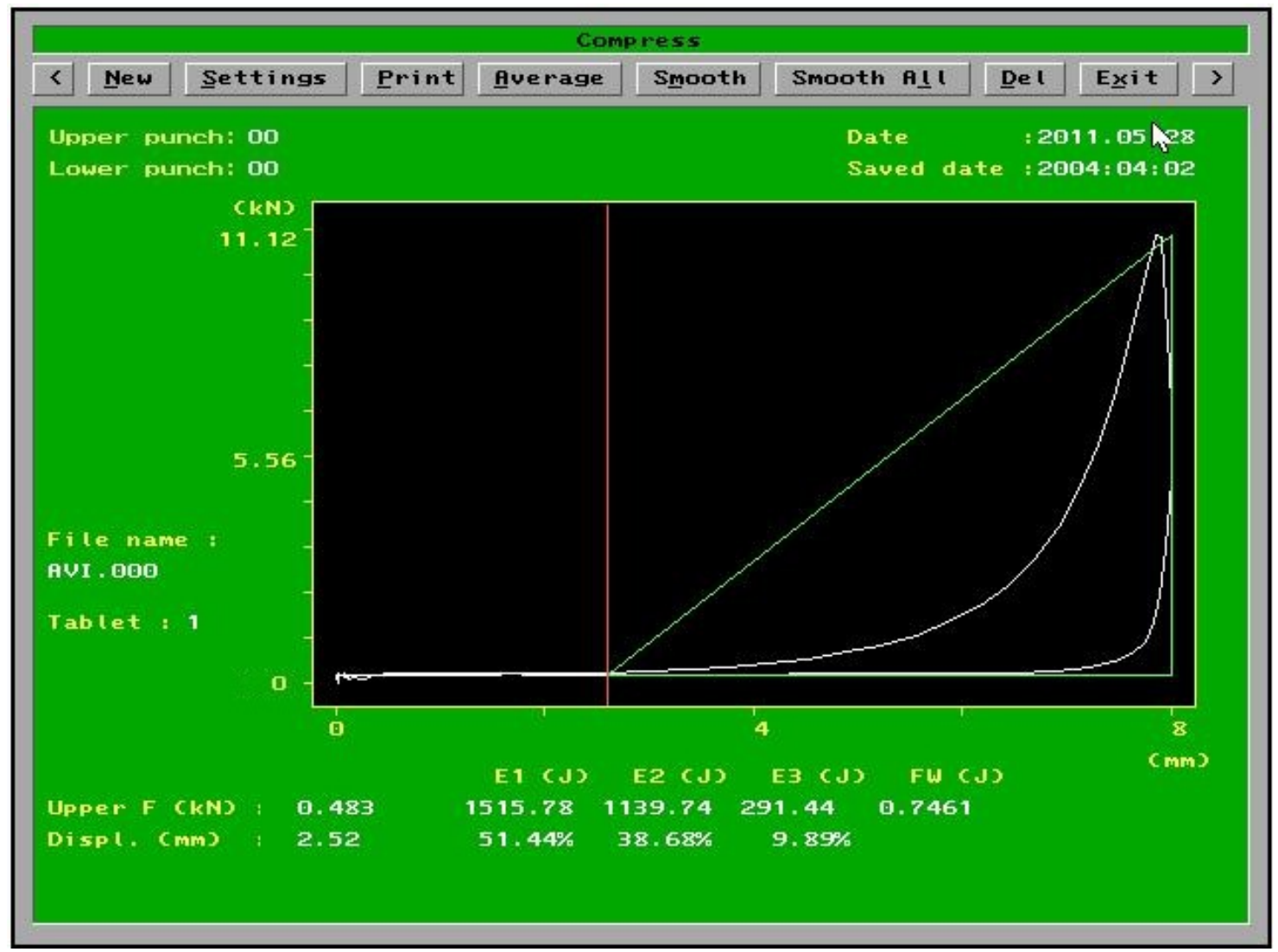

Figure 12. Screen shot of force-displacement curve analysis (AVICEL PH-101). E1: Energy lost by rearrangement of the particles during compression; E2: Energy of compaction; E3: Energy recovered during decompression; FW: $W_{f}$. For details, see the text.

In the case of the force displacement profile, energies E1, E2 and E3 are calculated via the following formulae respectively (for the bounds of the integrals see Figure 4) [51]:

$$
\begin{aligned}
& E 1=\frac{F_{\max } C}{2}-(E 2+E 3) \\
& E 2=\int_{A}^{B} F_{\text {upper }} d s-E 3 \\
& E 3=\int_{B}^{D} F_{\text {upper }} d s
\end{aligned}
$$

where $F_{\max }$ is the maximum value of the upper force during the compression, and $C$ is the displacement at maximum upper force. The $W_{f}$ work of friction is calculated via Eq. 3 . 


\subsection{Swelling force tester}

\subsubsection{Hardware and embedded software}

The equipment used to measure the swelling force $\left(F_{s}\right)$ was prepared on the basis of Figure 13.
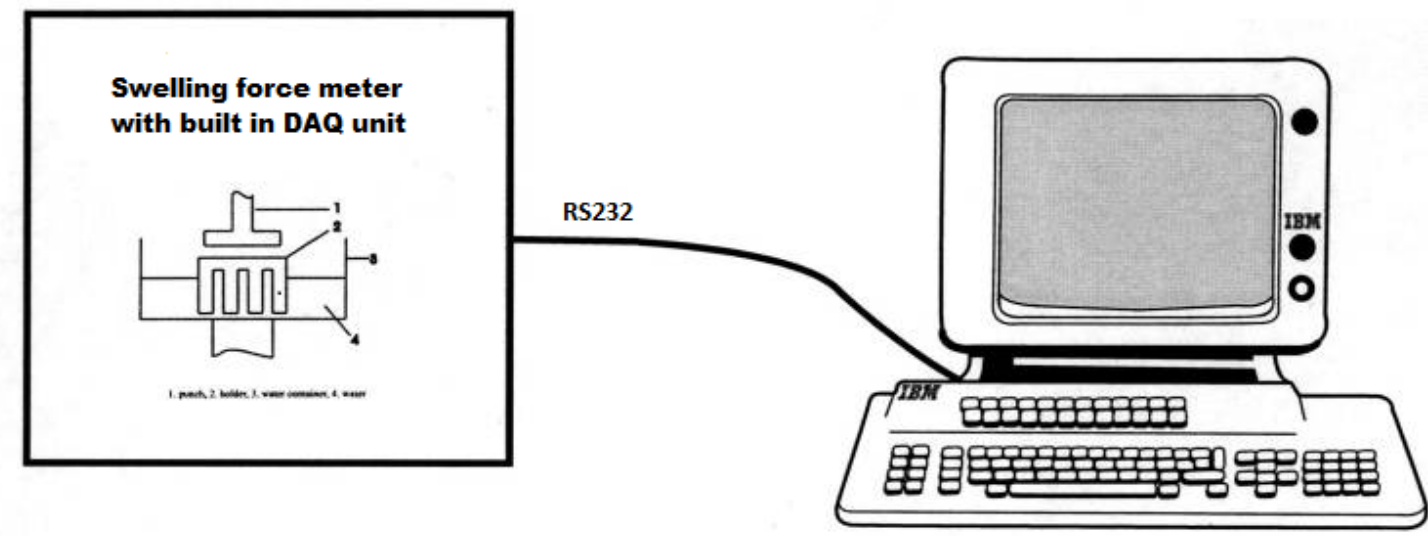

Figure 13. Setup of $F_{s}$ meter

The measurement is performed with a Sartorius microbalance with electronic compensation, which is built into the equipment with the DAQ hardware [37,38]. The built in DAQ unit is based on PIC16F871-I/P microcontroller. The Sartorius balance and the temperature sensor are connected to ADC channel 0 , channel 1 , respectively. The equipment is linked to a PC via an RS232 cable as shown in Figure 13, (connection parameters: 38400 baud, 8 data bits, 1 stop bit, no parity). The communication protocol between the PC and the DAQ unit is as follows: 


\section{\begin{tabular}{|l|l|l|}
\hline STX & DATA0,DATA1,DATA2 & ETX \\
\hline
\end{tabular}}

where

- $\operatorname{STX~(1~byte)~is~the~start~of~the~frame~(its~value~is~} 55 \mathrm{~h}$ ).

- DATA0 is the baseline value.

- DATA1 is the value of $F_{s}$.

- DATA2 is the temperature.

- $\operatorname{ETX~(1~byte)~is~the~end~of~the~frame~(its~value~is~} 41 \mathrm{~h})$.

The tablet holder is a copper cylinder $10 \mathrm{~mm}$ in diameter with slits in the side, into which a copper punch with the same diameter is fitted. The tablet holder is in a copper cup. A tablet is placed into the holder and $5 \mathrm{ml}$ of distilled water is injected into the water holder of the device at the start of the measurement, the device then heating the injected water to a set temperature. After this it drains off the water into the tablet holder. The water penetrates into the tablet through the slits. The force that builds up inside the comprimate as it absorbs the water is transmitted vertically and is detected by the balance (Figure 14).

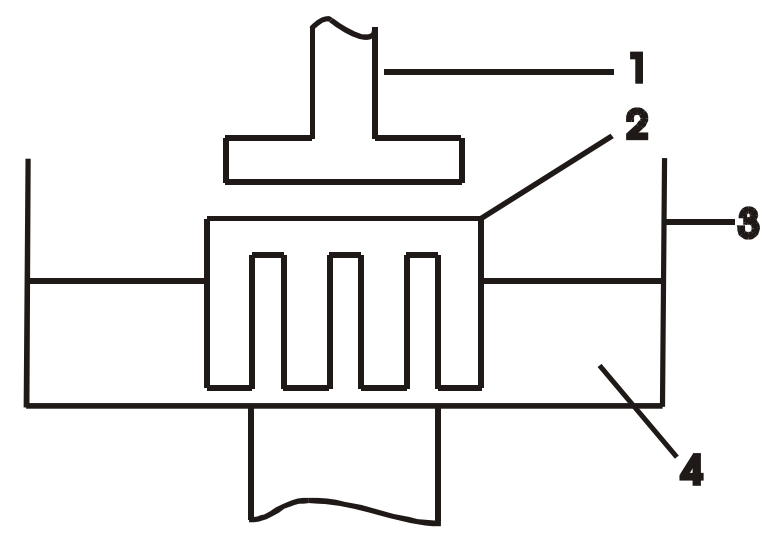

Figure 14. 1. punch, 2. holder, 3. water container, 4.water.

During the measurement, the embedded software uses the timer interrupt for the DAQ from the ADC channels. 


\subsection{2. $P C$ side software}

The software offers a broad array of possibilities through which to illustrate and evaluate the $F_{s}$ versus time curves with the important parameters (time, $F_{s}$, baseline, $\mathrm{t}_{63.2 \%}$, and $\mathrm{dF} / \mathrm{dt}$ ) exemplified in Figure 15.

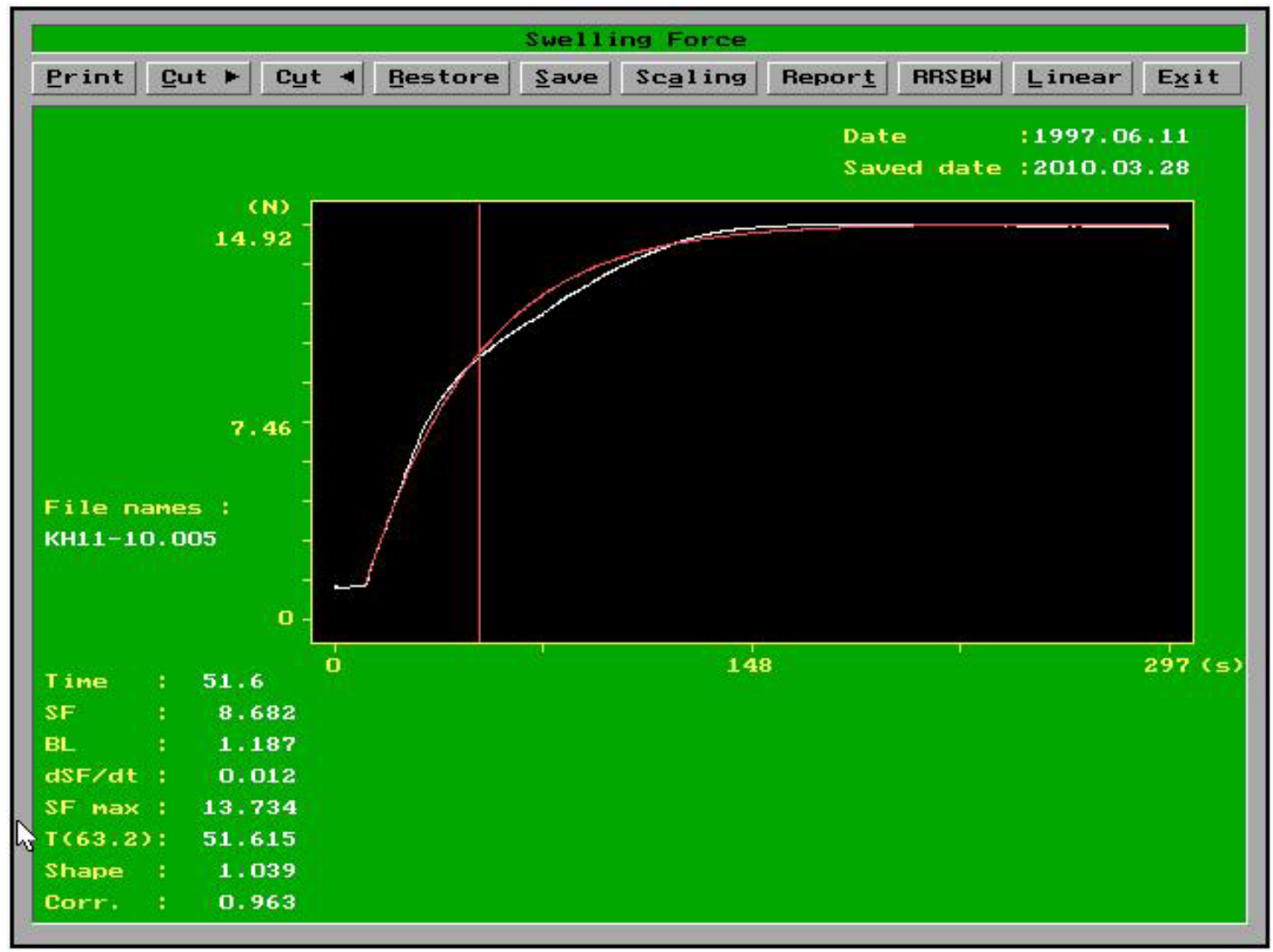

Figure 15. Screenshot of $F_{s}$ curve.

Curve: white is the force-time curve, Curve: red is the RRSBW curve fitted to the force-time curve. SF: $F_{s}, \mathbf{B L}$ : baseline, $\mathbf{d S F} / \mathbf{d t}$ : derivation of $F_{s}$ at the position of the cursor. SF max: maximum value of $F_{s}, \mathbf{T}(\mathbf{6 3 . 2})$ : the characteristic swelling time, Shape: shape parameter $(\beta)$, Corr: correlation coefficient

Rearrangement of Eq. 4 we obtain the following linear equation

$$
\ln \left(-\ln \left(1-\frac{F(t)}{F_{\infty}}\right)\right)=\beta \ln (t-T)-\ln a
$$


where the shape parameter $\beta$ is obtained from the slope of the line and the scale parameter $a$ estimated from the ordinate value. The characteristic swelling time $\left(\mathrm{t}_{63.2 \%}\right)$ and shape parameter are calculated from Eq. 12. by linear fitting.

Figure 16 shows the innovated $F_{s}$ tester.

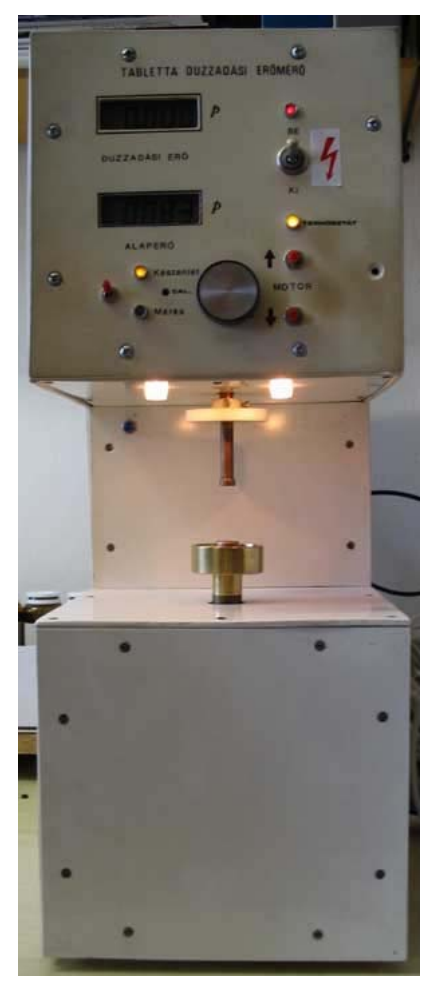

Figure 16. $F_{s}$ meter

\subsection{Hardness tester}

\subsubsection{Hardware and embedded software}

The equipment used to measure the deformation behaviour of solid dosage forms was prepared on the basis of Figure 17. This hardness tester is a modified version of the Chinoin breaking hardness tester (Chinoin Chemical and Pharmaceutical Works, Budapest Hungary). Technical parameters:

- range of measurment : 0-200 N

- rate of pressing jaw: $20 \mathrm{~mm} / \mathrm{min}$ 
- registering output: 0-500 $\mathrm{mV}$

- force sensor: Unicell load cell (MIKI) $20 \mathrm{~kg}$

With change of the pressure jowl and the sampling holder, the equipment is appropriate for measurements of the hardness of pellets and the tensile strength of films. With this equipment, the start of the DAQ is controlled manually, because the pressure jowl must be positioned exactly to the surface of the material. The end of DAQ is also controlled manually too, because the breaking point of the more elastic materials (e.g. films), can not be detected exactly.

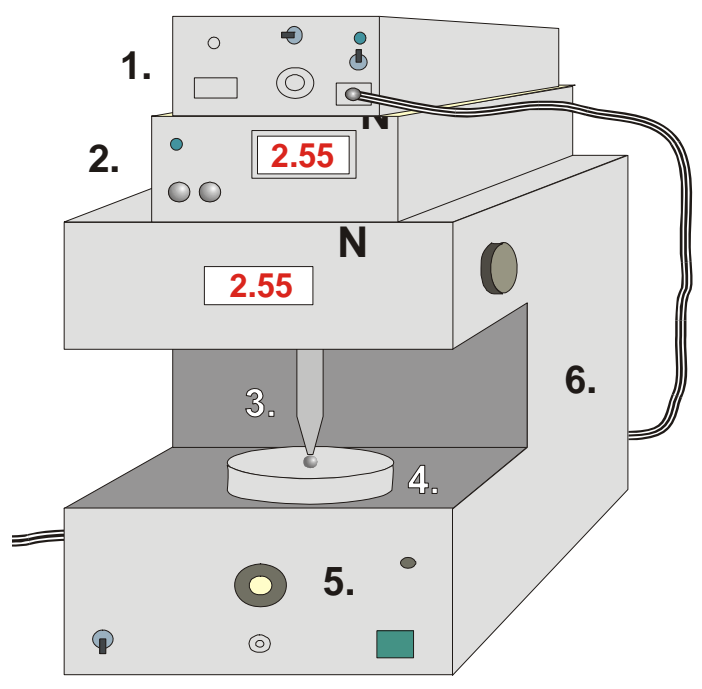

(a)

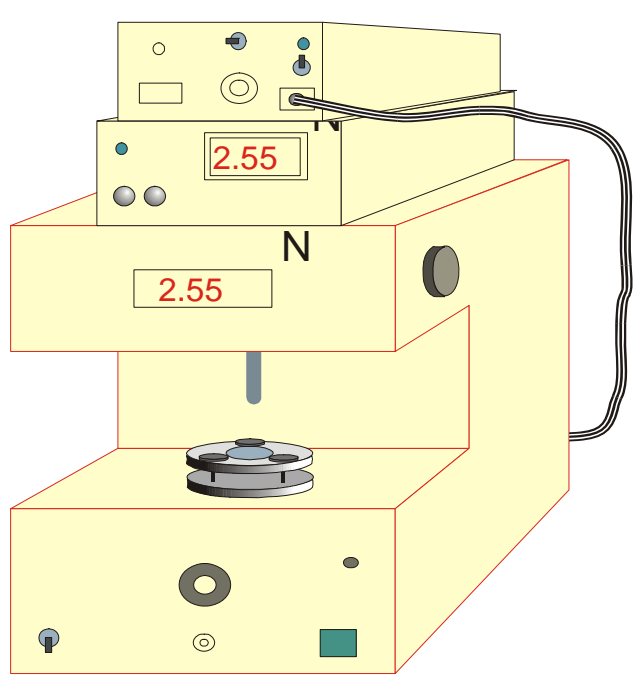

(b)

Figure 17. Outline of hardness tester. (a) suitable for tablets and pellets, (b) suitable for polymer films, [34] 1: DAQ unit; 2: current force display; 3: pressure jowl; 4: sampling holder; 5: force measurement unit; 6 : motor and analog velocity control for pressure jowl.

The pressure is measured through use of a Unicell load cell. The displacement of the pressure jowl is measured by using LVDT. The load cell and the LVDT are connected to the DAQ box (Figure 18), which is based on Silicon Laboratories C8051F124 microcontroller developing kit. It has a built-in ADC (resolution is 12 bits). To filter the analog signals of the transducers the DSP box uses Butterworth filters [22 24]. The DAQ box is linked to a PC by RS232 cable, (connection parameters: 115200 baud, 8 data bits, 1 stop bit, no parity). 
The pressure signal, the signal of the displacement of the pressure jowl and the measurement on-off switch are connected to ADC channel 0, channel 1 and channel 2, respectively.

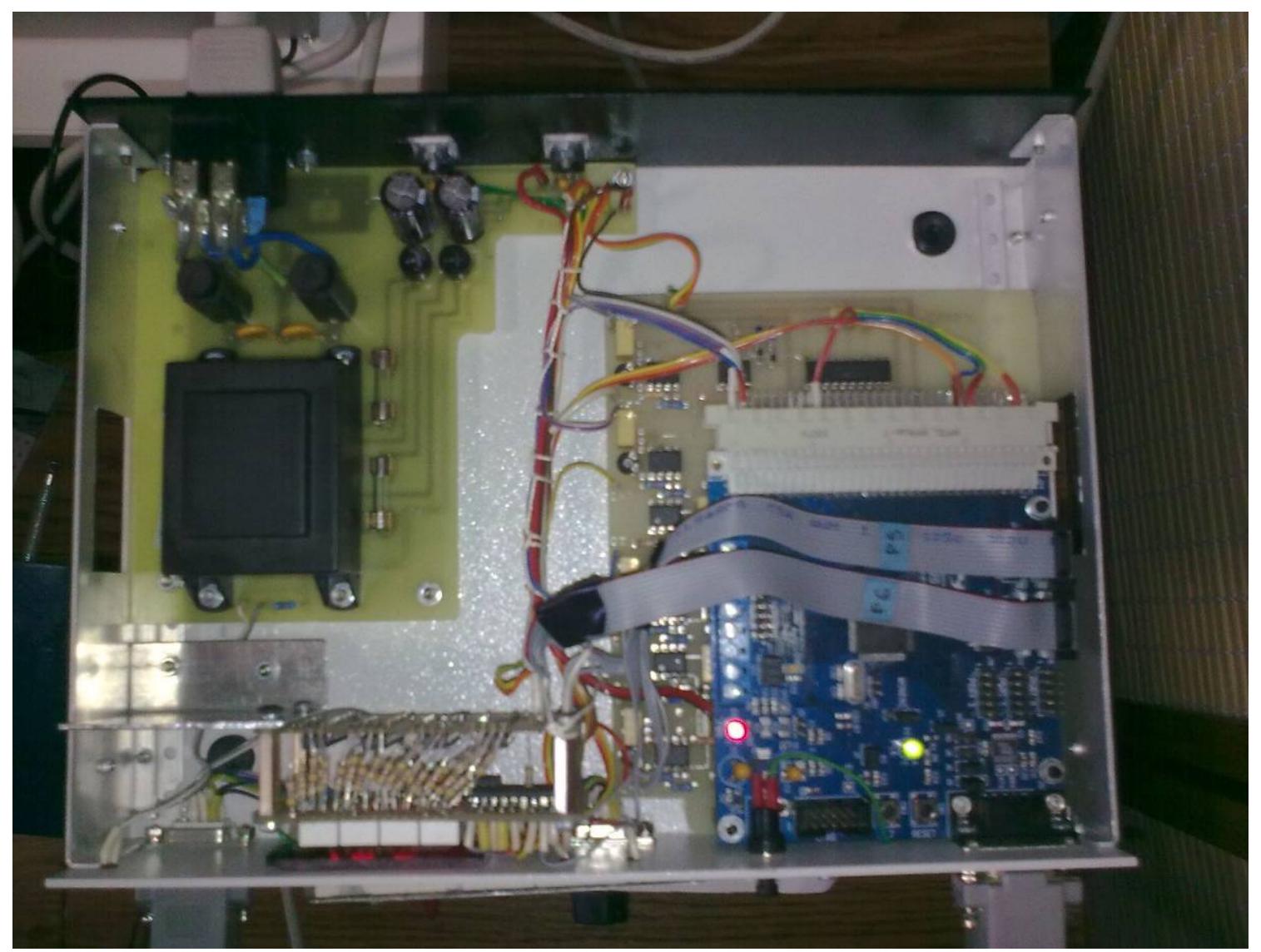

Figure 18. DAQ box to acquire analog signals from a hardness tester.

The communication protocol between the DAQ box and the PC side software is the same as used for the tablet machine, with the minor difference that the $0 \mathrm{~F} 2 \mathrm{~h}$ command has been added to the control frame to handle the DAQ stop signal. 


\subsubsection{PC side software}

During the DAQ the PC side software displays and saves data (Figure 19).

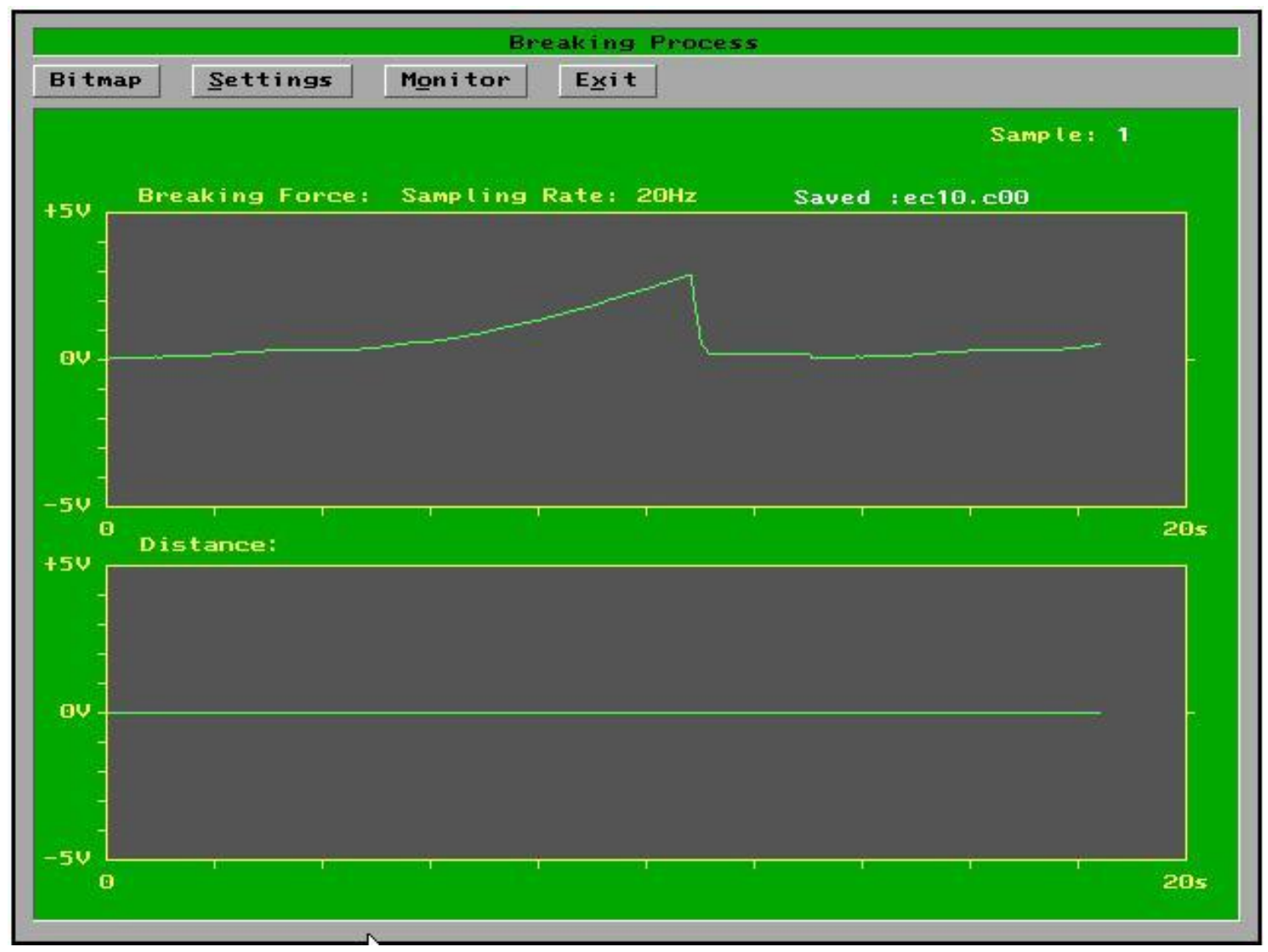

Figure 19. Screenshot of PC side software during the DAQ

Its DAQ algorithm reads the frames from the serial port. If the frame is a control frame, the routine saves the data to disk, initializes the buffers and drawing controls and waits for the DAQ to start signal; otherwise it displays and adds the data to the storing buffer.

During the evaluation, the software displays the deformation curve, the calculated work curve, the differential curve, and the parameters of the breaking point of the material (Figure 20). For polymer films and conventional tablets, the software calculates the location of the breaking point from the maximum absolute value of the differential 
curve. For a film, it is possible that the film does not break away. In that case, the breaking is the value of the force when the pressure jowl reaches the sample holder.

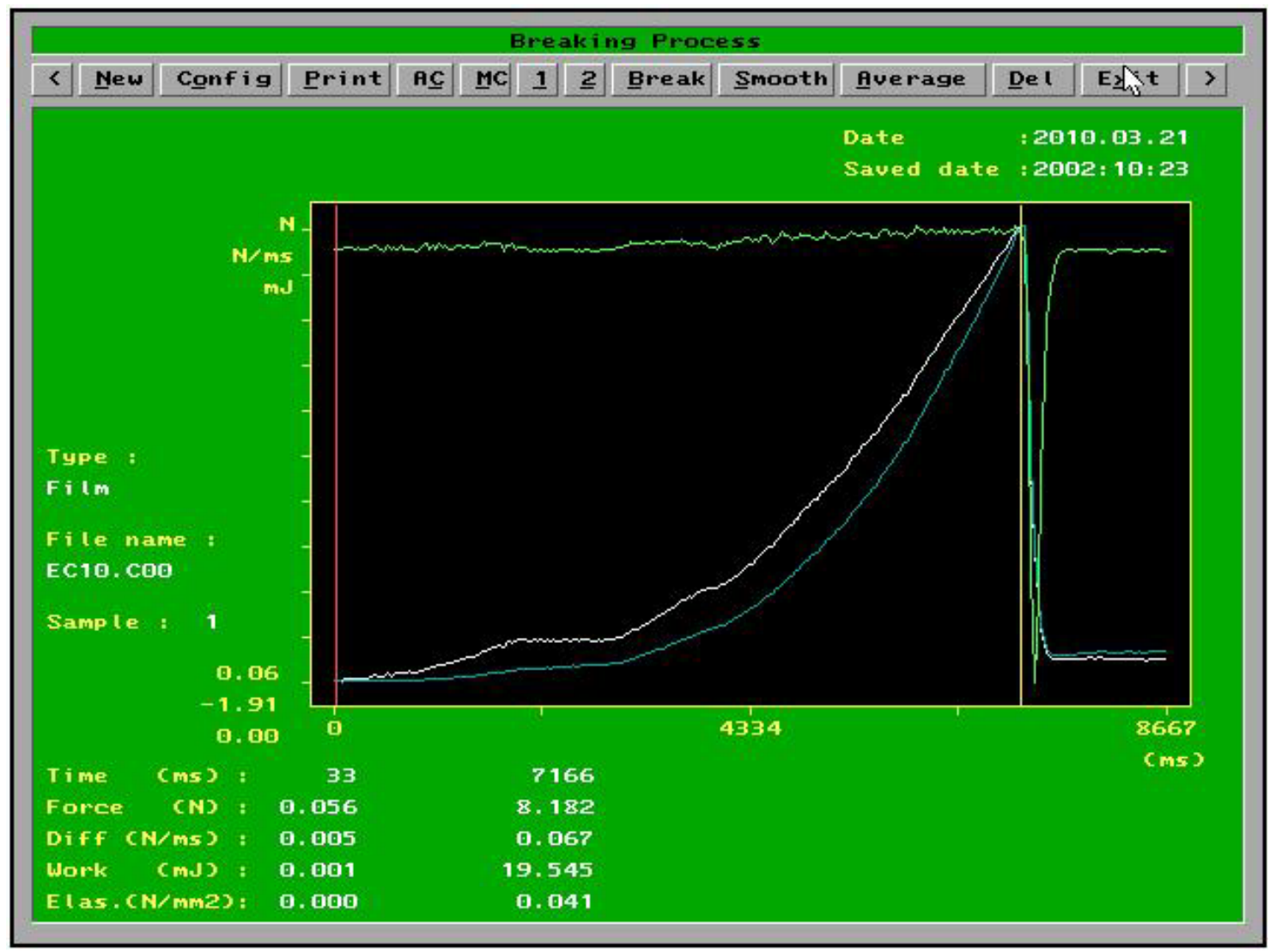

Figure 20. Screen shot of deformation curve of polymer film (the white curve depicts the force; the green curve the differential curve; and the dark blue curve the energy). For details, see the text.

The bottom part of Figure 20 shows the numerical results of the evaluation of the process of breaking of polymer film. The first column and the second list the results (force, work and elasticity) at the position of the cursor (vertical red line) and at the breaking point (vertical yellow line), respectively

For pellets, the software calculates four characteristic points (Figure 21). The deformation of a pellet starts short period of elastic deformation. The first characteristic point is the maximum value of the elastic deformation. In the second stage, a short period of plastic deformation occurs. The second characteristic point is the end of the plastic deformation. The third stage involves plastoelastic or viscoelastic deformation depending 
on the material. The third characteristic point is the end of this stage, at which point the pellet begins to break. The last characteristic point is the point when the pellet breaks totally and the pressure jowl reaches the sample holder.

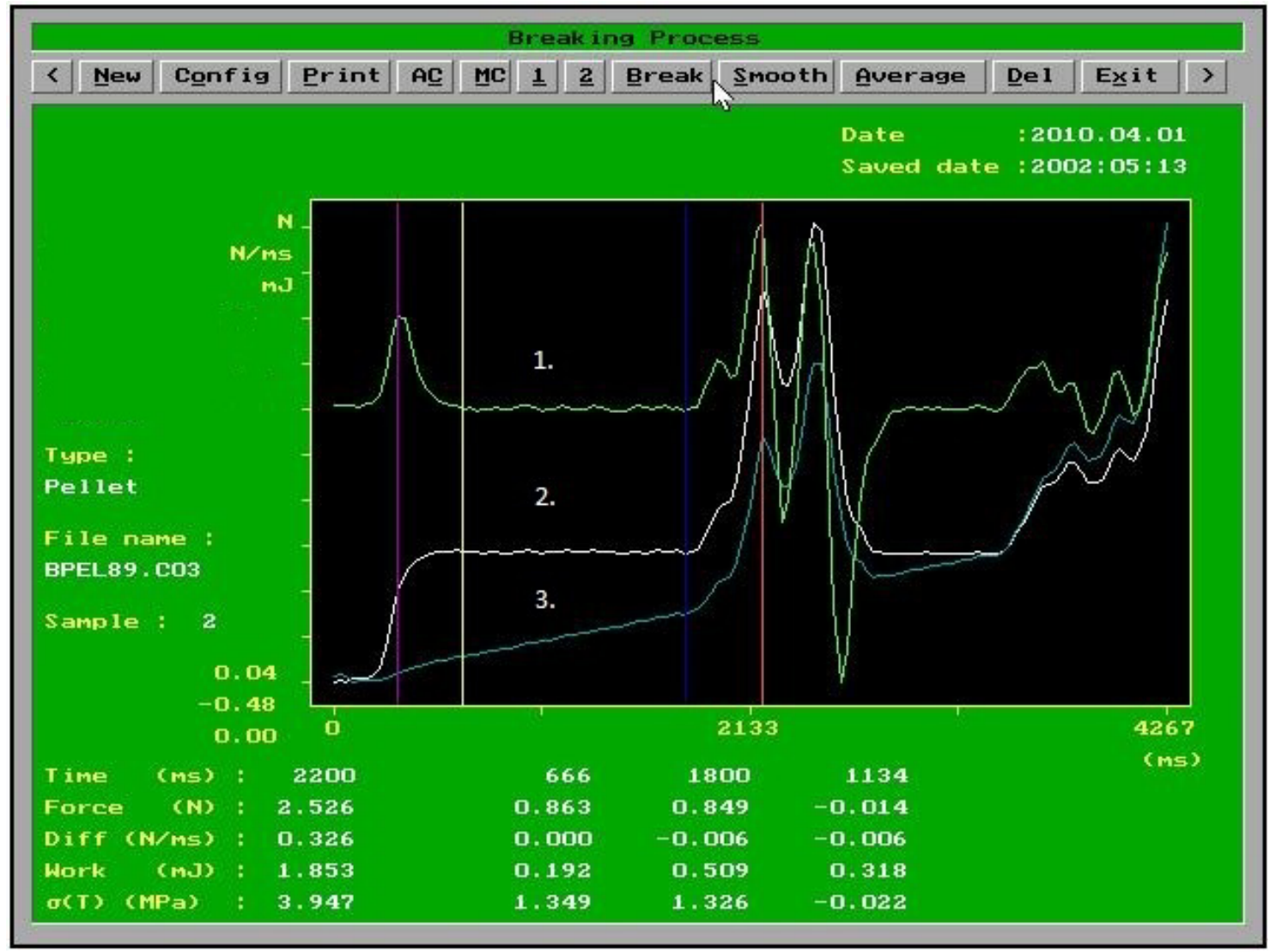

Figure 21. Deformation curve of a pellet

1: Differential curve, 2: deformation curve, 3: energy curve. For details, see the text.

The bottom part of Figure 21 presents the numerical results of the evaluation of the process of breaking of a pellet. The four columns show the results at the position of the cursor (red), at the first characteristic point (magenta), at the second characteristic point (yellow), and at the third characteristic point (blue). The cursor shows the breaking point of the pellet. The hardness (the values in the last row) is calculated via Eq. 8.

The calculation algorithm performs the following operations:

- It finds the maximum value of the first peak in the differential curve. This is the maximum value of elastic deformation. 
- It finds the starting point of the first horizontal section after the first peak in the differential curve. This is the end-point of plastic deformation.

- It finds the end-point of this section. This is the end of plasto- or viscoelastic deformation.

- It starts from this point to find the maximum value in the differential curve. This is the breaking point of the pellet.

Figure 22 illustrates the hardness tester with the DAQ box. The sample holder and pressure jowl are suitable for polymer films.

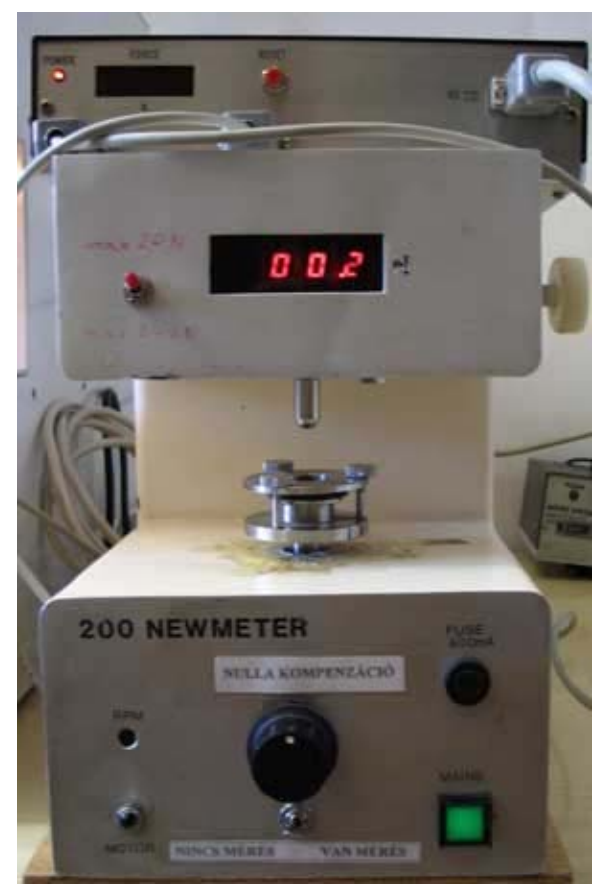

Figure 22. The hardness tester with the DAQ box. 


\section{RESULTS AND DISCUSSION}

This section presents some practical applications of the above-mentioned measurement systems.

\subsection{Study of the deformability process during loading}

\subsubsection{Deformability of medicated chewable polymers}

The topic of one of my studies was the compression physics of different gum bases, which can be used to prepare medicated chewing gum tablets [51].

Medicated chewing gum is a single-dose preparation that is to be chewed, but not swallowed. It contains one or more APIs. These ingredients are released by chewing [29].

Chewing gums have recently been produced by direct compression [32]. With this compression technology, these chewing gums can include higher levels of APIs than in traditional extruded gums, the lower temperature protects sensitive components, and the lower moisture content improves the shelf-life of active molecules. However, the most common drawback in the direct compression of a gum base is its tendency to stick to the punches of the tableting equipment, because of the adhesive nature of the gum, the main component of the formulation. For this reason, the procedure is difficult and demands a lower production speed and cooling operations in order to prevent to the damage tableting machine. The tableting tools are kept at temperatures below $18{ }^{\circ} \mathrm{C}$; however, it should be noted that the temperature should not be so low as to interfere with the handling of the medicated gums and the tableting process. Thus, the temperature should be above $10-12{ }^{\circ} \mathrm{C}$. In this work we studied the compression and breaking process at room temperature

Ascorbic acid was used as model API (Ph. Eur.), with Pharmagum C, M and S (gifts from SPI Pharma) as gum bases. Pharmagum M contains a 50\% greater gum base than Pharmagum S, which consists primarily of gum base and sorbitol. Pharmagum M contains gum base, mannitol and isomalt.

The data of the manufacturer indicate that, Pharmagum $\mathrm{S}$ is suitable for formulations with low drug loading and, when incorporated into tablets, gives them a 
chewable character. Pharmagum $\mathrm{M}$ is suggested for medium drug loading $(<50 \%)$; it improves the mouthfeel texture. Pharmagum $\mathrm{C}$ is suggested for high drug loading $(>50 \%)$; it has a real chewing gum character.

Pharmagum mixtures were prepared in different ratios to study the compactibility and deformability (Table 1) [51].

Table 1.: Compositions of powder mixtures

\begin{tabular}{|c|c|c|c|}
\hline \multirow[t]{2}{*}{ Sample } & \multicolumn{3}{|c|}{$\begin{array}{l}\text { Pharmagum composition } \\
\text { (\%) }\end{array}$} \\
\hline & $\mathrm{C}$ & $\mathrm{M}$ & $\mathrm{S}$ \\
\hline S 1 & 60 & 40 & \\
\hline $\mathrm{S} 2$ & 50 & 50 & \\
\hline S 3 & 40 & 60 & \\
\hline S 4 & 60 & & 40 \\
\hline S 5 & 50 & & 50 \\
\hline S 6 & 40 & & 60 \\
\hline S 7 & & 60 & 40 \\
\hline S 8 & & 50 & 50 \\
\hline S 9 & & 40 & 60 \\
\hline \multicolumn{4}{|c|}{ The amounts of the following ingredients were the same in all cases $(\%)$ : } \\
\hline Ascorbic acid & 8.33 & & \\
\hline Xylitol & 7.68 & & \\
\hline Aroma & 0.33 & & \\
\hline Magnesium stearate & 2.00 & & \\
\hline
\end{tabular}

Bindings formed during the compression phase can be broken in the elastic recovery phase. In the tablet compositions, therefore, the bulk gum powders were mixed with the other components in different ratios (see Table 1).

The tablets were prepared with the above-mentioned eccentric tablet machine. The compression tools were flat-faced bevel-edged punches $10 \mathrm{~mm}$ in diameter. The compression was carried out electrically at $36 \mathrm{rpm}$, at an air temperature of $24{ }^{\circ} \mathrm{C}$ and at a relative air humidity of $45 \%$. The average mass of the tablets was $0.47 \pm 0.01$ g. 10 tablets were compressed at compression forces of 5, 7.5, 10, 12.5 or $15 \mathrm{kN}$ for each sample. Lots with relative standard deviations not exceeding $5 \%$ were accepted. 
The force-displacement curves were plotted, and the compression parameters effective work $\left(E_{2}\right)$, elastic recovery $\left(E_{3}\right)$ and plasticity $\left(P_{l}\right)$ were calculated from the curves with our software developed for the tablet machine with use of Eq. 9-11 [51]. The plasticity was calculated with the Stamm-Mathis equaion (Eq. 2) based on the forcedisplacement diagram (Figure 23.; Sample S1), where the $E_{1}=44.58 \%$, the $E_{2}=46.22 \%$, and the $E_{3}=9.21 \%$.

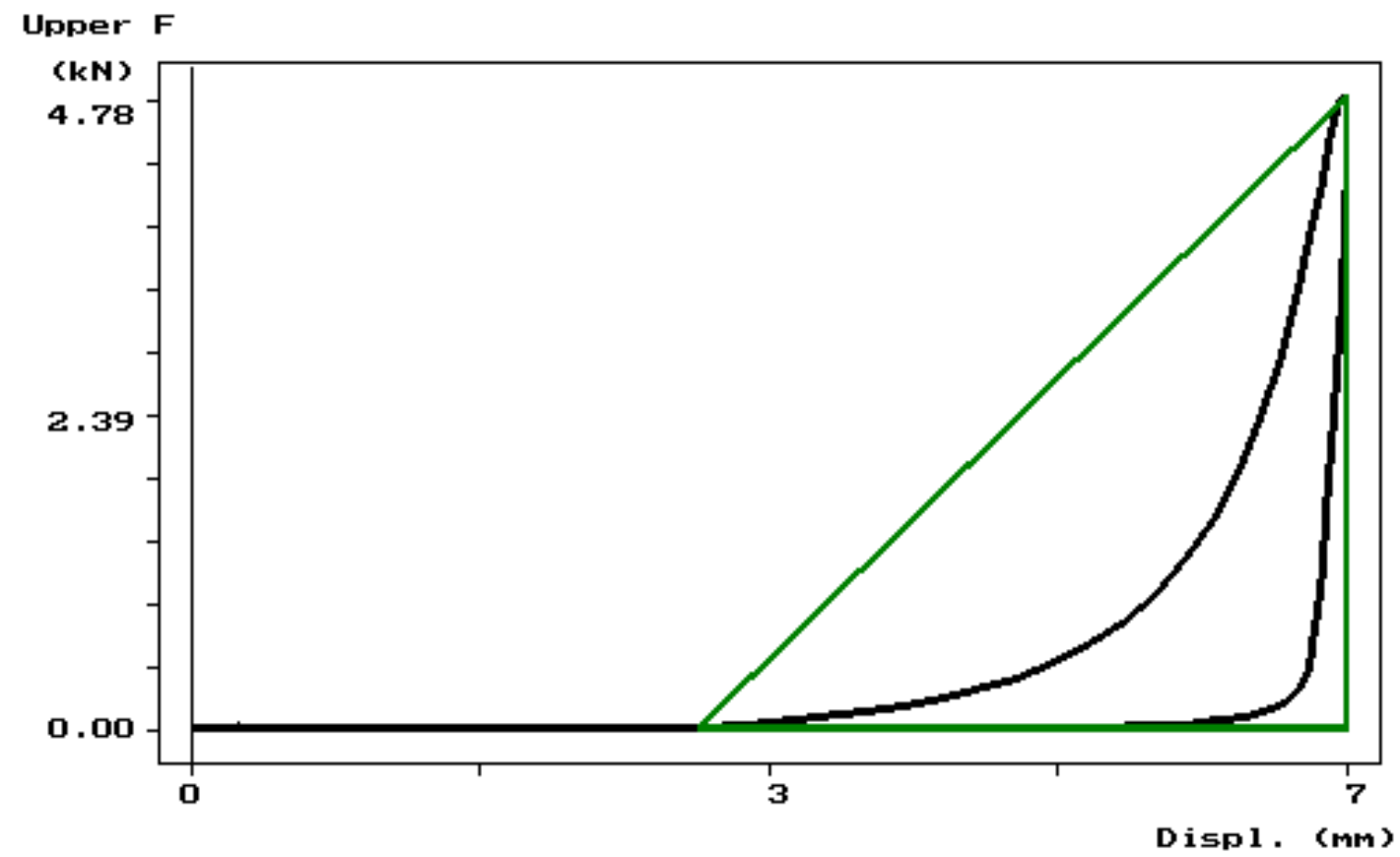

Figure 23. Recorded force-displacement diagram of sample S1 [51]. 
The compactibility tests on the bulk materials resulted in a high elastic recovery in every case (Table 2) [51].

Table 2.: Effects of compression force on the elasticity and friction for bulk gum bases

\begin{tabular}{|l|l|l|l|}
\hline Sample & $\begin{array}{l}\mathbf{F}_{\text {upper }} \\
(\mathbf{k N )}\end{array}$ & $\begin{array}{l}\mathbf{W}_{\mathbf{f}} \\
(\mathbf{J})\end{array}$ & $\begin{array}{l}\mathbf{E}_{3} \\
(\mathbf{J})\end{array}$ \\
\hline \multirow{3}{*}{ Gum C } & 5 & 0.022 & 0.43 \\
\cline { 2 - 4 } & 10 & 0.037 & 1.35 \\
\cline { 2 - 4 } & 15 & 0.047 & 3.61 \\
\hline \multirow{3}{*}{ Gum M } & 5 & 0.003 & 0.25 \\
\cline { 2 - 4 } & 10 & 0.013 & 1.24 \\
\cline { 2 - 4 } Gum S & 15 & 0.066 & 2.90 \\
\cline { 2 - 4 } & 10 & 0.100 & 0.49 \\
\cline { 2 - 4 } & 15 & 0.138 & 1.12 \\
\hline
\end{tabular}

$W_{f}:$ shows the work which arises during the tablet ejection (frictional work), $E_{3}$ : elastic recovery

For gums, elasticity is the most important property. After the compression maximum, when the upper punch starts to move upwards, elastic materials display some recovery. The degree of elastic recovery was found to vary linearly with the compression force ( $y=a \mathrm{x}+b$, where $y=E_{3}, a=$ slope, $x=$ compression force, and $b=$ intercept), with a very good correlation $\left(R^{2}=0.984-0.999\right)$ (Figure 24). Further, in all mixtures the degree of elastic recovery was increased after compression (Table 3) [51]. Pharmagum $\mathrm{M}$ influenced the elastic recovery to the highest degree. Tablets S1, S2 and S3 had the smallest $E_{3}$ values at a compression force of $5 \mathrm{kN}$ and these values decreased linearly with increasing Pharmagum $\mathrm{M}$ content. (From the aspect of tableting, the smallest $\mathrm{E}_{3}$ value is advantageous.) For tablets S2 and S3 the decreases in $E_{3}$ were smaller, and at 10 and $15 \mathrm{kN}$ the Pharmagum $\mathrm{M}$ and $\mathrm{C}$ mixtures with ratios of 50:50 and 40:60 had practically no effect on the $E_{3}$ values. For the other mixtures, the ratio usually had very little effect on the degree of elastic recovery at different compression forces, except for sample S6 compressed at $15 \mathrm{kN}$. The elastic properties of the API and other ingredients were not sufficiently high to cause any change in the elastic behaviour of the gum bases. 


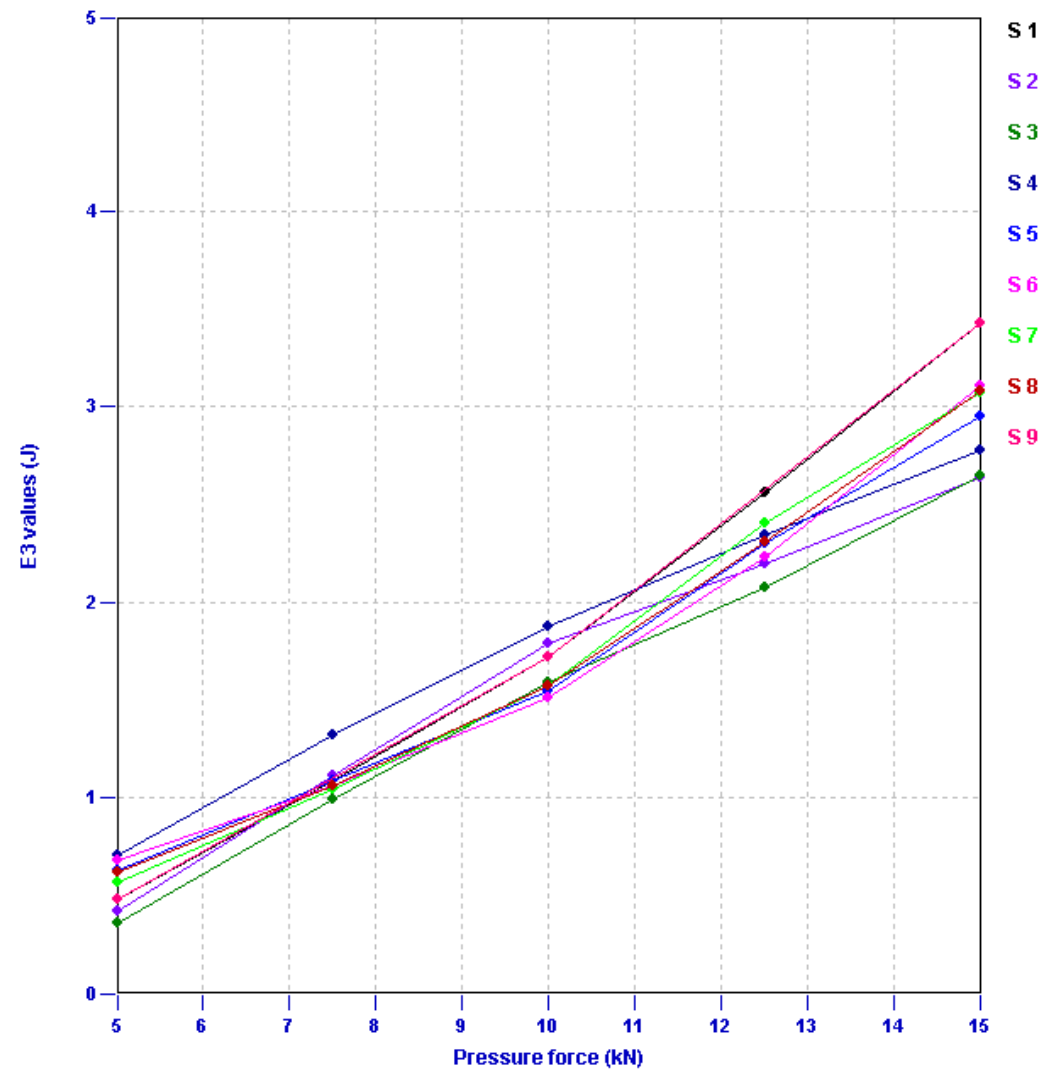

Figure 24. Relationship between the pressure and elastic recovery [51].

Table 3: Relationship between compositions and $E_{3}$ areas

\begin{tabular}{|c|c|c|c|c|c|c|c|c|}
\hline \multirow[t]{2}{*}{ Sample } & \multicolumn{3}{|c|}{$\begin{array}{l}\text { Composition } \\
\text { (Gum base) }\end{array}$} & \multicolumn{5}{|c|}{$\begin{array}{l}\text { Compression forces }(\mathrm{kN}) \\
E_{3}(\mathrm{~J})\end{array}$} \\
\hline & $\mathrm{C}$ & $\mathrm{M}$ & $\mathrm{S}$ & 5 & 7.5 & 10 & 12.5 & 15 \\
\hline S 1 & 60 & 40 & - & 0.48 & 1.07 & 1.69 & 2.51 & 3.36 \\
\hline S 2 & 50 & 50 & - & 0.42 & 1.10 & 1.76 & 2.16 & 2.59 \\
\hline S 3 & 40 & 60 & - & 0.36 & 0.98 & 1.56 & 2.04 & 2.60 \\
\hline $\mathrm{S} 4$ & 60 & - & 40 & 0.70 & 1.30 & 1.84 & 2.30 & 2.72 \\
\hline S 5 & 50 & - & 50 & 0.62 & 1.07 & 1.52 & 2.26 & 2.89 \\
\hline S 6 & 40 & - & 60 & 0.67 & 1.05 & 1.49 & 2.19 & 3.05 \\
\hline S 7 & - & 60 & 40 & 0.56 & 1.03 & 1.55 & 2.36 & 3.01 \\
\hline S 8 & - & 50 & 50 & 0.61 & 1.05 & 1.55 & 2.27 & 3.02 \\
\hline S 9 & - & 40 & 60 & 0.58 & 1.06 & 1.56 & 2.29 & 3.02 \\
\hline
\end{tabular}


A hardness tester is suitable for tracking the process of deformation of gum-based tablets. This is important because the stored elastic energy determines the chewability of these tablets. .The breaking strength tests were performed with a above-mentioned tablet hardness tester. These breaking tests differed from the case of conventional tablets because, after crushing, the tablets did not break completely. The deformation curves during loading demonstrate elastic deformation with a rather high slope (Figure 25). After a maximum, the force decreased, but the tablet did not break into small pieces; merely deformation was observed, with some cracks. Increase of the pressure did not cause any significant changes in the breaking process. It can be seen from the data that if the value of $E_{3}$ is low the deformation force is high, which means that appropriate chewability necessitates a higher force.

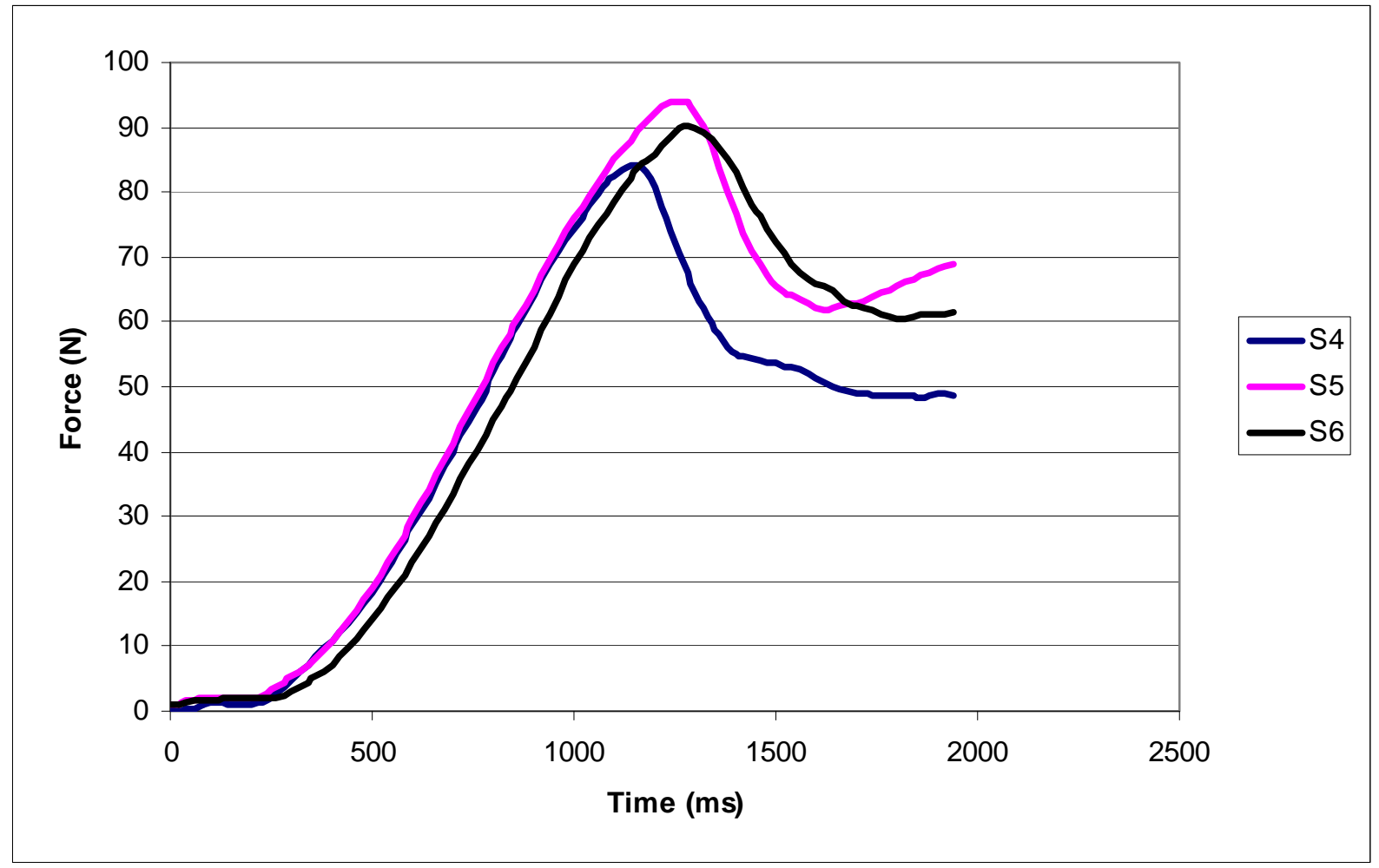

Figure.25. Deformation curves during loading (samples S4, S5 and S6, pressure $5 \mathrm{kN}$ ) [51].

\subsubsection{Deformability of coated crystals}

Film coating is a method that is widely used for the protection, retardation of breaking down and identification of solid dosage forms [30]. Gastric-soluble polymers 
are used to protect ingredients from light, moisture and oxygen, and for identification. Several types of gastric-soluble films (cellulose derivatives, poly(methacrylates), poly(ethylene-glycols), etc.) have been used for protection. The film smoothness and thickness determine the protective effect of the coating film. These parameters are well measurable on the surface of tablets or pellets by means of image analysis [40]. The film coating of fine particles can be a useful procedure in tablet making, but the adherence of these particles disturbs the determination of film thickness. It is difficult to avoid this sticking effect [41]. It is important to know whether the protective effect is modified or not by the quantity of coating material applied. One very important property of slid dosage forms is the compressibility. This was investigated with the above-mentioned instrumented tablet machine and software [49].

The model API used was dimenhydrinate (Ph. Eur. 3, B.No.:280-69-015), which is an ethanolamine derivative antihistamine used for the treatment of motion sickness, nausea and vomiting [30]. The film-forming agent was hydroxypropyl-methylcellulose (Sepifilm LP 010®, B.No.: 80741) (Seppic, Paris, France), which was applied in a 10\% aqueous dispersion, containing binder, pigment and plasticizer [42].

The samples were compressed into tablets. The compression was carried out electrically at $36 \mathrm{rpm}$ at an air temperature of $24{ }^{\circ} \mathrm{C}$ and a relative humidity of $45 \%$. The compressed volume was $100 \mathrm{~mm}^{3}$ for each sample. 10 tablets were compressed for each sample. The compression force on the upper punch was $18 \pm 1.8 \mathrm{kN}$. The deviation of the compression force for uncoated crystals was higher because of the uneven filling.

The force-displacement curve was determined and the plasticity was calculated. The force-displacement curve of the uncoated crystals may be seen in Figure 26. The coating did not influence the shape of the force-displacement curve significantly. The smooth line is the measured curve, while the dotted lines are lines facilitating the calculation. The plasticity $(P l)$ was calculated according to the Stamm and Mathis equation (Eq. 2). This parameter relates to the behaviour of a material under a load. If $P l$ is close to $100 \%$, the material deforms well under a load. 


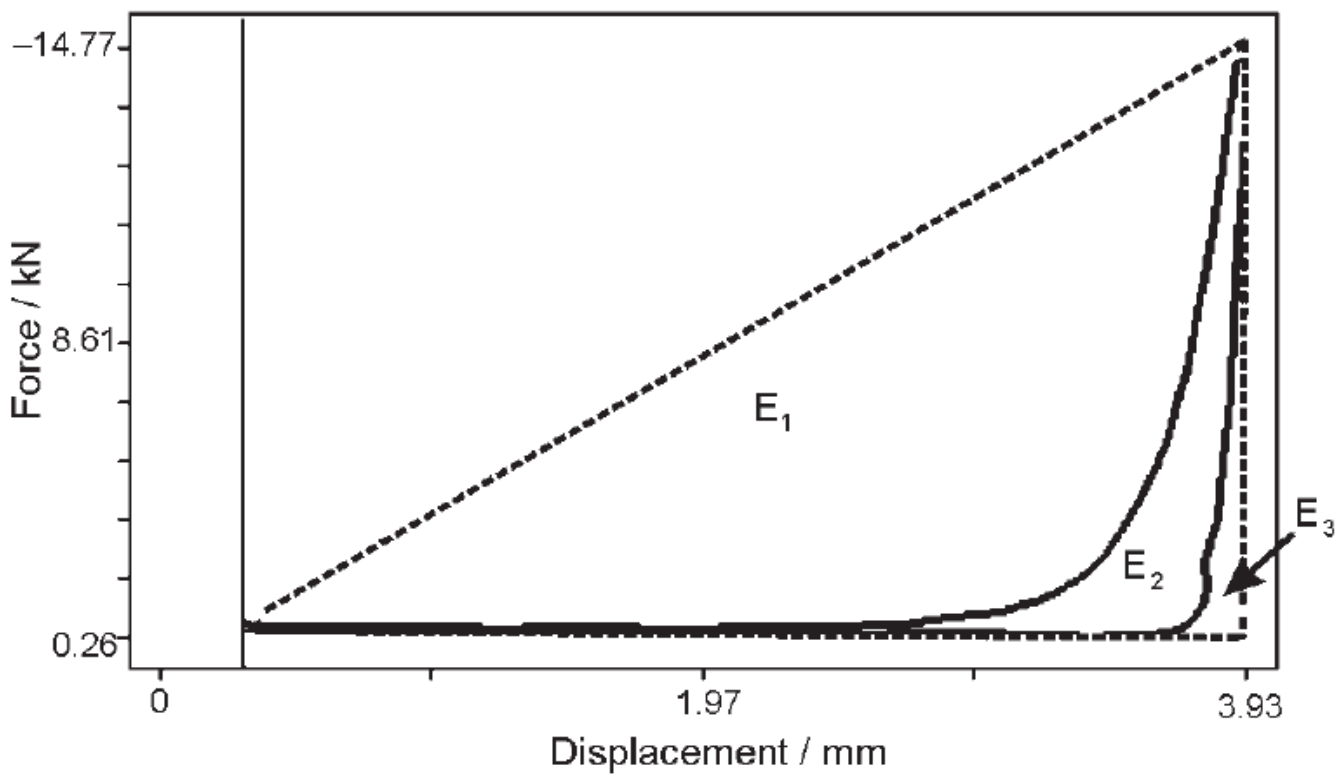

Figure 26. Force-displacement curve of uncoated crystals [49]. $E_{1}$ is the energy lost by rearrangement of the particles, $E_{2}$ is the useful energy and $E_{3}$ is the energy lost by elastic recovery.

The uncoated dimenhydrinate crystals exhibited the highest plasticity (Table 3). The coating caused a decrease in plasticity. This can be explained by the film between the crystals. The interactions between the crystals were influenced by the film. The free coating film exhibited elastic properties, which was supported by other experimental findings.

Not only the quantity of coating material influenced the plasticity: the uniform distribution on the surface also played an important part, for there was a relationship between the continuity and the elastic behaviour of the film, i.e. between the film uniformity and the plasticity. Sample Dim 2 exhibited the poorest plasticity, which can be explained in terms of the best protective effect of the coating film.

Table 3: Plasticity data (Stamm-Mathis) on samples [49].

\begin{tabular}{|l|l|l|l|l|}
\hline & Dimenhydrinate & Dim1 & Dim2 & Dim3 \\
\hline Pl (\%) & 69.66 & 59.61 & 43.77 & 52.93 \\
\hline SD & 6.61 & 2.32 & 2.01 & 3.07 \\
\hline
\end{tabular}


Despite the decreased plasticity, the tabletability of dimenhydrinate was not appreciably decreased by the coating because the tableting process is influenced by many parameters (the flow rate of material, the rearrangement of particles, the lubrication, etc. [32]). Some parameters even improved the tabletability (uniform filling, better lubrication, a smaller proportion of friction, etc.).

On the basis of the results, it can be concluded that the instrumented tablet machine with the developed software is suitable for the study of the deformability and compressibility of different materials. It is a very useful tool in the development of pharmaceutical solid dosage forms.

\subsection{Study of swelling force profiles}

\subsubsection{Swelling forces of some superdisintegrants}

The swelling properties of several experimental superdisintegrants (e.g. sodium starch glycolates (SSGs)) were investigated with the above-mentioned $F_{s}$ tester [48]. The SSG samples were based on the sodium salts of the partially substituted carboxymethyl ethers of potato starch. They have a moisture content that is lower than that of starches $(<10 \%)$. The sodium chloride content is less than $1 \%$. Different types are produced as regards the degree of crosslinking. The degree of substitution is the same.

Some tablets were prepared from the SSG products with the aim of a study of the swelling. Dicalcium phosphate dihydrate was used as binder. It was necessary to apply a lubricant as well (magnesium stearate). These materials do not swell in aqueous medium. After sieving ( $0.8 \mathrm{~mm}$ wire distance), the components were blended at $50 \mathrm{rpm}$ for $10 \mathrm{~min}$ in a Turbula mixer. The moisture contents of the powder mixtures were determined gravimetrically, through water removal with an IR lamp mounted on a quick dryer. The moisture content was 0.3-0.45 in every case.

Compression was carried out with the tablet press equipment described above. The parameters of compression were as follows (Table 4):

Table 4: Technical parameters of compression

Punches:

Pressure force:

Air temperature:

Rate of pressing flat, $10 \mathrm{~mm}$ in diameter

5,10 or $15 \pm 1 \mathrm{kN}$

$23{ }^{\circ} \mathrm{C}$

36 tablets/min 
The characteristic swelling time and shape parameter were calculated via Eq. 12 by linear fitting (Figure 27).

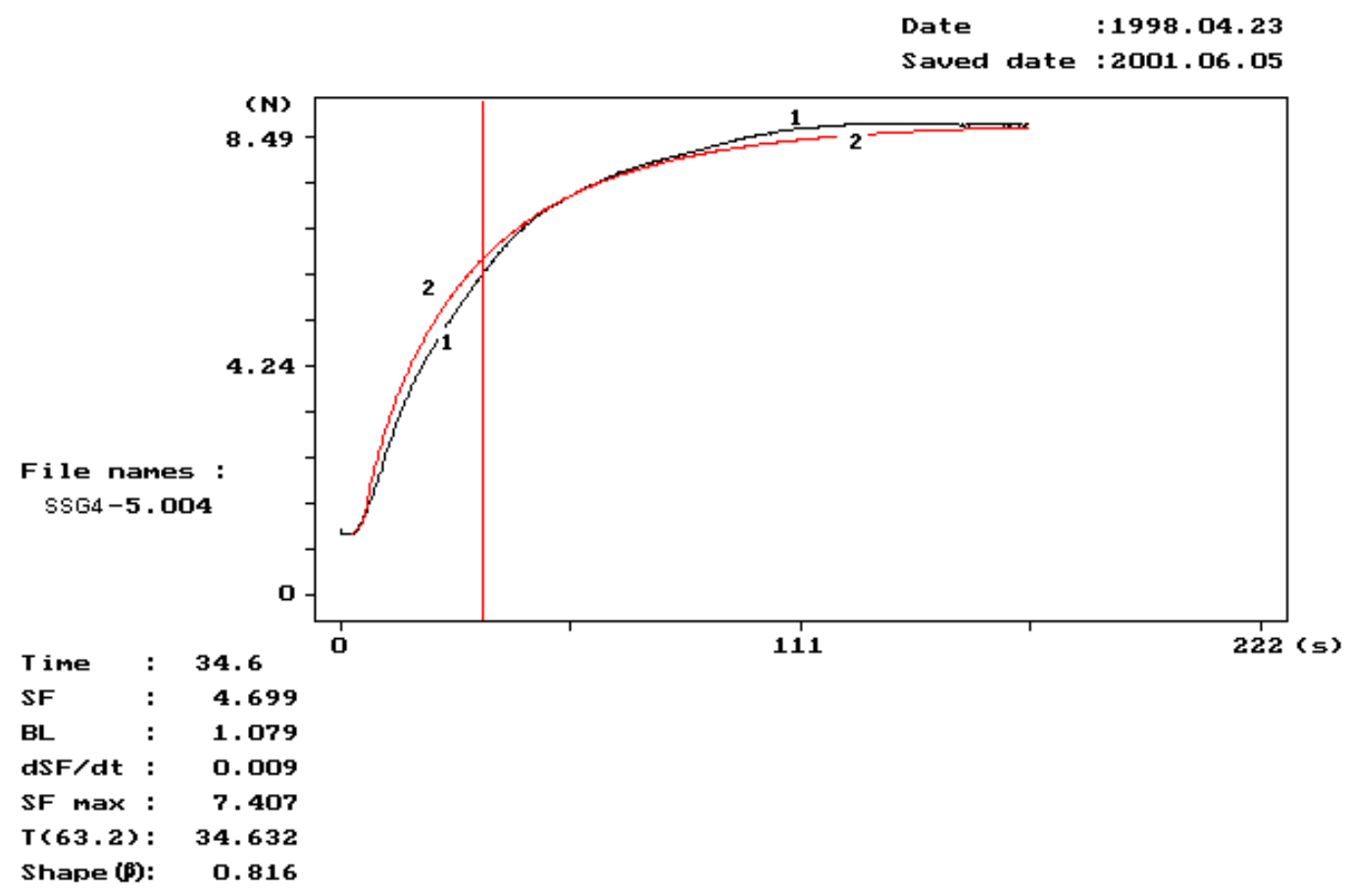

Figure 27. $F_{s}$ profile and fitting according to the RRSBW equation

$\mathbf{S F}=F_{s}$ (at the vertical measuring line); $\mathbf{B L}=$ baseline; $\mathbf{S F m a x}=$ maximum value of $F_{s} ; \mathbf{T}(63.2)=$ characteristic swelling time; $\mathbf{d S F} / \mathbf{d t}=$ rate of change of force (at the vertical measuring line). The pressure force was $5 \mathrm{kN}$. 1 . Curve 1 , is $F_{s}$ profile of SSG4 comprimates and curve 2 is the fitted curve [48].

Results are shown in Table 5. It can be seen that at $5 \mathrm{kN}$ the SSG5 comprimates exhibited the highest, and the SSG2 comprimates the lowest $F_{s}$ (Table 1, Figure 28). The SSG1 and SSG6 comprimates $(5 \mathrm{kN})$ displayed almost the same $F_{s}$ maximum, but there was a considerable difference in the $t_{63.2 \%}$ values. The $F_{s}$ increased at higher pressure, but to different degrees. 
Table 5.: Results of the swelling tests [48].

\begin{tabular}{|c|c|c|c|c|}
\hline Sample & $\begin{array}{c}\text { Punch force } \\
(\mathrm{kN})\end{array}$ & $\begin{array}{c}\text { Swelling force (N) } \\
\text { (RSD \%) }\end{array}$ & B & $t_{63.2 \%}(s)$ \\
\hline SSG1 & $\begin{array}{l}5 \\
10 \\
15\end{array}$ & $\begin{array}{c}8.56 \\
\text { RSD }=5.57 \\
10.09 \\
\text { RSD }=9.95 \\
12.49 \\
\text { RSD }=5.46\end{array}$ & \begin{tabular}{r|}
0.83 \\
0.836 \\
0.858
\end{tabular} & $\begin{array}{r}119.13 \\
108.82 \\
125.87\end{array}$ \\
\hline SSG2 & $\begin{array}{l}5 \\
10 \\
15\end{array}$ & $\begin{array}{c}5.45 \\
\text { RSD }=11.56 \\
7.16 \\
\text { RSD }=7.16 \\
14.23 \\
\text { RSD }=11.09\end{array}$ & \begin{tabular}{r|}
0.858 \\
0.832 \\
0.83
\end{tabular} & $\begin{array}{r}66.35 \\
61.67 \\
78.99\end{array}$ \\
\hline SSG3 & $\begin{array}{l}5 \\
10 \\
15\end{array}$ & $\begin{array}{c}6.96 \\
\text { RSD }=6.44 \\
8.18 \\
\text { RSD }=7.62 \\
18.33 \\
\text { RSD }=3.80\end{array}$ & \begin{tabular}{r|}
0.816 \\
0.814 \\
0.83
\end{tabular} & $\begin{array}{r}48.55 \\
47.48 \\
95.36\end{array}$ \\
\hline SSG4 & $\begin{array}{l}5 \\
10 \\
15\end{array}$ & $\begin{array}{c}6.92 \\
\text { RSD }=6.21 \\
8.14 \\
\text { RSD }=9.74 \\
9.59 \\
\text { RSD }=11.09\end{array}$ & \begin{tabular}{r|}
0.864 \\
0.808 \\
0.832
\end{tabular} & \begin{tabular}{|l|}
53.36 \\
30.1 \\
33.1
\end{tabular} \\
\hline SSG5 & $\begin{array}{l}5 \\
10 \\
15\end{array}$ & $\begin{array}{c}9.94 \\
\text { RSD }=7.36 \\
13.84 \\
\text { RSD }=8.58 \\
13.49 \\
\text { RSD }=3.11\end{array}$ & \begin{tabular}{r|}
0.832 \\
0.819 \\
0.831
\end{tabular} & \begin{tabular}{r|}
89.24 \\
82.33 \\
40.71
\end{tabular} \\
\hline SSG6 & $\begin{array}{l}5 \\
10 \\
15\end{array}$ & $\begin{array}{c}8.59 \\
\text { RSD }=0.37 \\
11.25 \\
\text { RSD }=4.22 \\
11.87 \\
\text { RSD }=2.85\end{array}$ & \begin{tabular}{r|}
0.825 \\
0.813 \\
0.816
\end{tabular} & 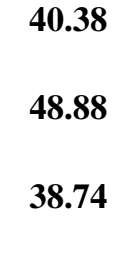 \\
\hline
\end{tabular}




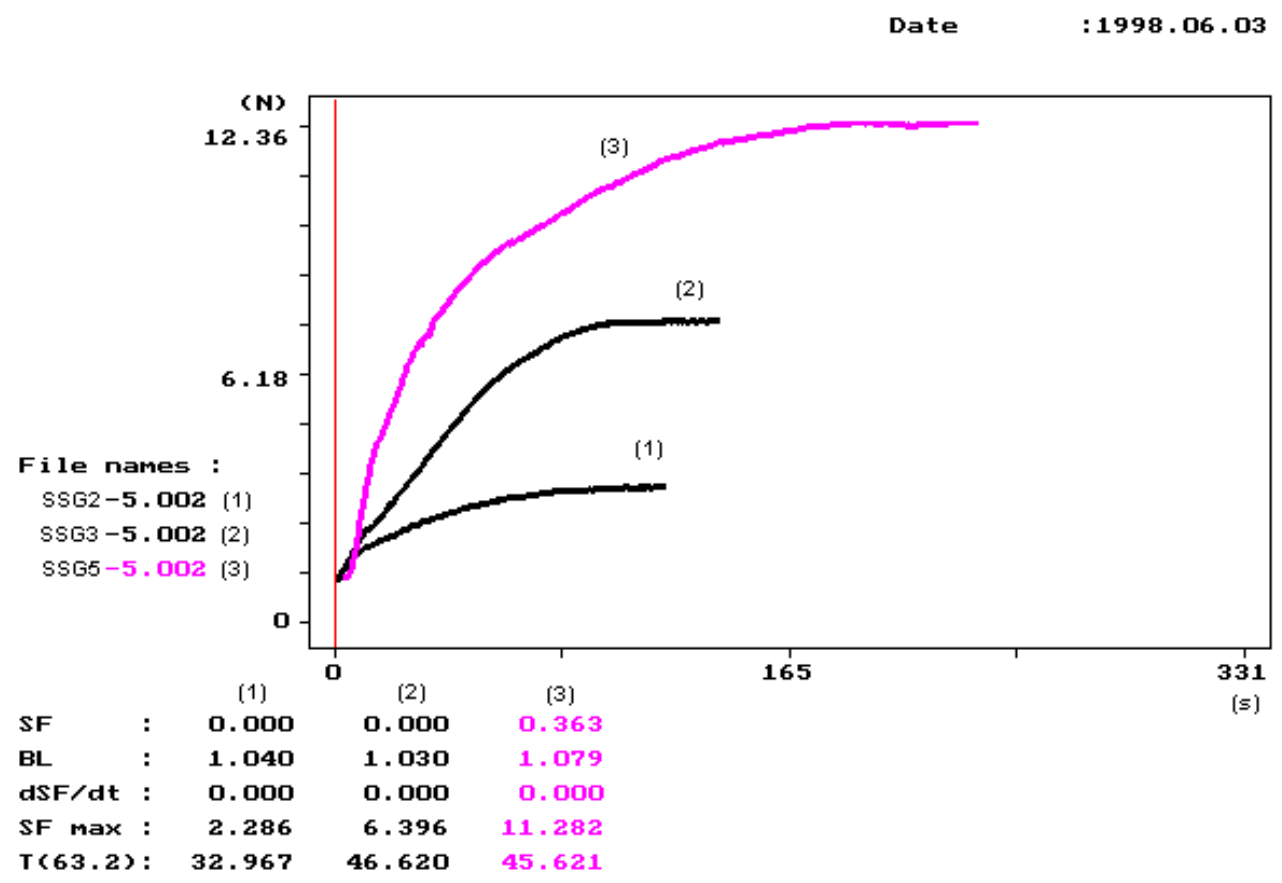

Figure 28. Swelling processes of SSG2, SSG3, and SSG5 comprimates (pressure : $5 \mathrm{kN}$ ) $\mathbf{S F}=F_{s}$ (at the vertical measuring line); $\mathbf{B L}=$ baseline; $\mathbf{S F m a x}=$ maximum value of $F_{s}$; $\mathbf{T}(63.2)=$ characteristic swelling time; $\mathbf{d S F} / \mathbf{d t}=$ the rate of change of force (at the vertical measuring line) [48].

The reason lies in the texture of the comprimates and in the properties of the materials. Increase of the pressure generally resulted in a decrease in porosity, and a more compact texture. This has an important role in the disintegration. If the character of the composition is hydrophilic, the $F_{s}$ (the disintegration force) can be better mediated by the water and the disintegration process will be rapid. The degree of the increase in $F_{s}$ depends on the properties and the swelling ability of the disintegrants. By changing the disintegrant at a given composition, it is possible to study the influence of the pressure on $F_{s}$.

The results of these experiments suggest that the maximum $F_{s}$ and the factor $t_{63.2 \%}$ may be used to compare the intrinsic capability of a disintegrant. Study of the swelling process is also important with respect to the pressure. The porosity of the tablets depends on the deformability of the particles and the porosity has an important role in the transport of water into the interior of the tablets and hence in the swelling process too.

On the basis of such results, it is possible to choose the pressure suitable for tableting. If increase of pressure causes no or only a very small change in $F_{s}$, it is 
unnecessary to use a high pressure during tableting. The other advantage is the choise of suitable disintegrants in the tablet composition.

\subsubsection{Swelling forces of swellable matrices}

In the past decade, swellable matrix systems have become very popular solid dosage forms for controlled-release API delivery systems. The study of the swelling behaviour of these matrices plays an important role in prediction of the API release profile. In this study, the model matrices were based on kappa-carrageenan. Its $F_{s}$ profile is not described by with RRBSW distribution as for conventional tablets. The mathematical model used to fit this profile was the Korsmeyer-Peppas or power law model Eq. 13 [Figure 29].

$\begin{array}{ll}\mathrm{n} & : 0.74 \\ \mathrm{k} & : 0.0241 \\ \text { Corr. } & : 0.9985 \\ & \\ \text { Time (s) } & : 0.00 \\ \mathrm{SF}(\mathrm{N}) & : 0.18 \\ & \\ \text { Lag time (s) } & : 14.84 \\ \text { SF } \max (\mathrm{N}) & : 8.61\end{array}$

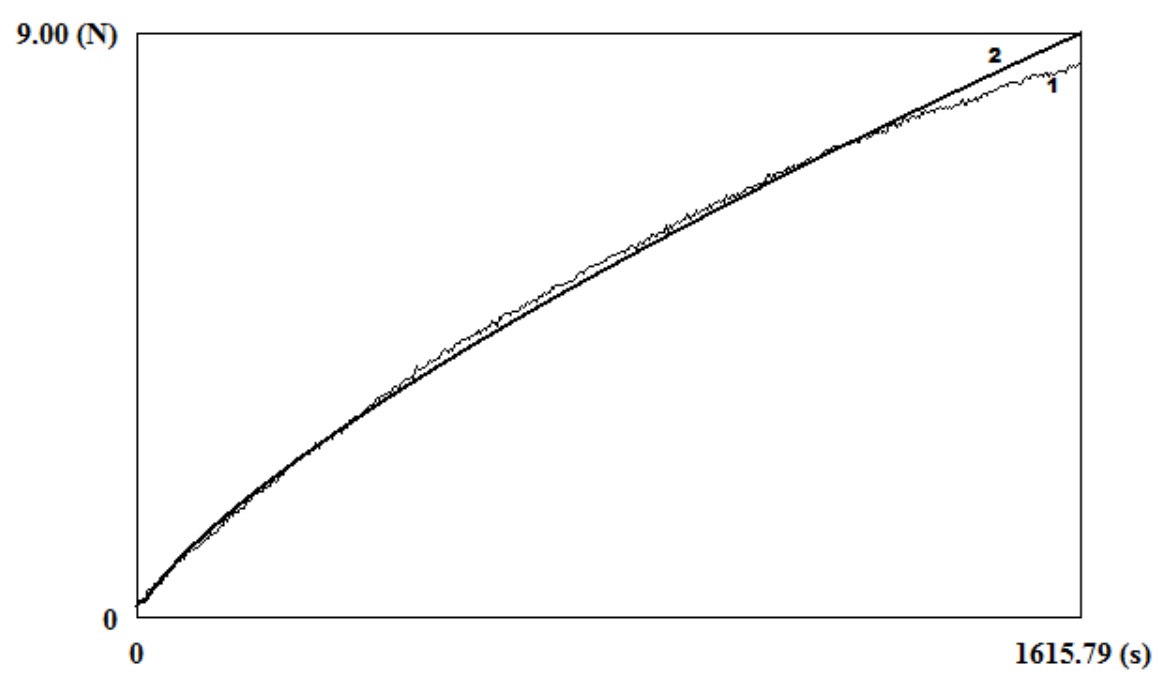

Figure 29. $F_{s}$ profile of kappa-carrageen. The profile was fitted by the power law model. Curve 1 is the swelling profile. Curve 2 is the fitted curve.

$$
\frac{F(t)}{F_{\infty}}=k t^{n}
$$

where $F(t)$ is the measured swelling force at time $t, F_{\infty}$ is the maximum value of $F_{s}, n$ is the shape parameter and $k$ is the swelling rate constant.

If the $n>0.5$ and $n<1$ the swelling drives by non Fickian diffusion [35-37]. 
At the end of the measurement the measured curve differs from the fitted curve. The reason is the partial erosion of the sample. This effect is small, but detectable.

\subsection{Measurement of breaking process of smaller particles}

Breaking is a very important parameter in the qualification of a solid dosage form (granule, pellet, tablet or polymer film). Different instruments are available for tablet hardness testing, but in the case of smaller particles (granules or pellets) only the friability test is described in the pharmacopeia. The mechanical resistance of pellets can be characterized in terms of the friability, but the individual breaking strength can not be shown. With the developed equipment, it is possible to test the granules and pellets too. It is also possible to determine breaking points of the particles and to follow the deformation processes.

A pellet is an agglomerate with nearly spherical symmetry and usually a diameter of 0.5-1.5 mm, though this can vary with the production technology [43]. As compared with classical granules, pellets not only differ in shape, but also have a more compact texture, resulting in better flow characteristics.

In this work the hardness of the pellets was studied with the above-mentioned breaking hardness tester [50]. Figure 30 depicts the pellet deformation behaviour.

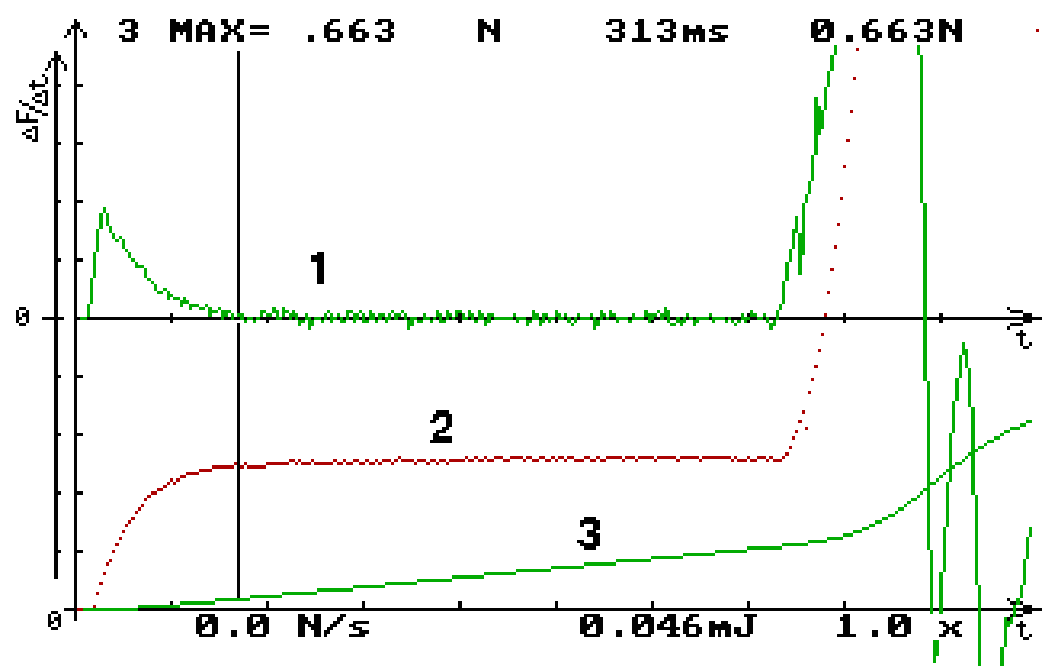

Figure 30. Deformation process of an uncoated pellet. 1: differential curve, 2: force-time curve. 3: integral curve [50]. 
The initial linear section of the force-time curve displays elastic deformation and then initially plastic, and later plastoelastic deformation. This demonstrates the deformation point (= the hardness), when the rate of force change $(\mathrm{N} / \mathrm{s})$ is zero or less than zero (negative value). The software presents the deformation work computed from the onset of loading to the completion of deformation. The slope of the linear section, the limiting hardness and the deformation work are characteristic properties of the pellet. The relative standard deviation of the hardness is within a range of $5 \%$, whilst that of the deformation work is $15-20 \%$ (Table 6 ).

Table 6. Deformation parameters of pellets [50] $\left(S_{\text {rel }}\right.$ denotes the relative standard deviation).

\begin{tabular}{|l|l|l|l|l|l|l|}
\hline \multirow{2}{*}{ Size } & \multicolumn{3}{|l|}{ Force } & \multicolumn{2}{l|}{ Work } & \multicolumn{2}{l|}{ Time } \\
\cline { 2 - 7 } & $(\mathrm{N})$ & $\mathrm{S}_{\text {rel }}$ & $(\mathrm{mJ})$ & $\mathrm{S}_{\text {rel }}$ & $(\mathrm{ms})$ & $\mathrm{S}_{\text {rel }}$ \\
\hline $0.8-1.2 \mathrm{~mm}$ & 0.712 & 3.83 & 0.038 & 13.07 & 2800 & 11 \\
$1.2-2.0 \mathrm{~mm}$ & 0.59 & 2.07 & 0.035 & 11.26 & 267 & 10.28 \\
\hline
\end{tabular}

The mean values were calculated from 20 measured values. It can be seen, that the particle size influences the deformation parameters. It is very interesting that the deformation (breaking) force value of the larger pellet particles is lower, and the difference is significant. The reason is that the larger particles are built up from smaller pellet particles, and in the early stages of loading the larger particles break down into these smaller particles. It can be seen that with this measurement the breaking deformation of the smallest agglomerates can be followed. 


\section{SUMMARY}

The main aim of the research work described in this dissertation was to develop measurement equipment with which to study the mechanical force effects in preformulation studies.

- A DAQ box (device and embedded software) was developed for digitalization of the strain gauge and LDTV signals of instrumented tablet machine and the hardness tester.

- Software and hardware were developed to suitable study of the deformability and compactibility of pharmaceutical powders with on instrumented eccentric tablet machine. The software acquires the upper punch force, the lower punch force and the upper punch displacement. It has a wide range of possibilities to display and evaluate the different force profiles (force-time, displacement-time, forcedisplacement). The standard profile parameters, the work of friction and the plasticity were automatically calculated.

- Software was developed to evaluate the swelling force of conventional tablets. As swelling follows second-order kinetics in the most common cases, the software uses the RRSBW distribution to fit the swelling force curve and to calculate the characteristic swelling time $\left(t_{63.2 \%}\right)$ and shape parameter $\beta$.

- The software of a swelling tester was improved to allow study of swellable matrices.

- Software was developed for studies of the hardness and deformation behaviour of solid dosage forms. The software acquires the signals of the load cell and the displacement of the pressure jowl. During evaluation, it displays the deformation curve and the calculated work curve, and calculates the hardness of the material.

- These instruments were validated and widely tested on well-known materials in practice.

- The main findings were as follows: 
1. The effect of pressure was studied in the case of the deformability of medicated chewable polymers.

2. Via the effect of the compression force, the deformability of coated crystals was studied. It turned out that the film coating caused a decrease in plasticity. This can be explained by the film between the crystals.

3. The swelling behaviour of some sodium starch glycolate products was studied. It was established that it is possible to choose the pressure suitable for tableting. If the increase of pressure causes no or only a very small change in the swelling force, it is unnecessary to use a high pressure during tableting.

4. The software is suitable for study of the swelling force of a swellable matrix system during water uptake. It was found that it is possible to apply the power law model to fit the swelling kinetics of swellable matrices; and the driving force of this kinetics is the non Fickian diffusion of water.

5. "Breaking software" was used to study of the breaking behaviour of pellets containing theophylline. The developed breaking hardness equipment can be used very well for the investigation of the deformation behaviour of pellets. 


\section{PRACTICAL USEFULNESS}

The practical result of this work is to development of computer-aided measurement and analysis systems for preformulation studies and quality insurance of solid dosage forms.

- In tests based on the qualitative and quantitative results of compressibility, it is possible to determine the optimum composition (disintegrants, binding agents, lubricants, etc.) of tablets. The developed equipment in conjunction with the software is suitable for determination of all the critical compressional parameters which play important roles in production and in the quality of tablets.

- The deformation behaviour of tablets plays a condiserable role in the preparation of the final forms.

- The deformability of granules/pellets may also be critical from the aspect of the qualification of the product.

- Study of the deformability of polymer films is also important for the preparation of a suitable composition.

- The swelling force plays an important part in the qualification, and in the choise of the suitable disintegrants. The knowledge of swellability is also important in the development of swellable matrix tablets.

The developed equipment is now in everyday use in the scientific research work and in the educational work in pre- and postgraduate courses at our department $[33,34$, 44-47].

Process analytical technology is currently playing an important role in the development and manufacturing of dosage forms in the pharmaceutical industry. It permits the monitoring and control of every step in the development cycle. The application of new equipment and algorithms makes possible the more precise determination of the preformulation parameters for the pharmaceutical industry. 


\section{REFERENCES}

1. Park, J. and Mackay, S.: Practical Data Acquisition for Instrumentation and Control Systems. Elsevier Science (2003)

2. Kuo, S. M. and Lee, B. H.: Real-Time Digital Signal Processing. John Wiley \& Sons Ltd. (2001)

3. Parker, M.: Digital Signal Processing. Elsevier Inc. (2010)

4. Austerlitz, H.: Data Acquisition Techniques Using PCs. Elsevier Science (2003)

5. Rabiner, L. R., and Gold, B.: Theory and Application of Digital Signal Processing. Prentice-Hall Inc, (1975)

6. Simth, S. W.: The Scientist and Engineer's Guide to Digital Signal Processing. 2nd Edition. California Technical Publishing (1999)

7. Levin, M: Tablet Press Instrumentation. Marcel Dekker Inc. (2002)

8. Ridgway, P. Watt, Tablet machine instrumentation in pharmaceutics: principles and practice. Ellis Horwood Ltd., Chichester, 1988, p. 23.

9. Emscherman, B. and Müller, F.: Auswertung der Kraftmessung beim Tablettieren. Pharm. Ind. 43, 191- 194 (1981)

10. Alderborn, G., Nyström, C.: Pharmaceutical Powder Compaction Technology. Marcel Dekker Inc. (1996)

11. Stamm, A. and Mathis, C. :Acta Pharm. Technol., 22 (1976) 7.

12. Järvinen, M. and Juslin M. J.: On frictional work at die wall during tablet compression. Farm. Aikak. 83, 1-8.

13. Lowenthal, W.: J.Pharm. Sci. 1972, 61, 1695-1711

14. Kang, J. I. and Rudnic, E. M.: Pharm Technol. 1984, 8,50-58, 61-63.

15. Bolhuis, G.K. van Kamp, H. V., Lerk, C.F. and Sessink, F. G. M. Acta Pharm Technol 1982, 28, 111-114.

16. van Kamp, H. V, Bolhuis, G.K., de Boer, A. H, Lerk, C.F and Lie-A-Huen, L.: Pharm Acta Helv. 1986, 61, 22-29

17. List, P, H. and Muazzam, U. A.: Pharm Ind. 1979, 41, 459-464 
18. Langenbucher, F. : Parametric representation of Dissolution-Rate Curves by the RRSBW Distribution. Pharm Ind. 38. Nr. 5 (1976)

19. Xie, M. and Jiang, R.: Weibull Models. John Wiley \& Sons, Inc. (2004)

20. Fell, J. T. and Newton, J. M.: Determination of tablet strength by the diametrical compression test. J. Pharm. Sci. 59, 688-691.

21. Arnold, K.: Embedded Controller Hardware Design. LLH Technology Publishing. (2000)

22. Johnson, D. E. and Moore, H. P.: A Handbook of Active Filters. Prentice-Hall Inc. (1980)

23. Robinson, E.A. and Silvia, M.T.: Digital Dignal Processing and Time series Analysis. Holden-Day Inc. 1978.

24. Simonyi, E: Digitális Szűrők. Műszaki Könyvkiadó Budapest 1984.

25. Zurell, K.: C Programming for Embedded Systems. R\&D Books Lawrence. (2000)

26. Kernighan, B. W., Ritchie, D.: The C Programming Language Prentice-Hall Inc. (1978)

27. Barr, M.: Programming Embedded Systems in C and C++. O'Reilly (1999)

28. Stroustrup, B.: The C++ Programming Language. 3th Edition. Addison-Wesley Inc. (1997)

29. Barabolak, R., Hoerman, K., Kroll, N. and Record, D. :Gum chewing profiles in the U.S. population. Commun. Dent. Oral Epidemiol. 1991; 19:125-6.

30. Rider, J.N., Brunson, E.L., Chambliss, W.G., Cleary, R.W., Hikal, A.M., Rider, P.H., Walker, L.A., Wyandt, C.M. and Jones, A.B. Development and Evaluation of a Novel Dissolution Apparatus for Medicated Chewing Gum Products. Pharm. Res. 1992; 9: $255-259$.

31. Rassing M.R.: Chewing gum as a drug delivery system. Adv Drug Del Rev (1994); 13:89-21

32. Testa, E.S., U.S. Patent 1999;5:866,179

33. Kása, P., Bajdik J., Zsigmond Zs. and Pintye-Hódi K. Study of the compaction behaviour and compressibility of binary mixtures of some pharmaceutical excipients during direct compression. Chem. Eng. Process. (2009); 48:859-863. 
34. Hódi K.: Korszerü vizsgáló módszerek alkalmazása a szilárd gyógyszerformák fejlesztésében és minőségbiztosításában. DSC dissertation, Szeged, 2004

35. Crank, J.: The mathematics of diffusion. 2nd Edition.Oxford University Press (1975).

36. Korsmeyer, R.W., Gurny, R.,Doelker E.M., Buri P.and Peppas N.A.: Mechanism of solute release from porous hydrophilic polymers. Int J Pharm. (1983).15:25-35

37. Peppas, N.A.: Analysis of Fickian and non-Fickian drug rlelase from polymers. Pharm acta Helv. (1985) 60: 110-111

38. Yuasa, H., Nakano, T. and Kanaya, Y.: Int. J. Pharm., 178 (1999) 1.

39. Muskó, Zs., Pintye-Hódi, K., Szabó-Révész, P., Kása Jr, P., Erős I. and Deák, D. Pharmazie, 55 (2000) 465.

40. Seppic brochure, Seppic INC. Paris 1994

41. Prafitt, K.: Martindale, the Complete Drug Reference, 34th Edition, Pharmaceutical Press, London 1999, p.408.

42. Cartensen, J. T,: Solid Pharmacetics:Mechanical Properties and Rate Phenomena, Academic Press, New York 1980, p. 184.

43. Ghebre-Sellassie, I.: Pharmacetical Pelletization Technology, pp. 1-15. WarnerLambert Morris Plains, New Jersey (1989)

44. Pintye-Hódi, K., Regdon Jr., G., Erős, I., Süvegh, I., Marek, T., Kéry, I. and Zelkó, R. : Metolose-PEG interaction as seen by positron annihilation spectroscopy, Int. J. Pharm. 2006, 313, 66-71

45. Bajdik, J. and Pintye-Hódi, K.: Study of deformation process of stored polymethacrylate free films, Pharmazie, 2006, 61, 887-888

46. Hamedelniel E. I., Bajdik J. and Pintye-Hódi K.: Optimization of preparation of matrix pellets containing ethylcellulose, Chem. Eng. Process. 2010, 49, 120-124

47. Sovány T., Kása P. jr. and Pintye-Hódi K.: Comparison of the halving of tablets prepared with eccentric and rotary tablet presses, AAPS, 2009, 10, 430-436

Related publication of author

48. Kelemen, A., Szöllösi, A., Zsótér, A., Pintye-Hódi, K., Török, C. and Erős, I.: Measurement of the swelling force of some sodium strach glycolate products with new software. Hung. J. Ind. Chem. Vol. 30 pp. 73-76 (2002) 
49. Bajdik, J., Pintye-Hódi, K., Novák, Cs., Kelemen A., Regdon Jr, G. and Erős. I,: Indirect methods for determination of the protective effects of coating films on the surface of crystals. J. Therm. Anal. Calorim., Vol 68 (2002) 613-627.

50. Muskó, Zs., Bajdik, J., Pintye-Hódi, K., Szabó-Révész, P., Kelemen, A. and Erős, I.: Preparation of pellets containing theophylline. Pharm. Ind. 64. Nr.11. 1194-1198. (2002).

51. Kása Jr, P., Jójárt, I., Kelemen, A. and Pintye-Hódi, K. (2011): Formulation study of directly compressible chewable polymers containing ascorbic acid. Pharm. Dev. Tech. (DOI: 10.3109/10837450.2011.646426) IF: 1,107 


\section{Acknowledgements}

I am very grateful to my supervisor

Professor Dr. Klára Pintye-Hódi

for her support. I greatly appreciate her continuous help during the preparation of my thesis and for providing the excellent facilities for this study. I owe my warm gratitude to her for criticism, encouragement and numerous discussions during my Ph.D. work.

I would like to thank Professor Dr. Erős István

Head of the Ph.D. programme Pharmaceutical Technology for providing me with the possibility to complete my work.

My warmest thanks go to Professor Dr. Piroska Szabó-Révész, present Head of the Department of Pharmaceutical Technology for her support.

I express my kindest thanks to all my co-authors for their collaboration in this work.

I thank all members of the department for their help and friendship.

I owe my thanks to my family for their support, encouragement and understanding attitude during these years. 


\section{ANNEX}

\section{Related articles}


I. 


\title{
Formulation study of directly compressible chewable polymers containing ascorbic acid
}

\author{
P. Kása ${ }^{1}$, I. Jójárt ${ }^{1}$, A. Kelemen², and K. Pintye-Hódi ${ }^{1}$ \\ ${ }^{1}$ Department of Pharmaceutical Technology and ${ }^{2}$ Department of Applied Informatics, University of Szeged, \\ Szeged, Hungary
}

\section{Abstract}

The topic of this article is the compression physics of different gum bases which can be used to prepare chewing gum tablets by direct compression. Three different gum bases, Pharmagum ${ }^{\circledR}$ C, M and S, were tested alone and in different combinations. The preparations were compressed with a Korsch EKO eccentric tableting machine at compression forces of 5, 7.5, 10, 12.5 and $15 \mathrm{kN}$. The compression and breaking processes and the physical parameters of the tablets were investigated. The results revealed that increase of the compression force did not significantly change the studied parameters of the tablets.

Keywords: Chewing gum, direct compression, deformation, dissolution, Pharmagum, ascorbic acid

\section{Introduction}

Chewing gum has been used world-wide since ancient times when man experienced the pleasure of chewing a variety of gum-like substances, such as tree resins, leaves, waxes and animal skins.

The dosage form or delivery system is critical for the success of a pharmaceutical or a food product. Today, chewing gum is undergoing new consideration as a drug delivery system; it provides patient benefit and compliance, and has new competitive advantages from the technological and marketing aspects. Medicated chewing gums are solid, single-dose preparations that have to be chewed but not swallowed. Chewing gums contain one or more active pharmaceutical ingredients (APIs) that are released by chewing (Ph.Eur.). ${ }^{[1]}$ A medicated chewing gum is intended to be chewed for a certain period of time, required to deliver the dose, after which the remaining mass is discarded. ${ }^{[2,3]}$ During the chewing process, the drug contained in the gum product is released from the mass into the saliva and can be absorbed through the oral mucosa or swallowed, reaching the stomach for gastrointestinal absorption.

Chewing gum consists basically of a neutral and tasteless masticatory gumbase and several non-masticatory ingredients, such as fillers, softeners, sweeteners, favoring and texture regulating agents. ${ }^{[1,4]}$ The gum bases currently used are mostly of synthetic origin and comprised of elastomers, resins, waxes, fats and emulsifiers. The elastomers are styrene-butadiene copolymers mixed with polyisobutene. The addition of rosin esters and polyvinyl acetate improves the texture, allows longer-lasting flavor and reduces the tendency of the gum to stick to the teeth. Other agents, such as glycerol monostearate and lecithin, act as emulsifiers and promote the uptake of saliva during chewing. ${ }^{[5]}$

Powdered sugar and corn syrup were originally used as bulk sweeteners; nowadays, a mixture of sorbitol, xylitol, mannitol and aspartame is more commonly used in sugar-free, non-cariogenic gums and medicinal products. ${ }^{\left[{ }^{[6}\right]}$

Unfortunately, the thermal instability of many active ingredients (vitamins, vegetable extracts, etc.) precludes traditional chewing gum production methods because the temperature profiles associated with this type of production may reach $90^{\circ} \mathrm{C} \cdot{ }^{[7]}$

Recently, chewing gums produced by direct compression have been proposed. ${ }^{[8]}$ With this conventional tablet compression technology, these chewing gums can include higher levels of active ingredients than in traditional extruded gums; the lower temperature protects sensitive

Address for Correspondence: Prof. Klára Pintye-Hódi, Department of Pharmaceutical Technology, University of Szeged, H-6720 Szeged, Eötvös u. 6, Hungary. Tel: +36/62545576. Fax: +36/62545571. E-mail: klara.hodi@pharm.u-szeged.hu 
bioactive and phytochemical components and the lower moisture content improves the shelf-life of active molecules. However, the most common drawback in direct compression of the gum base is that it sticks to the punches of the tableting equipment. This is due to the adhesive nature of the gum, the main component of the formulation; for this reason, the procedure is difficult and needs a lower production speed and cooling operations in order to prevent tableting machine damage. The tableting tools are kept at temperatures below $18^{\circ} \mathrm{C}$; however, it should be noted that the temperature should not be so low as to interfere with the handling of the medicated gums and the tableting process. Thus, the temperature should be above $10-12^{\circ} \mathrm{C}$.

For investigation of the dissolution of active pharmaceutical ingredients (API's) from medicated chewing gum tablets, different apparatuses have been developed. The chewing equipment applied was developed by Erweka $\mathrm{GmbH}$, and described by Kvist et al. ${ }^{[9]}$ Further descriptions of dissolution and chewing gum tablet investigations have been reported by Azarmi et al. ${ }^{[10]}$

The objective of this work was to study the compression and breaking processes of different gum bases at room temperature by a direct compression technique with conventional pharmaceutical equipment efficiently providing the product, and to investigate the dissolution of an API.

\section{Materials and methods}

\section{Materials}

Ascorbic acid was used as model material (Ph. Eur.). Pharmagum C, M and S (gifts from SPI Pharma) were used as gum bases. Pharmagum $M$ has a $50 \%$ greater gum base than Pharmagum S, which consists primarily of gum base and sorbitol. Pharmagum $\mathrm{M}$ contains gum base, mannitol and isomalt.

According to the manufacturer data, Pharmagum $\mathrm{S}$ is suitable for formulations with low drug loading and when incorporated into tablets gives them chewable character. Pharmagum $\mathrm{M}$ is suggested for medium drug loading $(<50 \%)$; it improves the mouthfeel texture. Pharmagum $\mathrm{C}$ is suggested for high drug loading ( $>50 \%)$; it has a real chewing gum character.

Pharmagum mixtures were prepared in different ratios to study the compactness and deformability (Table 1). Compactness means the permanent bindings which are formed during loading and deformability refers to the shape modification of the particles during loading. Besides ascorbic acid as API, additional components of the mixtures were xylitol (frequently used in tablets as a sweetener), magnesium stearate (as a lubricant) and aroma (to give the tablets a better smell).

\section{Methods}

\section{Tableting}

The tablets were prepared with a Korsch EK0 eccentric tableting machine, E. Korsch Maschinenfabrik, Germany. The compression tools were flat-faced, bevel-edged punches $10 \mathrm{~mm}$ in diameter and equipped with strain gauges and a displacement transducer. The strain gauges allowed the pressure forces on the upper and lower punches to be followed with force-measuring equipment, which was calibrated with a Wazau HM-HN-30kN-D cell (Kaliber Ltd., Budapest, Hungary). The displacement transducer (Micropulse, BTL5A11-M0050-P-532, Balluff, Neuhausen/Filder, Germany) was fitted over the upper punch. The transducer distance accuracy was checked by using five measuring pieces of different accurately known thicknesses (2.0, 5.0, 7.5, 10.0 and $15.0 \mathrm{~mm}$ ) under zero load (Mitutoyo, Tokyo, Japan). The compression was carried out electrically at $36 \mathrm{rpm}$, at an air temperature of $24^{\circ} \mathrm{C}$ and at a relative air humidity of $45 \%$. The average mass of the tablets was $0.47 \pm 0.01 \mathrm{~g}$. Ten tablets were compressed at compression forces of $5,7.5,10,12.5$ and $15 \mathrm{kN}$ for each sample (when possible). Lots with relative standard deviations not exceeding $5 \%$ were accepted.

The force-displacement curves were plotted, and the compression parameters - effective work $\left(E_{2}\right)$, elastic recovery $\left(E_{3}\right)$ and plasticity $\left(P_{1}\right)$ - were calculated from the curves with our own software Kása et al. ${ }^{[11]}$

The $E_{1}, E_{2}$ and $E_{3}$ energies are calculated by the following equations:

$E_{1}=\frac{F_{\max } C}{2}-\left(E_{2}+E_{3}\right)$

$E_{2}=\int_{A}^{B} F_{\text {upper }} d s-E_{3}$

$E_{3}=\int_{B}^{D} F_{\text {upper }} d s$

where

$F_{\max }=$ maximum force during compressing; $C=$ displacement; $F_{\text {upper }}=$ maximum force measured on the upper punch; $d s=$ elemental value of the displacement.

The plasticity was calculated with the formula: $\mathrm{Pl}=\mathrm{E} 2$ / E2 + E3.

Table 1. Compositions of powder mixtures.

\begin{tabular}{llll}
\hline \multicolumn{4}{c}{ Pharmagum (\%) } \\
\hline & C & M & S \\
\hline S 1 & 60 & 40 & \\
S 2 & 50 & 50 & \\
S 3 & 40 & 60 & \\
S 4 & 60 & & 40 \\
S 5 & 50 & & 50 \\
S 6 & 40 & & 60 \\
S 7 & & 60 & 40 \\
S 8 & & 50 & 50 \\
S 9 & & 40 & 60
\end{tabular}

The amounts of the following materials were the same in all cases (\%)

$\begin{array}{ll}\text { Ascorbic acid } & 8.33 \\ \text { Xylitol } & 7.68 \\ \text { Aroma } & 0.33\end{array}$

Magnesium stearate 2

API concentration: $33 \mathrm{mg} /$ tablet.

Average tablet weight: $0.47 \mathrm{~g}$. 
The real force-displacement diagram can be seen in Figure 1. (S1 sample) where $E_{1}=44.58 \%, E_{2}=46.22 \%$ and $E_{3}=9.21 \%$.

\section{Friability test}

The friability of the chewing gum tablets was tested with an Erweka TA 100 friabilator (Erweka $\mathrm{GmbH}$, Heusenstamm, Germany).

\section{Breaking strength}

The breaking strength was tested with a self-developed tablet hardness tester, which is connected to a computer and a special software is applied to edit the force-time diagram.

Technical parameters of the hardness tester:

- Range of measurement: 0-200 N

- Rate of pressing jaw: $20 \mathrm{~mm} / \mathrm{min}$

- Registration output: 0-500 mV

- Force sensor: Unicell load cell (MIKI) $200 \mathrm{~N}$

\section{Preparation of mixtures}

The mixtures of two of the Pharmagum materials in various ratios were prepared with a Turbula mixer (Willy A

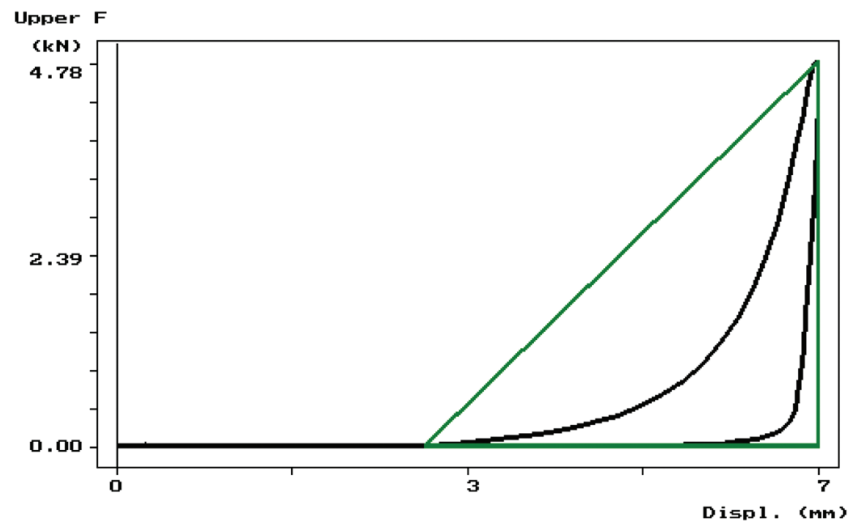

Bachofen, Switzerland) at $50 \mathrm{rpm}$ for $8 \mathrm{~min}$, after which the other components were added, and mixing was continued for a further $2 \mathrm{~min}$ (Table 2). The mass of each powder mixture was $200 \mathrm{~g}$.

\section{Dissolution test}

Conventional tablet or capsule dissolution testers are not applicable for the investigation of chewing gum tablets because of the nature of the preparation. Solid oral dosage forms are generally swallowed and the API subsequently dissolves in various parts of the gastrointestinal tract. Chewing gum tablets are usually not swallowed but masticated, and the API dissolves in a very small amount of dissolution medium. The effective material does not come into direct contact with the stomach, but must dissolve in the saliva. After dissolution, the saliva is swallowed and only a diluted quantity of the API reaches the gastric juice.

For the dissolution tests, an Erweka chewing apparatus was used. ${ }^{[9]}$ Each chewing gum sample was chewed with this apparatus for 10,20 or $30 \mathrm{~min}$, in the presence of 20 of dissolution medium (purified water), after which the ascorbic acid content of the liquid was determined by spectrometry.

Table 3. Compressionability of the mixtures.

\begin{tabular}{lcccc}
\hline & B.d.g/cm & T.d.g $/ \mathrm{cm}^{3}$ & C.i. \% & Tr.d. g/ $\mathrm{cm}^{3}$ \\
\hline S 1 & 0.59 & 0.64 & 8.72 & 1.31 \\
S 2 & 0.58 & 0.64 & 10.00 & 1.31 \\
S 3 & 0.59 & 0.64 & 7.95 & 1.32 \\
S 4 & 0.68 & 0.74 & 8.46 & 1.33 \\
S 5 & 0.71 & 0.76 & 5.38 & 1.33 \\
S 6 & 0.70 & 0.74 & 4.88 & 1.33 \\
S 7 & 0.70 & 0.73 & 4.61 & 1.32 \\
S 8 & 0.70 & 0.75 & 5.90 & 1.33 \\
S 9 & 0.72 & 0.77 & 6.41 & 1.33 \\
\hline
\end{tabular}

B.d., bulk density; C.i., Carr's index; T.d., tapped density; Tr.d., true density.

Figure 1. Recorded force-displacement diagram of S1 sample.

Table 2. Powder rheological test.

\begin{tabular}{|c|c|c|c|c|c|c|}
\hline & $\begin{array}{l}\text { Material of the } \\
\text { funnel }\end{array}$ & Flowing time (s) & $\begin{array}{l}\text { Agitation speed } \\
(\mathrm{r} / \mathrm{min})\end{array}$ & Angle of slope $\left(^{\circ}\right)$ & $\begin{array}{l}\text { Heap volume } \\
(\mathrm{ml})\end{array}$ & Heap mass (g) \\
\hline Ascorb. acid & $\mathrm{T}$ & 12.3 & 25 & 33.1 & 85.6 & 77.8 \\
\hline Phg C & $\mathrm{T} / \mathrm{M}$ & - & - & - & - & - \\
\hline Phg M & $\mathrm{T} / \mathrm{M}$ & - & - & - & - & - \\
\hline Phg S & $\mathrm{T}$ & 7.5 & 25 & 26.2 & 64.4 & 56.6 \\
\hline S 1 & M & 12.3 & 10 & 29.3 & 73.4 & 58.8 \\
\hline S 2 & M & 10.3 & 10 & 29.4 & 73.9 & 59.7 \\
\hline S 3 & M & 10.0 & 10 & 29.8 & 75.0 & 58.8 \\
\hline S 4 & M & 7.6 & 5 & 26.6 & 65.6 & 66.9 \\
\hline S 5 & M & 7.3 & 10 & 27.5 & 68.2 & 67.8 \\
\hline S 6 & M & 7.4 & 10 & 28.3 & 70.6 & 65.5 \\
\hline S 7 & M & 8.3 & 10 & 29.1 & 73.0 & 66.4 \\
\hline S 8 & M & 8.4 & 10 & 28.4 & 70.9 & 68.6 \\
\hline S 9 & M & 8.1 & 10 & 28.1 & 71.5 & 69.3 \\
\hline
\end{tabular}

M, metal; T, teflon.

$-=$ not measurable. 


\section{Results and discussion}

The tests on the flow properties of the bulk gum samples showed that Pharmagum $C$ and $M$ could not flow out from either a teflon or a metal funnel, in spite of the agitation of the powder. Pharmagum S displayed good flowability from a teflon funnel on mixing at $25 \mathrm{rpm}$ (Table 3 ). The API flowed from a teflon funnel on agitation at $25 \mathrm{rpm}$.

Table 4. Effect of compression force on elasticity and friction for bulk gum bases.

\begin{tabular}{lclc}
\hline Sample & $F_{\text {upper }}(\mathrm{kN})$ & FW $(\mathrm{J})$ & $E_{3}(\mathrm{~J})$ \\
\hline Gum C & 5 & 0.022 & 0.43 \\
& 10 & 0.037 & 1.35 \\
Gum M & 15 & 0.047 & 3.61 \\
& 5 & 0.003 & 0.25 \\
& 10 & 0.013 & 1.24 \\
Gum S & 15 & 0.066 & 2.90 \\
& 5 & 0.100 & 0.49 \\
& 10 & 0.138 & 1.12 \\
& 15 & 0.162 & 3.91 \\
\hline
\end{tabular}

FW shows the work which arises during the tablet ejection. $E_{3}$ shows the elastic recovery.
The compaction tests on the bulk materials resulted in every case in high elastic recovery (Table 4). As concerns tablettability, the flowability and compactness can be important properties. Solid bridges formed during compression phase can be broken in the elastic recovery phase. In the tablet compositions, therefore the bulk gum powders were mixed with the other components in different ratios (Table 1).

Table 5. Relationship between compositions and $E_{3}$ areas.

\begin{tabular}{|c|c|c|c|c|c|c|c|c|}
\hline \multirow[b]{2}{*}{ Sample } & \multicolumn{3}{|c|}{$\begin{array}{l}\text { Compositions } \\
\text { (Gum base) }\end{array}$} & \multicolumn{5}{|c|}{$E_{3}(\mathrm{~J})$ Compression forces $(\mathrm{kN})$} \\
\hline & $\mathrm{C}$ & M & $\mathrm{S}$ & 5 & 7.5 & 10 & 12.5 & 15 \\
\hline$S 1$ & 60 & 40 & - & 0.48 & 1.07 & 1.69 & 2.51 & 3.36 \\
\hline $\mathrm{S} 2$ & 50 & 50 & - & 0.42 & 1.10 & 1.76 & 2.16 & 2.59 \\
\hline S 3 & 40 & 60 & - & 0.36 & 0.98 & 1.56 & 2.04 & 2.60 \\
\hline S 4 & 60 & - & 40 & 0.70 & 1.30 & 1.84 & 2.30 & 2.72 \\
\hline S 5 & 50 & - & 50 & 0.62 & 1.07 & 1.52 & 2.26 & 2.89 \\
\hline S 6 & 40 & - & 60 & 0.67 & 1.05 & 1.49 & 2.19 & 3.05 \\
\hline S 7 & - & 60 & 40 & 0.56 & 1.03 & 1.55 & 2.36 & 3.01 \\
\hline S 8 & - & 50 & 50 & 0.61 & 1.05 & 1.55 & 2.27 & 3.02 \\
\hline S 9 & - & 40 & 60 & 0.58 & 1.06 & 1.56 & 2.29 & 3.02 \\
\hline
\end{tabular}

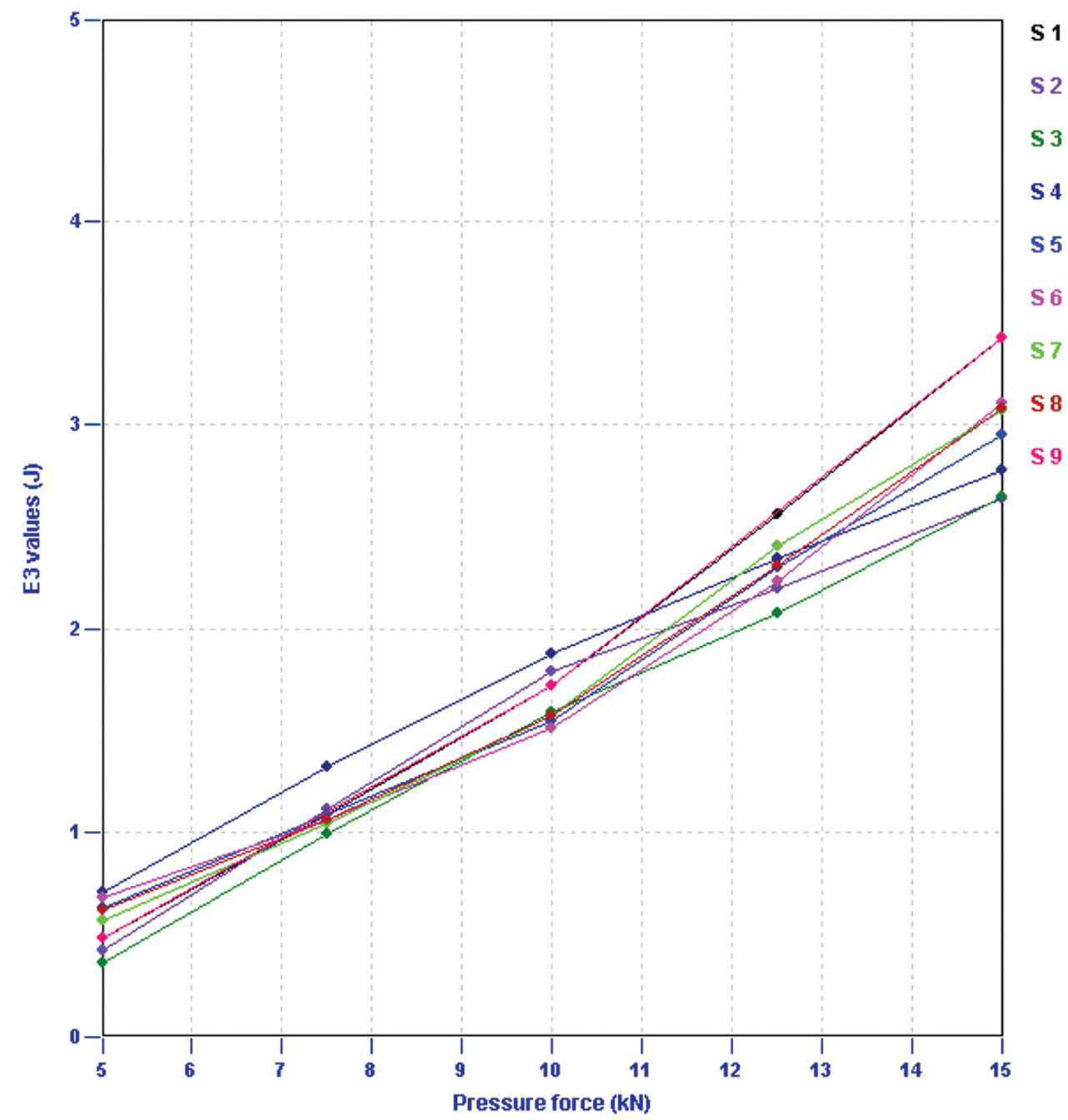

Figure 2. Relationship between the Pressure force and Elastic recovery. (See colour version of this figure online at www.informahealthcare. $\mathrm{com} / \mathrm{phd})$ 
The data in Table 3 reveal that the powder mixtures could flow from a metal funnel on moderate stirring. Mixture S4, which contains Pharmagum S, exhibited the best flowability to which an agitation speed of only $5 \mathrm{rpm}$ was applied. The flowability properties of the mixtures containing Pharmagum S were generally better. These data are in accordance with the other powder rheological parameters.

The Carr index, calculated from the bulk and tapped densities, indicates that the powder mixtures have excellent compressibility (Table 3). However the mixtures adhered to the punches during tableting, which is an unfavorable property. Fortunately, this could be eliminated through the use of a teflon film on the punch surface.

The different compression parameters for the mixtures were calculated at different compression forces (effective work $=E_{2}$, elastic recovery $=E_{3}$, plasticity $=P_{1}$ ).

For gums, elasticity is the most important property. After the compression maximum, when the upper punch starts to move upwards, elastic materials display some recovery. The degree of elastic recovery varied linearly with the compression force $\left(y=a x+b\right.$, where $y=E_{3}$, $a=$ slope, $x=$ compression force, and $b=$ intercept), with a very good correlation $\left(R^{2}=0.984-0.999\right)$ (Figure 2). Further, the degree of elastic recovery increased in all mixtures after compression (Table 5). Pharmagum M influenced the elastic recovery to the highest degree. S1, S2 and S3 tablets had the smallest $E_{3}$ values at a compression force of $5 \mathrm{kN}$ and these values decreased linearly with increasing Pharmagum M content. (from the aspect of tableting, the smallest $E_{3}$ value is advantageous.) For S2 and S3 tablets, the decreases in $E_{3}$ were smaller, and at 10 and $15 \mathrm{kN}$ the Pharmagum $M$ and $C$ ratios of $50: 50$ and 40:60 had practically no effect on the $E_{3}$ values. For the other mixtures, the ratio usually had very little effect on the degree of elastic recovery at different compression forces, except for the S6 mixture compressed at $15 \mathrm{kN}$. The elastic properties of the API and other ingredients do not have such high effect which causes any changes of the elastic behavior of the gum bases.

The friability of the tablets was less than $0.1 \%$ in all cases, and they met the requirements of Ph.Eur., but this is expected from a gum tablet. Another postcompression test involves the breaking strength; this differs from the case of conventional tablets because after crushing the tablets did not break completely. The deformation curves during loading demonstrate elastic deformation with a rather high slope (Figure 3). After a maximum, the force decreased, but the tablet did not break into small pieces; only deformation was observed, with some cracks. Increase of the pressure did not cause any significant changes in the breaking process. If the $E_{3}$ value is low the deformation force is high, which means that the appropriate chewability needs a higher force.

During the dissolution investigation the 5, 10, and $15 \mathrm{kN}$, compressed samples were tested. The results show that the dissolution of ascorbic acid did not depend on the compression force (Figure 4 ). In all cases, $90 \%$ of the

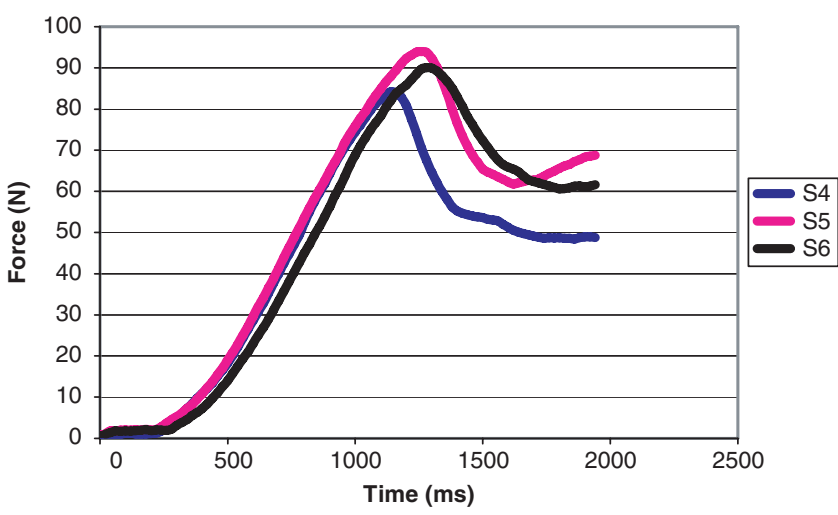

Figure 3. Deformation curves during loading (samples S4, S5 and $\mathrm{S6}$, pressure force $5 \mathrm{kN}$ ). (See colour version of this figure online at www.informahealthcare.com/phd)

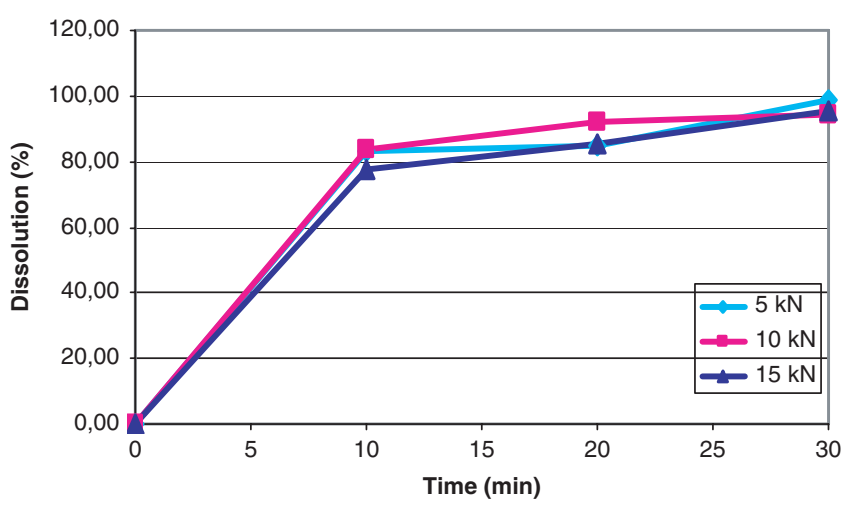

Figure 4. Dissolution profile of sample S5.

API dissolved in the first $10 \mathrm{~min}$, and after chewing for 30 min the whole amount had dissolved.

\section{Conclusions}

The powder rheological parameters, and especially the flowability, conclude that Pharmagum $\mathrm{C}$ and $\mathrm{M}$ are not suitable for the preparation of direct-compressed chewing gum tablets. Pharmagum $S$ increased the powder rheological properties and the compressibility, but all of the compositions resulted in suitable tablets at a compression force of $5 \mathrm{kN}$. The physical parameters and the dissolution rate from these tablets were very good, so that increase of the compression force was unnecessary.

Finally, it can be stated that chewing gum is an alternative drug delivery system with several advantages especially for kids and geriatric patients who experience difficulties swallowing the traditional oral solid dosage forms, and it is possible to prepare by direct compression, which is economic preparation procedure.

\section{Acknowledgments}

The authors' thanks go to Erweka GmbH, Heusenstamm, for help with the dissolution investigations. 


\section{Declaration of interest}

The project named TÁMOP-4.2.1/B-09/1/Konv-20100005- Creating the Center of Excellence at the University of Szeged" is supported by the European Union and cofinanced by the European Regional Fund.

\section{References}

1. Barabolak R, Hoerman K, Kroll B, Record D. Gum chewing profiles in the U.S. population. Community Dent Oral Epidemiol 1991;19:125-126.

2. Rider JN, Brunson EL, Chambliss WG, Cleary RW, Hikal AH, Rider PH et al. Development and evaluation of a novel dissolution apparatus for medicated chewing gum products. Pharm Res 1992;9:255-259.

3. Rassing MR. Chewing gum as a drug delivery system. Adv Drug Del Rev 1994;13:89-121.

4. Eisenstadt B, Cash PA, Bakal AI. US Patent 1998;5:846,557.
5. Pedersen M, Rassing MR. Chewing gum as a drug delivery system for nystatin influence of solubilising agents upon the release of water insoluble drugs. Drug Dev Ind Pharm 1990;16: 2015-2030.

6. Rowe RC. By gum-a buccal delivery system. Drug Discov Today 2003;8:617-618.

7. Zyck DJ, Greenberg MJ, Barkalow DG, Marske SW, Schnell PG, Mazzone P, Witkewits DL. US Patent 1999;6:541,048.

8. Testa ES. US Patent 1999;5:866,179.

9. Kvist C, Andersson SB, Fors S, Wennergren B, Berglund J. Apparatus for studying in vitro drug release from medicated chewing gums. Int J Pharm 1999;189:57-65.

10. Azarmi S, Roa W, Löbenberg R. Current perspectives in dissolution testing of conventional and novel dosage forms. Int J Pharm 2007;328:12-21.

11. Kása P, Bajdik J, Zsigmond ZS, Pintye-Hódi K. Study of the compaction behaviour and compressibility of binary mixtures of some pharmaceutical excipients during direct compression. Chem Eng Process 2009;48:859-863.
59

60

61

62

63

64

65

66

67

68

69

70

71

72

73

74 
II. 


\title{
INDIRECT METHODS FOR DETERMINATION OF THE PROTECTIVE EFFECTS OF COATING FILMS ON THE SURFACE OF CRYSTALS
}

\author{
J. Bajdik ${ }^{1}$, K. Pintye-Hódi ${ }^{1}$, Cs. Novák ${ }^{2}$, A. Kelemen ${ }^{3}$, G. Regdon Jr. ${ }^{1}$ \\ and I. Erös ${ }^{1}$ \\ ${ }^{1}$ Department of Pharmaceutical Technology, University of Szeged, Eötvös u. 6, H-6720 Szeged, \\ Hungary \\ ${ }^{2}$ Research Group for Technical Analytical Chemistry of the Hungarian Academy of Sciences \& \\ Institute of General and Analytical Chemistry, Budapest University of Technology and Economics, \\ Szent Gellért tér 4, H-1111 Budapest, Hungary \\ ${ }^{3}$ Department of Medical Informatics, University of Szeged, Korányi fasor 9, H-6720 Szeged, \\ Hungary
}

\begin{abstract}
The extents of the protective effects of coating films on the surface of crystals were determined. Three different samples were made with different quantities of coating fluid (Sepifilm LP 010 in 10\% aqueous solution). Since the atomizing rate was constant, the coating time increased in parallel with the volume of coating fluid applied. The direct measurement of film thickness and smoothness is very difficult, and therefore indirect methods were used. Dimenhydrinate was chosen as model drug; this is a heat-sensitive antihistamine with a low melting point. This temperature can be reached during the tableting process. The behaviour of samples on exposure to heat was examined by differential scanning calorimetry. The water uptakes of the samples were determined with an Enslin apparatus. Plasticity was studied with an instrumented tablet machine. These indirect methods (thermal conductivity, water uptake and plasticity measurements) revealed connections between the results of the various experiments. An overlong coating time decreased the protective effect of the coating film.
\end{abstract}

Keywords: dimenhydrinate, DSC, film coating, HPMC, plasticity, thermal conductivity, water uptake

\section{Introduction}

Film coating is a method that is widely used for protection, retardation and identification. Gastric-soluble polymers are used to protect ingredients from light, moisture and oxygen, and for identification. Intestine-soluble polymers or permeable polymers which provide drug diffusion are utilized for retardation [1]. Several types of gastric-soluble films (cellulose derivatives, poly(methacrylates), poly(ethylene-glycols), etc.) have been used for protection. The film smoothness and thickness determine the protective effect of the coating film. These parameters are well measurable on the surface of tablets or pellets by means of image analysis [2]. The film coating of fine particles can be a useful procedure in tablet making but the sticking of these particles 
disturbs the determination of film thickness. It is difficult to avoid this sticking effect [3]. It is important to know whether the protective effect is modified or not by the quantity of coating material applied. The film coating of fine crystals could possibly be more widely used if the film smoothness and thickness can be determined.

Knowledge of the process of compression is very important in the technology of tablet making. Compression during tableting is a complex and irreversible dynamic process [4]. The behaviour of powders during such processes may be followed well with instrumented tablet machines or other indirect methods. Modern instrumented tablet machines measure the pre-compression and main compression forces on the upper and lower punches, the punch displacements, the ejection force, etc. [5]. A number of methods can be used to study compressibility from different determined data [6-8].

The determination of temperature is very important because the melting points of many organic materials are low, and are readily reached during the process of compression, e.g. busulfan 115-118, hyoscyamine 106-109, phenylbutazone 104-107 or dimenhydrinate $102-105^{\circ} \mathrm{C}$ [9]. It is well known that, if crystals are arranged side by side with a high thermal conductivity axis, this promotes the attainment of a higher temperature in a very small volume. This increased temperature can be higher than the melting point of the material and accordingly the crystals melt. Since melted materials recrystallize after compression, the particles lose their individuality. Such sites in the texture are called hot spots [10-12]. If a material decomposes at the melting point, hot spots must be avoided. This problem can arise with hormones (betamethazone or spironolactone), carbohydrates, enzymes (pancreatin $[13,14])$, etc.

Direct measurement of the heat originating in the texture of tablets during compression is very difficult. Indirect methods such as 'compaction calorimetry' [15], or differential scanning calorimetry (DSC) [16] (temperature modulated or conventional) are used to learn the behaviour of materials exposed to compression and heat. Indirect experiments demonstrated that the energy distribution and therefore the heat produced in the texture are not even [17]. A thermoanalytical method (DSC) has been used as an indirect method to establish the changes in material properties at elevated temperature.

The water uptake (wetting) is also an important characteristic because it can influence the disintegration of tablets [18]. The bioavailability of a tablet therefore can be influenced by methods which modify the water uptake.

The aim of this study was to determine the protective effect of films on the surface of crystals. It was examined how the protective effect of a coating film is modified when the quantity of coating fluid is increased. The above-mentioned parameters (thermal conductivity, water uptake and compressibilty) were examined with regard to the prediction of the smoothness and thickness of films. 


\section{Experimental}

Materials

The model drug used was dimenhydrinate (Ph. Eur. $3^{\text {rd }}$, B.No.:280-69-015), which is an ethanolamine derivative antihistamine used for the treatment of motion sickness, nausea and vomiting [19]. This material is sensitive to heat: it decomposes at the melting point, as indicated by industrial experience and a previous study [16]. The drug is well absorbed from the gastrointestinal tract. In the event of oral administration, the onset of the effect occurs after about $15 \mathrm{~min}$ [20]. A gastric-soluble polymer was therefore used. The film-forming agent was hydroxypropyl-methylcellulose (HPMC) (Sepifilm LP 010 ${ }^{\circledR}$, B.No.: 80741) (Seppic, Paris, France). Sepifilm LP $010^{\circledR}$ was applied in a $10 \%$ aqueous dispersion, containing binder, pigment and plasticizer [21].

\section{Coating}

A Strea-1 apparatus (Niro-Aeromatic AG., Switzerland) was applied with the top spray method. The coating material was a $10 \%$ aqueous dispersion of Sepifilm LP $010^{\circledR}$.

Parameters: nozzle diameter: $0.8 \mathrm{~mm}$, inlet temperature: $45^{\circ} \mathrm{C}$, outlet temperature: $30^{\circ} \mathrm{C}$, blow-out pressure: 5.6 bar, atomizing pressure: 2 bar, peripump: $10 \mathrm{ml} \mathrm{min}$, air volume: $30-40 \mathrm{~m}^{3} \mathrm{~h}^{-1}$, yield of the coating experiment: $75-80 \%$.

Sample 1 (Dim 1) - A $40 \mathrm{~g}$ aqueous dispersion was used for $100 \mathrm{~g}$ dimenhydrinate.

Sample 2 (Dim 2) - A 55 g aqueous dispersion was used for $100 \mathrm{~g}$ dimenhydrinate.

Sample 3 (Dim 3) - A $70 \mathrm{~g}$ aqueous dispersion was used for $100 \mathrm{~g}$ dimenhydrinate.

The experiments were made three times.

\section{Morphological study}

Microscopy, and especially scanning electron microscopy (SEM), has been widely used to test the shape and surface of particles. Modern SEM allows particles much smaller in size than a micrometre to be measured and the roughness of the surface to be observed. A Hitachi S 2400 (Hitachi Scientific Instruments Ltd., Tokyo, Japan) scanning electron microscope was utilized. A sputter coating apparatus (Bio-Rad SC 502, VG Microtech, UK) was applied to induce electric conductivity on the surface of the sample. The air pressure was $1.3-13 \mathrm{mPa}$.

\section{Particle size distribution}

A Laborlux S light microscope and a Quantimet 500 (Q500MC) image processing and analysis system (Leica Cambridge Ltd., Cambridge, UK) were used. 500 particles were measured. Before the tests, the dimenhydrinate crystals were dispersed in 
paraffin because of their tendency to aggregate. The coated crystals were measured without this treatment.

\section{Water uptake}

The Enslin number $\left(\mathrm{mL} \mathrm{g}^{-1}\right)$ was determined with a glass sieve and a pipette with $0.01 \mathrm{~mL}$ accuracy [18]. A monolayer of particles took up the maximum quantity of water possible through a filter paper under these conditions.

\section{Compressibilty test}

The samples were compressed into tablets with a Korsch EK0 instrumented eccentric tablet machine (Emil Korsch Maschinenfabrik, Berlin, Germany). The compression tools were single flat punches $10 \mathrm{~mm}$ in diameter, furnished with strain gauges and a displacement transducer. The strain gauges allow the forces on the upper and lower punches to be followed with force measuring equipment, which was calibrated with a Wazau HM-HN-30 kN-D cell (Kaliber Ltd., Budapest, Hungary). The displacement transducer was fitted over the upper punch. The transducer distance accuracy was checked by using five measuring pieces (made of hardened steel) of different thickness $(2.0,5.0,7.5,10.0$ and $15.0 \mathrm{~mm}$ ) under a minimal measurable load (Mitutoyo, Tokyo, Japan). The compression was carried out electrically at $36 \mathrm{rpm}$ at an air temperature of $24^{\circ} \mathrm{C}$ and a relative humidity of $45 \%$. The compressed volume was 100 $\mathrm{mm}^{3}$ for each sample. 10 tablets were compressed for each sample. The compression force on upper punch was $18 \pm 1.8 \mathrm{kN}$. The deviation of pressing force was higher for uncoated crystals because of uneven filling.

DSC

A DSC $821^{\mathrm{e}}$ (Mettler-Toledo GmbH, Switzerland) apparatus was used to check the features of the material on exposure to heat. 7.3-7.6 mg dimenhydrinate was measured into the pans. Two heating methods were applied, each involving an isothermal segment and a dynamic segment (Table 1).

Table 1 Heating segments of DSC experiments

\begin{tabular}{ccccccc}
\hline & \multicolumn{2}{c}{ Isothermal segment } & & \multicolumn{2}{c}{ Dynamic segment } \\
\cline { 2 - 3 } \cline { 5 - 6 } & Temperature $/{ }^{\circ} \mathrm{C}$ & Time $/$ min & & End-temperature $/{ }^{\circ} \mathrm{C}$ & $\begin{array}{c}\text { Heating rate/ } \\
{ }^{\circ} \mathrm{C} \mathrm{min}^{-1}\end{array}$ \\
\hline Program 1 & 25 & 3 & & 250 & 5 \\
Program 2 & 25 & 3 & & 107 & 5 \\
\hline
\end{tabular}

The heating methods were combined with each other, the methods being separated by slow cooling $\left(5^{\circ} \mathrm{C} \mathrm{min}^{-1}\right)$. If possible the melting point was determined after the first heating. Three parallel examinations were made in every case. The mathe- 
matical evaluation was carried out with the Anova test, with the SPSS 9.0 package; the confidence limit was $95 \%$.

\section{Results and discussion}

The habit of the crystals is shown in the SEM photo. The dimenhydrinate consisted of crystals with mainly a columnar form and a broad size distribution (Fig. 1; Table 2). Many particles were broken. An increase in the size of the crystals was detected during coating, but this was different from that generally observed during granulation or pelletization (Figs 2-4; Table 2). The shape of the coated crystals was not similar to that of granules or pellets. Thus, this method does not involve granulation. An increase in particle size occurs during the coating of the fine particles and is difficult to avoid [3]. The cause of this significant increase is that the small and broken particles stick into the macromolecular film. Dim 2 exhibited the best shape. The thickness of the film can be determined for pellets by image analysis methods [2]. In this case, sticking disturbed such measurements. There was no relationship between the quantity of coating fluid (and therefore the coating time) and the particle size, which can be explained by the simultaneous breaking of the crystals and of the breaking film

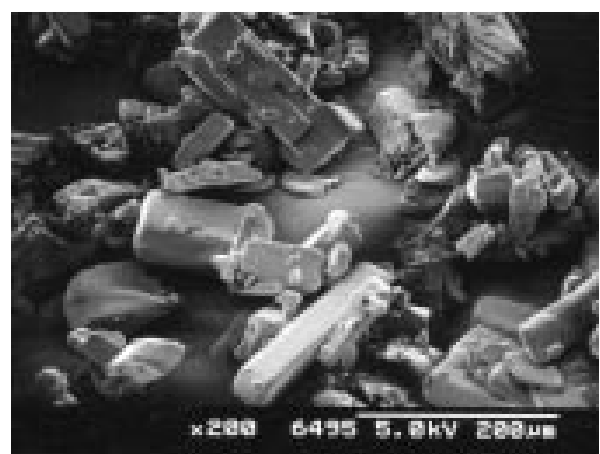

Fig. 1 Dimenhydrinate crystals (SEM)

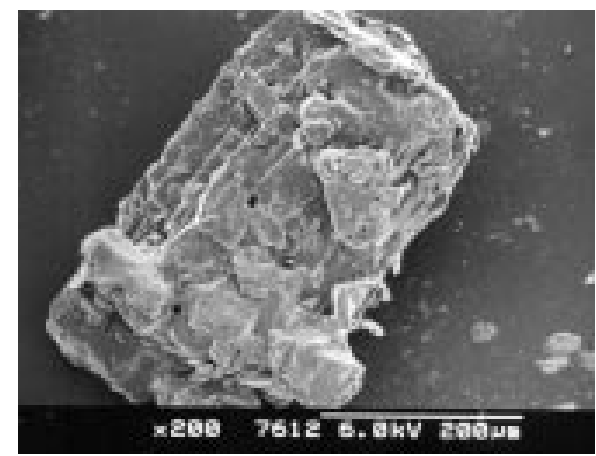

Fig. 2 Dim 1 sample (SEM) 


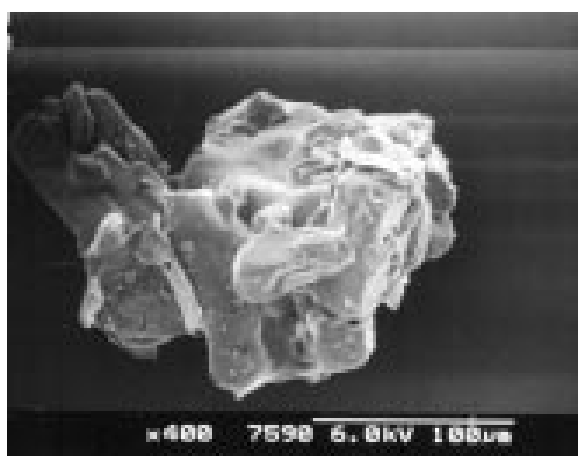

Fig. 3 Dim 2 sample (SEM)

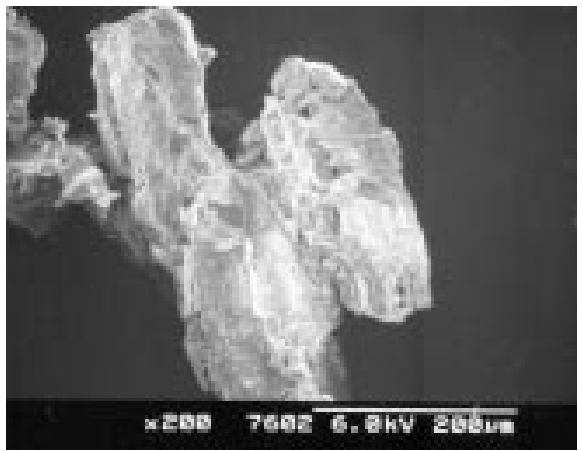

Fig. 4 Dim 3 sample (SEM)

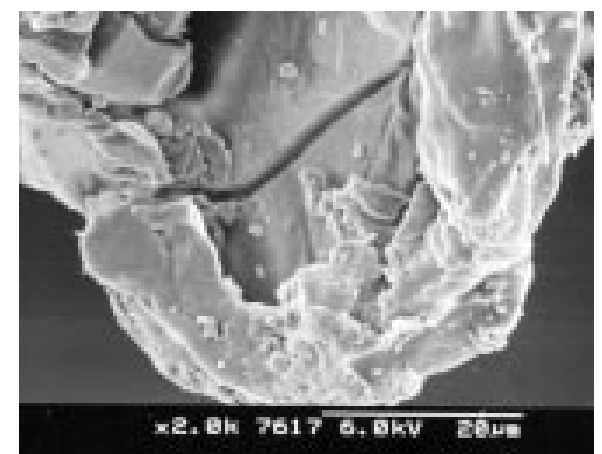

Fig. 5 Crack in coated crystals (Dim 3) (SEM)

during the film coating. Increase of the coating time led to a higher possibility of breaking of the coated crystals (Fig. 5), and therefore a decreased quality of the protecting film.

SEM photos indicated that Dim 2 exhibited the best of coating film quality. Since many parameters disturbed the exact determination of film thickness and 
smoothness by means of image analysis, other indirect methods were used in the remaining part of the work reported here, and these support the assumption that the best product was Dim 2.

Table 2 Particle sizes of samples

\begin{tabular}{lcc}
\hline Sample & Length $/ \mu \mathrm{m}$ & Breadth $/ \mu \mathrm{m}$ \\
\hline \multirow{2}{*}{ Dimenhydrinate } & 83.84 & 49.40 \\
& $(S D=54.50)$ & $(S D=29.28)$ \\
Dim 1 & 201.95 & 133.68 \\
& $(S D=114.47)$ & $(S D=73.63)$ \\
Dim 2 & 239.49 & 155.09 \\
& $(S D=129.69)$ & $(S D=80.75)$ \\
Dim 3 & 229.90 & 149.93 \\
& $(S D=159.57)$ & $(S D=102.24)$ \\
\hline
\end{tabular}

\section{Water uptake}

The extent of water uptake of crystals is very important for the bioavailiability of a tablet, because a large amount of water can promote tablet disintegration. The untreated crystals exhibited a good ability and a rapid water uptake (Table 3; Fig. 6). The coating film decreased the water uptake because it meant a restriction for the water. The coating film and the crystals did not dissolve in this quantity of water. In this case, therefore, there is a connection between the water uptake and the uniformity of the film. As the film uniformity and the thickness increased, the water uptake decreased. For Dim 3, the amount of the coating material was higher, but the coating time was therefore also increased which enhanced, the possibility of crystal breaks. The resultant of the two parallel features was the somewhat surprising result that Dim 2 displayed the smallest Enslin number. This was in accordance with the result of the morphological study: the smoothest film was observed for Dim 2.

Table 3 Enslin numbers of samples

\begin{tabular}{lcccc}
\hline & Dimenhydrinate & Dim 1 & Dim 2 & $\operatorname{Dim} 3$ \\
\hline Enslin number $/ \mathrm{mL} \mathrm{g}^{-1}$ & 0.80 & 0.68 & 0.56 & 0.65 \\
$S D$ & 0.04 & 0.04 & 0.03 & 0.02 \\
\hline
\end{tabular}

\section{Compressibility test}

The force-displacement curve was determined and the plasticity was calculated.

The force-displacement curve of the uncoated crystals may be seen in Fig. 7. The coating did not influence the shape of the force-displacement curve significantly. The smooth line is the measured curve, while the dotted lines are lines facilitating the calculation. There are three areas in the triangle. $E_{1}$ is the energy lost by rearrangement of the particles, $E_{2}$ is the useful energy and $E_{3}$ is the energy lost by elastic recovery [5]. 
The plasticity was calculated according to Stamm and Mathis equation $\left(P L_{\mathrm{S}-\mathrm{M}}\right)[22]$ :

$$
P L_{\mathrm{S}-\mathrm{M}}=\frac{E_{2}}{E_{2}+E_{3}} 100
$$

This parameter relates to the behaviour of the material under a load. If $P L_{\mathrm{S}-\mathrm{M}}$ is close to $100 \%$, the material deforms well under the load.

The uncoated dimenhydrinate crystals exhibited the highest plasticity (Table 4). The coating caused a decrease in plasticity. This can be explained by the film between the crystals. The interactions between the crystals were influenced by the film. The free coating film exhibited elastic properties, which was supported by other experiment. Not only the quantity of coating material influenced the plasticity: the uniform distribution on the surface also plays an important part, for there is a relationship between the continuity and the elastic behaviour of the film, i.e. between the film uniformity and the plasticity. Dim 2 exhibited the poorest plasticity, which can be explained in terms of the best protective effect of the coating film.

Table 4 Plasticity of samples

\begin{tabular}{lcccc}
\hline & Dimenhydrinate & Dim 1 & Dim 2 & Dim 3 \\
\hline$P L_{\mathrm{S}-\mathrm{M}} / \%$ & 69.66 & 59.61 & 43.77 & 52.93 \\
$S D$ & 6.61 & 2.32 & 2.91 & 3.07 \\
\hline
\end{tabular}

Despite the decreased plasticity, the tablettability of dimenhydrinate was not appreciably decreased by the coating because the tableting process is influenced by many parameters (flow rate of material, rearrangement of particles, lubrication, etc. [23]). Some parameters even improved (uniform filling, better lubrication, a smaller proportion of friction, etc.).

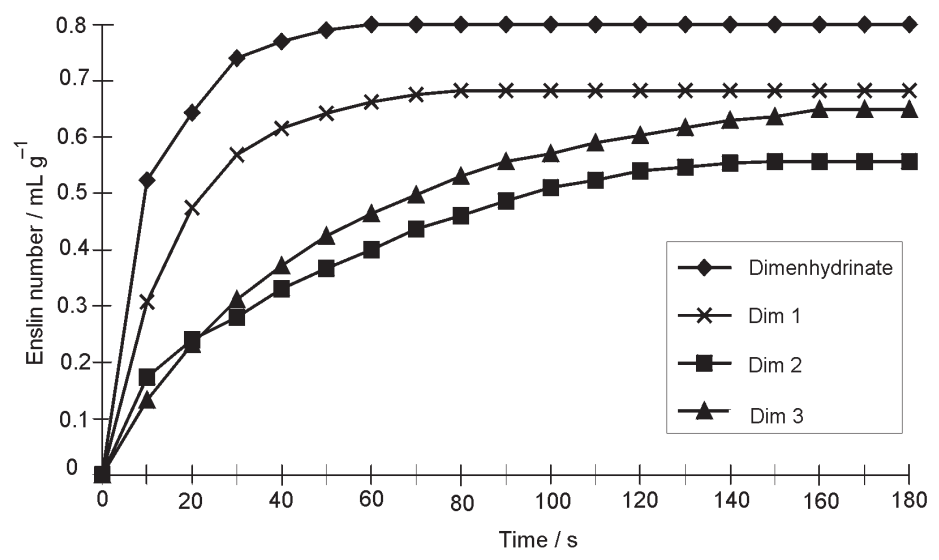

Fig. 6 Water uptake of samples 


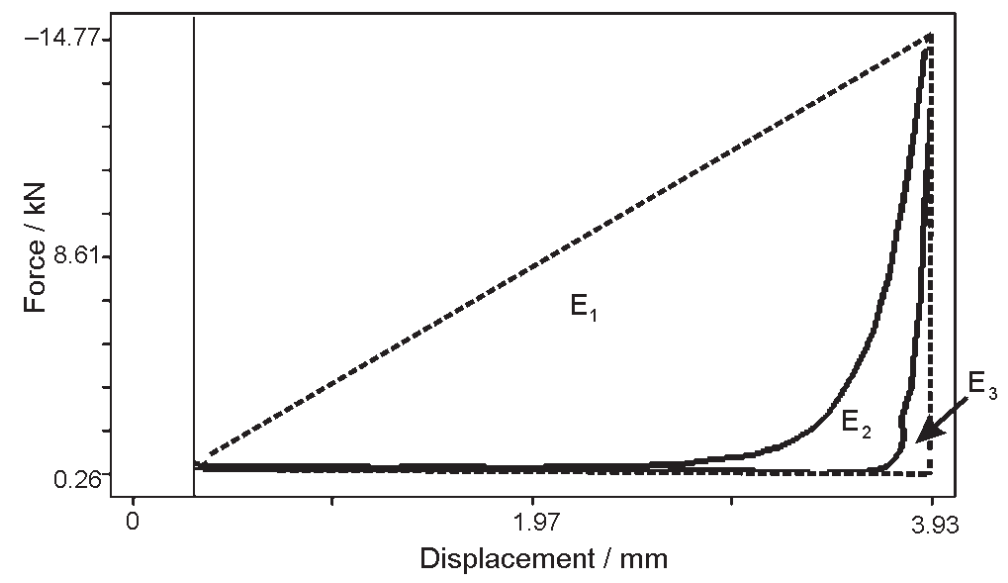

Fig. 7 Force-displacement curve of uncoated crystals

\section{DSC measurements}

Samples were heated, cooled and re-heated according to program 1 (Table 1) at first, however, the curve had a quite different shape during reheating (Figs 8 and 9). The
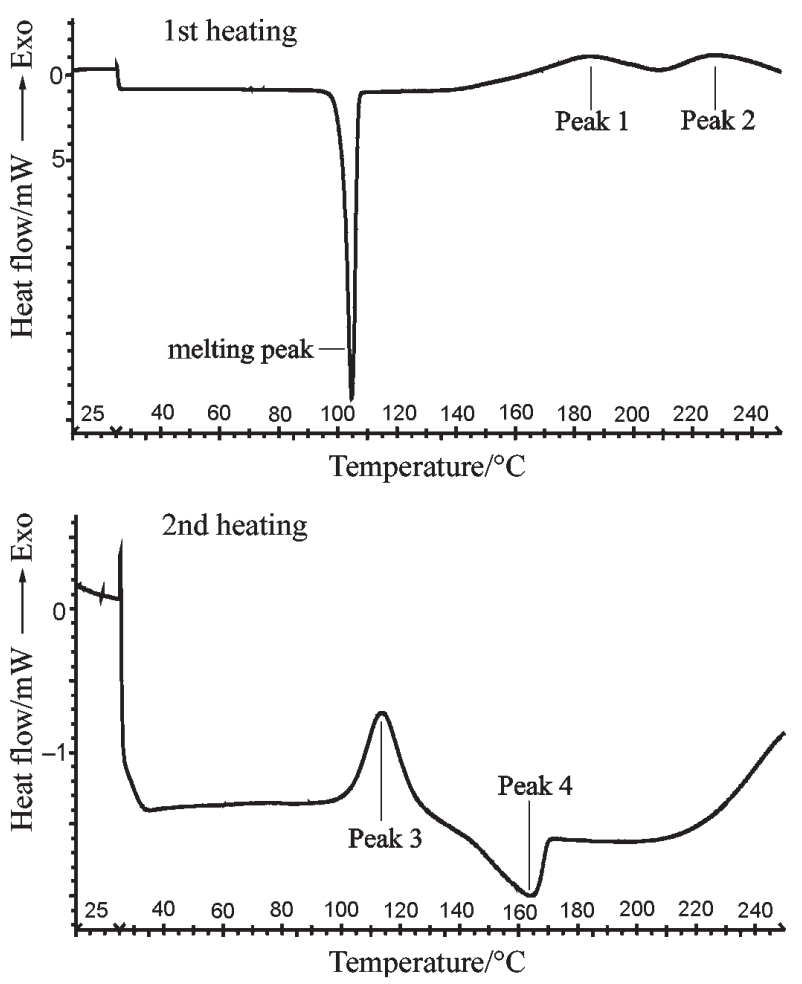

Fig. 8 DSC curves of uncoated crystals, applying program 1 


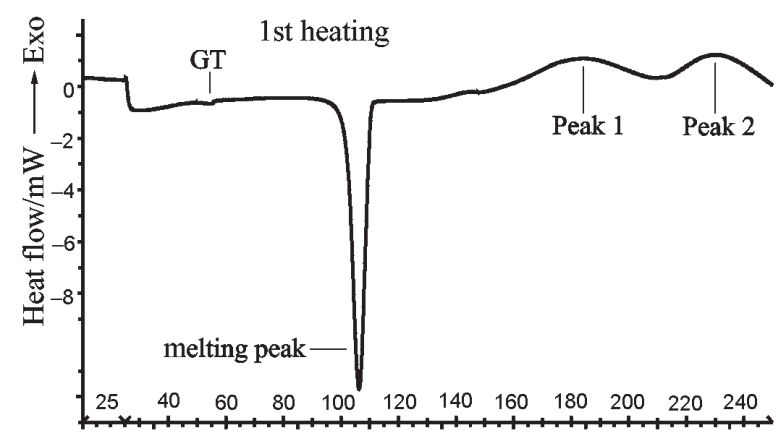

Temperature $/{ }^{\circ} \mathrm{C}$

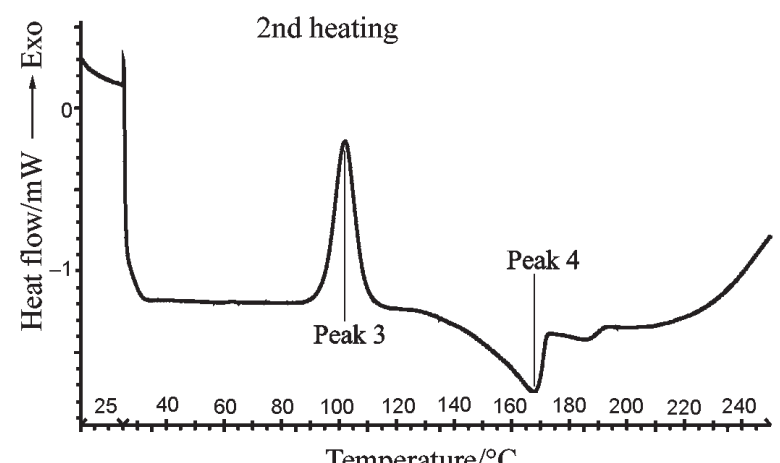

Temperature $/{ }^{\circ} \mathrm{C}$

Fig. 9 DSC curves of Dim 2, applying program 1

coated and uncoated samples exhibited similar behaviour. The slight change at about $55^{\circ} \mathrm{C}$ in the curve of the coated crystals was explained by the presence of Sepifilm LP. This alteration was caused by the glass transition (GT) of HPMC and the congealing temperature of the plasticizer stearic acid [9] (Fig. 9). During the reheating the GT disappeared. The cause of this phenomenon can be the change of structure of macromolecular film. This phenomena can depend on heating, cooling and re-heating time. The structure of the substance needs enough time to be re-built. During re-heating the endotherm melting peak and the two exotherm peaks disappeared, while another exotherm peak and an endothermal peak appeared at other temperatures. These alterations in the shape of the curve were explained by the decomposition of the material at these high temperatures. The second exothermal peak in the first heating related to the material involved in the decomposition: when the heating was stopped after the first peak, only an exotherm peak (peak 2) was detected at about $230^{\circ} \mathrm{C}$, which accorded with the second exotherm peak in the first heating of the uncoated crystals. Therefore, the material was not decomposed after the first exotherm peak, but was not transformed to the crystalline state after cooling, and the process continued as during the first heating. This problem also arose if heating was stopped after the melting peak. The virtual melting point of the coated crystals was 
higher; this could be caused by reduction of the thermal conductivity of the crystals by a macromolecular film (Table 5).

Table 5 Virtual melting points of samples, applying program 1

\begin{tabular}{lcrrr}
\hline & Dimenhydrinate & Dim 1 & Dim 2 & Dim 3 \\
\hline Melting point $/{ }^{\circ} \mathrm{C}$ & 103.35 & 105.24 & 105.98 & 105.44 \\
SD & 0.65 & 0.50 & 0.66 & 0.56 \\
\hline
\end{tabular}

Applying program 2, heating was interrupted during the rising part of the endotherm melting peak (Table 1) and, after cooling, the effect of heating to $250^{\circ} \mathrm{C}$ was examined (Figs 10 and 11). The melting peak in the first period was not evaluated statistically, because the peak was not complete. There was no significant difference in the melting point in the second heating period (Table 6). There was a difference in the shapes of the curves on re-heating. A lower melting enthalpy value has been obtained during the second heating for the melting of uncoated crystals than for the coated samples. The change was significant $(p<0.05)$ (Table 7). This alteration was explained by the differing thermal conductivities of the crystals. Since a thin macromolecular film separates the coated crystals, this can impede the transport of the heat from crystals to crystals. As the time of heat transport above the melting point was short (about $20 \mathrm{~s}$ ) and the heat transport was restricted, a smaller fraction of the dimenhydrinate decomposed than in the case of the uncoated crystals. This difference was observed if exactly the same mass of crystals was measured. The more the active ingredient remaining in the given volume, higher melting enthalpies have been calculated. In the remainder of this paper the values of heat of fusion will be compared with regarded to the result of water uptake and the plasticity of the material.

Table 6 Virtual melting points of samples in re-heating part, applying program 2

\begin{tabular}{lcrrr}
\hline & Dimenhydrinate & Dim 1 & Dim 2 & Dim 3 \\
\hline Melting peak $/{ }^{\circ} \mathrm{C}$ & 104.20 & 104.50 & 104.89 & 104.84 \\
$S D$ & 0.37 & 0.11 & 0.09 & 0.41 \\
\hline
\end{tabular}

Table 7 Comparison of heat of fusion of melting peaks in re-heating parts, applying program 2

\begin{tabular}{lcccc}
\hline & Dimenhydrinate & Dim 1 & Dim 2 & Dim 3 \\
\hline Heat of fusion $/ \mathrm{J} \mathrm{g}^{-1}$ & 3.51 & 9.78 & 25.45 & 9.76 \\
SD & 4.72 & 3.83 & 10.62 & 1.77 \\
\hline
\end{tabular}

\section{Comparative studies}

The different indirect methods of determining the protective effect of the film were compared mathematically by linear regression (the $t$-test was significant $(p<0.05)$ ). 

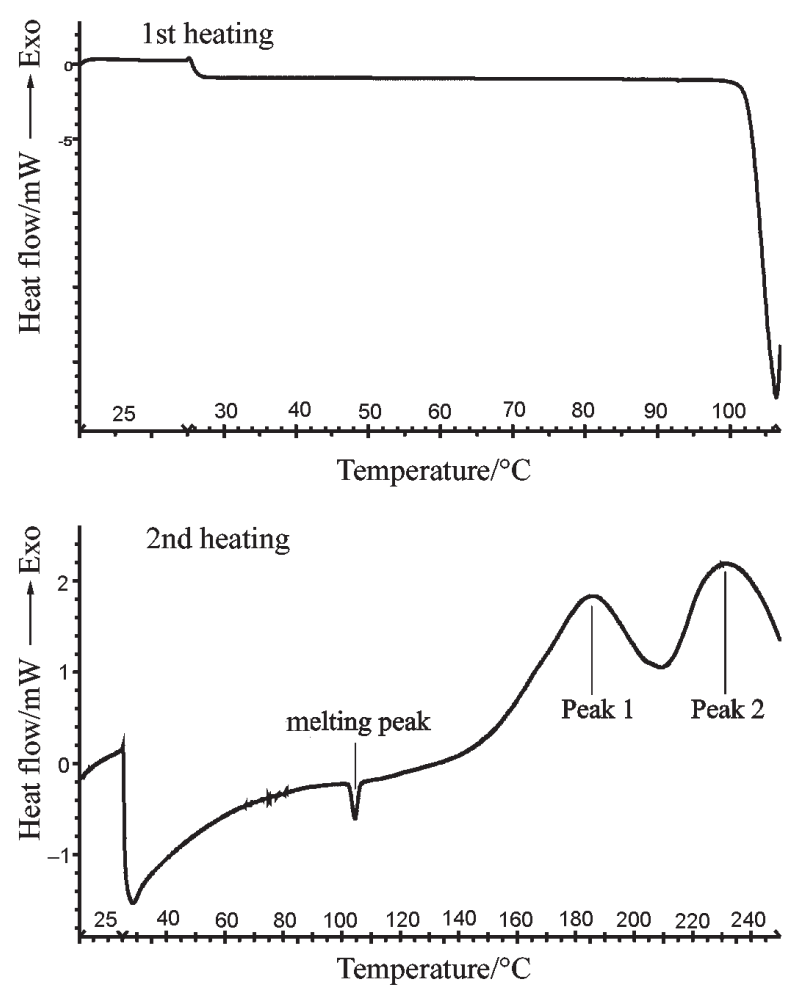

Fig. 10 DSC curves of uncoated crystals, applying program 2

The first comparison was that of the Enslin number and the heat of fusion value of the DSC curve. The relationship is shown in Fig. 12. DSC measurement in this study can be used to predict the impedance of water uptake.

Comparison of the plasticity of the investigated materials and the melting enthalpies, a linear correlation was observed between these two parameters (Fig. 13).

It can be stated that for the investigated materials the three parameters can be used to the predict the protective effect of the film. DSC is therefore a good method with which the control of the film coated fine particles production can be done.

\section{Conclusions}

Thermoanalytical studies reveal that dimenhydrinate crystals are sensitive against heating. Different DSC heating methods demonstrated that this change is caused by decomposition at a temperature of $250^{\circ} \mathrm{C}$. At temperatures below the temperature of the second exotherm peak during of the first heating of dimenhydrinate, but above the melting point, the material does not decompose, but the dimenhydrinate loses its crystalline state. If this occurs during compression, it disturbs the possibility of uniform, exact and rapid tablet making. Film coating, a method widely used in pharmaceutical technology, does not alter 

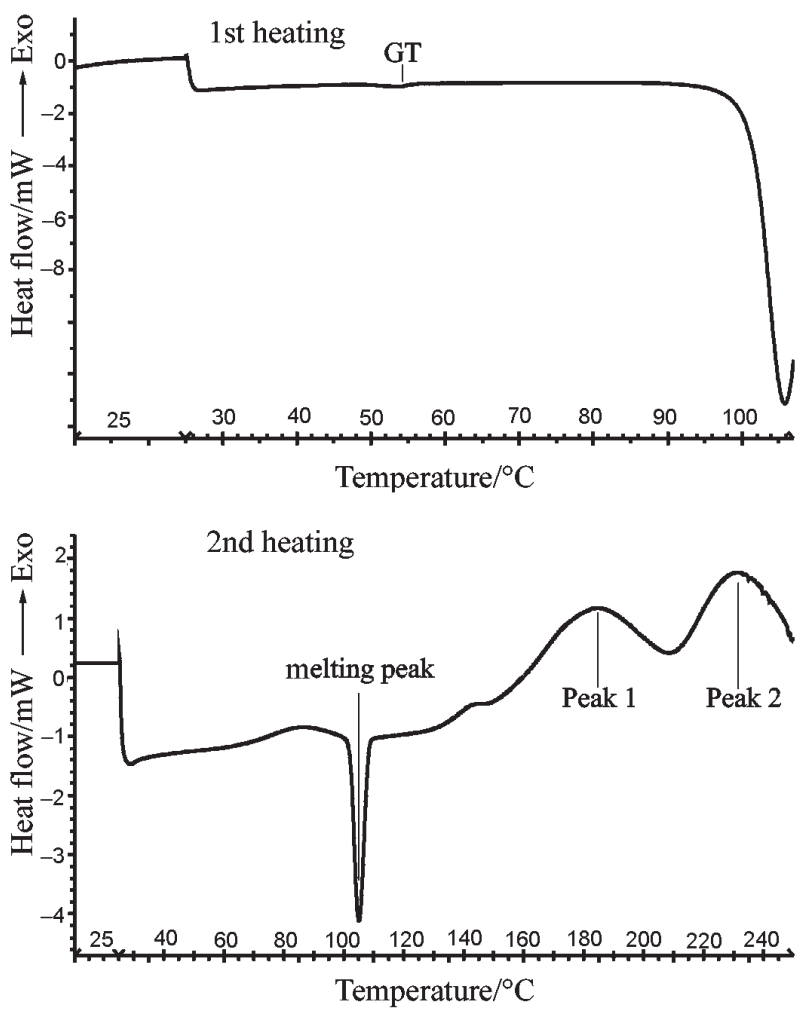

Fig. 11 DSC curves of Dim 2, applying program 2

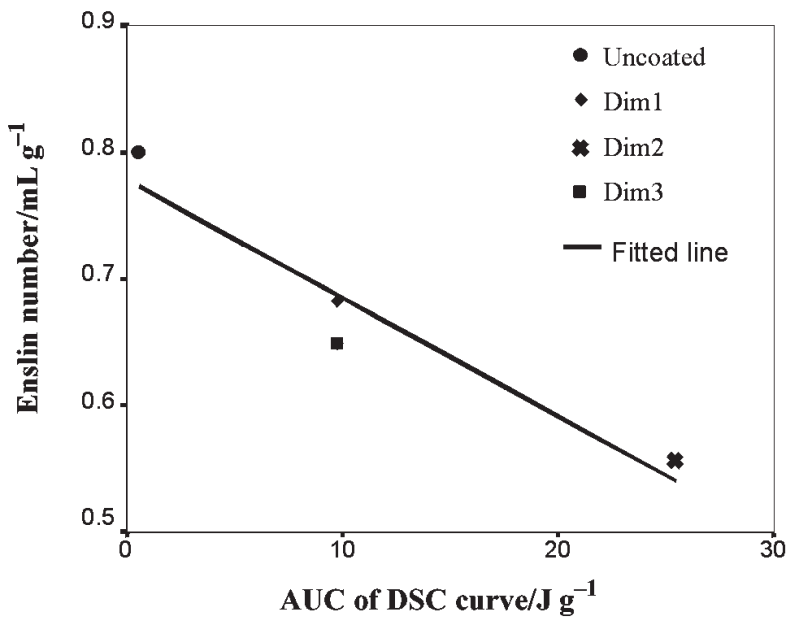

Fig. 12 Relationship between melting enthalpies of samples and Enslin number ( $R$ value: 0.9588 , slope: 0.0093 , intercept: 0.7782 ) 


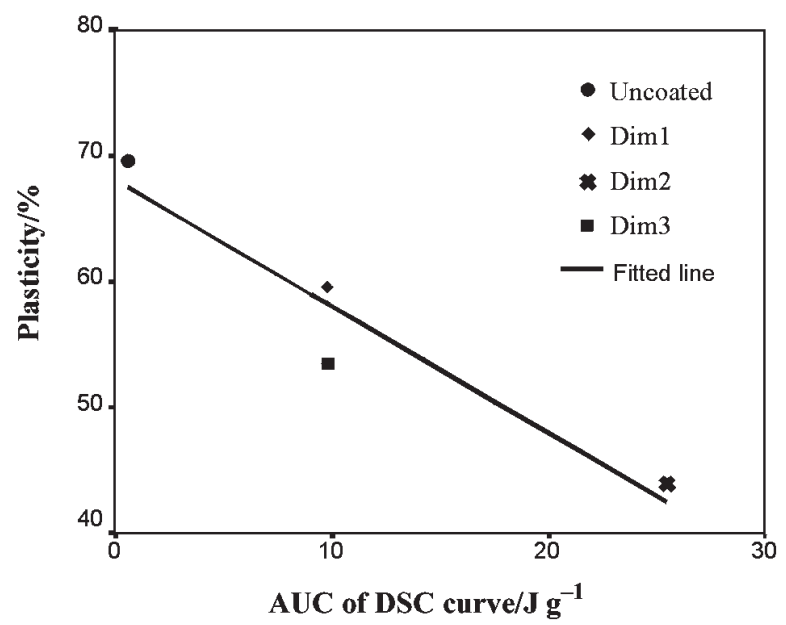

Fig. 13 Relationship between the melting enthalpies of samples and plasticity $(R$ value was 0.9553 , slope: 0.9084 , intercept: 62.83 )

the shape of the DSC curve of dimenhydrinate, but it increases the melting point of coated crystals compared with the uncoated crystals. This can be explained by the presence of a macromolecular film which reduces the thermal conductivity, because it separates the particles.

An increased time of film coating increases the possibility of the crystals breaking with accompanying decreases in the smoothness and uniformity of the film. The particle size of coated crystals does not vary linearly with the coating time.

Since the determination of film uniformity on the crystals by direct methods is very difficult, the indirect methods mentioned in this work can be used. There are linear relationships between the protective effect of the coating film and water uptake, plasticity of samples and thermal conductivity of the investigated materials. Determination of these parameters can therefore be useful for prediction of the protective effect of a coating film. The use of DSC can lead to direct information on the material and can be utilized to predict other information.

Finally, it may be stated that the film coating of crystals may facilitate the tablet making of materials that are heat-sensitive, exhibit low flow ability and are difficult to compress.

This work was supported by grants from the Hungarian Scientific Research Fund (OTKA): T-026351, T-026459, T-026579 and T-033054.

\section{References}

1 G. Cole, Pharmaceutical coating technology, Taylor \& Francis Ltd., London, 1995, p. 9.

2 Zs. Muskó, K. Pintye-Hódi, P. Szabó-Révész, P. Kása Jr., I Erős and D. Deák, Pharmazie, 55 (2000) 465. 
3 H. Yuasa, T. Nakano and Y. Kanaya, Int. J. Pharm., 178 (1999) 1.

4 E. G. Rippie and D. W. Danielson, J. Pharm. Sci., 70 (1981) 476.

5 P. Ridgway, Watt, Tablet machine instrumentation in pharmaceutics: principles and practice, Ellis Horwood Ltd., Chichester, 1988, p. 23.

6 G. Ragnarsson and J. Sjögren, J. Pharm. Pharmacol., 37 (1985) 145.

7 M. Celik and K. Marshall, Drug. Dev. Ind. Pharm., 15 (1989) 759.

8 M. Siaan, K. Pintye-Hódi, P. Szabó-Révész, P. Kása, Jr. and I. Erős, Drug. Dev. Ind. Pharm., $26(2000) 1013$.

9 USP 23, United States Pharmacopeial Convention Inc,. Rockville, 1994, pp. 228., 781., 1210., 526.

10 G. Kedvessy and M. Garamvölgyi-Horvát, Pharmazie, 28 (1973) 748.

11 C. Fuhrer and W. Parmentier, Acta Pharm. Technol., 23 (1977) 205.

12 U. Bogs and E. Lenhardt, Pharm. Ind., 33 (1971) 850.

13 E. Graf and A. Sahr, Pharm. Ind., 41 (1979) 86.

14 K. Thoma and K. Bechtold, Eur. J. Pharm. Biopharm., 47 (1999) 39.

15 M. T. DeCrosta, J. B. Schwartz, R. J. Wigent and K. Marshall, Int. J. Pharm., 198 (2000) 113.

16 J. Bajdik, K. Pintye-Hódi, Cs. Novák, P. Szabó-Révész, G. Regdon Jr., I. Erős and G. Pokol, J. Therm. Anal. Cal., 62 (2000) 797.

17 K. Pintye-Hódi, P. Szabó-Révész, M. Miseta and B. Selmeczi, Acta Pharm. Hung., 54 (1984) 127.

18 M. Abdou, Dissolution, Bioavailability \& Bioequivalence, MACK Publishing Co., Easton 1989, p. 37.

19 K. Parfitt, Martindale, the Complete Drug Reference, Thirty-second edition, Pharmaceutical Press, London, 1999, p. 408.

20 L. Hendeles, M. Massanari and M. Weinberger, Dimenhydrinate in: Gilman, A. G., Goodman, L. S., \& Gilman, A. (Eds) Goodman \& Gilman's The Pharmacological Basis of Therapeutics, $6^{\text {th }}$ ed. MacMillan Publishing Co., New York 1980 in Micromedex, Inc., Englewood, Co., Vol. 97 Exp. 30/09/98 Topic: Dimenhydrinate.

21 Seppic brochure, Seppic INC, Paris 1994.

22 A. Stamm and C. Mathis, Acta Pharm. Technol., 22 (1976) 7.

23 J. T. Carstensen, Solid Pharmaceutics: Mechanical Properties and Rate Phenomena, Academic Press, New York, 1980, p. 184. 
III. 


\title{
MEÁSUREMENT OF THE SWELLING FORCE OF SOME SODIUM STARCH GLYCOLATE PRODUCTS WITH NEW SOFTWARE
}

\author{
A. Kel.EMEN', A. SZOLlösi, A. ZSÓtér, K. PINTYE-HÓd, C. TÖRÖK² and I. ERÖS \\ (Department of Pharmaceutical Technology. Univertity of Szeged, Eötvös str. 6. H-6720 Szeged. HUNGARY \\ 'Department of Medical Informatics, University of Szeged, Korányi fasor 9, H-6720 Szeged, HUNGARY \\ ${ }^{2}$ Agrokémia Sellye Lid, Malom str. 1 H-7960 Sellye, HUNGARY)
}

Received: October 12, 2001

\begin{abstract}
The swelling properties of several experimental sodium starch glycolates (SSG) were investigated with new equipment and software. The characteristic swelling time $\left(\mathrm{L}_{63.2 \%}\right)$ was calculated. The effects of the molecular structure (degree of substitution) on the swelling ability were also studied. It was found that the degree of cross-linking influenced the swelling ability of SSG products. The described equipment and the developed software are suitable for study of the swelling process and characterization of the different disintegrants.
\end{abstract}

Keywords: disintegrant, swelling force, force-time curve, characteristic sweiling time

\section{Introduction}

Disintegrants are always added to conventional tablets in order to promote the break-up of the tablets when they are placed in an aqueous environment.

The first step in the process of dissolution of the drug is disintegration. The disintegrant causes rapid disintegration of the tablet, the increase in the surface area of the tablet promoting rapid release of the drug.

The mechanism of disintegration is influenced by different factors, among which the water uptake and swelling play very important roles [1-3]. The uptake of water by disintegrants is thought to initiate the process of disintegration $[4,5]$.

The swelling force is responsible for the breaking-up of the tablet. List and Muazzam [5] drew attention to the importance of the swelling force, and Caramella et al. $[6,9]$ also dealt with measurement of the swelling force.

The most common disintegrant employed in tablet formulation is starch. There are many types of modified starches (sodium starch glycolate $=$ SSG) on the market. This material can be regarded as a super-disintegrant. It is official in the USP, BP and Ph.Eur. While the quantity of starch required is about $20 \%, 4-5 \%$ of SSG is sufficient.

Many reports have been published on Primojel and Explotab [8-16], the most widely used types.

The effectrveness of SSG is influenced by various factors. The degree of substitution, the degree of crosslinking and the sodium chloride content play important roles in the disintegration of the tablets [12, 16].

The present article reports an examination of the influence of the above-mentioned parameters on the swelling process. The most informative factor, the characteristic swelling time $\left(\mathrm{t}_{63.2 \%}\right)$, was calculated from the modified Weibull equation (Rosin-RammlerSperling-Benett-Weibull $=$ RRSBW) by nonlinear regression, $\mathrm{t}_{63.2 \%}$ being the time needed to attain $63.2 \%$ of the maximum swelling force. This factor could be utilized to compare the different disintegrants.

\section{Experimental}

\section{Materials}

The present experimental SSG samples (from Agrochemia Co., Sellye, Hungary) are based on a sodium salt of a partially substituted carboxymethy! ether of potato starch. They have a moisture content that is lower than that of starches $(<10 \%)$. The sodium chloride content is less than 1\%. Different types are produced as regards the degree of crosslinking. The degree of substitution is the same (Table I).

Indifferent tablets were prepared from the SSG products with the aim of a study of the swelling (Table 2). Dicalcium phosphate dihydrate (Parmcompress ${ }^{(0)}$, Parmentier AG, Germany) was used as binder. It was 
Table I Parameters of SSG products

\begin{tabular}{lcccc} 
Product & $\begin{array}{c}\mathrm{NaCl} \\
\text { content } \\
(\%)\end{array}$ & $\begin{array}{c}\mathrm{Na}- \\
\text { glycolate } \\
(\%)\end{array}$ & $\begin{array}{c}\text { Sedimentation } \\
(\mathrm{ml} / 100 \mathrm{ml})\end{array}$ & $\begin{array}{c}\text { Degree of. } \\
\text { substitution } \\
(\mathrm{mol}-\mathrm{COOH} / \\
\mathrm{mol} \text { starch })\end{array}$ \\
\hline SSG 1 & 0.65 & 0.80 & 82 & 0.24 \\
SSG 2 & 0.62 & 0.80 & 57 & 0.24 \\
SSG 3 & 0.72 & 1.00 & 48 & 0.25 \\
SSG 4 & 0.74 & 1.00 & 36 & 0.25 \\
SSG 5 & 0.81 & 1.05 & 28 & 0.24 \\
SSG 6 & 0.94 & 1.10 & 17 & 0.24
\end{tabular}

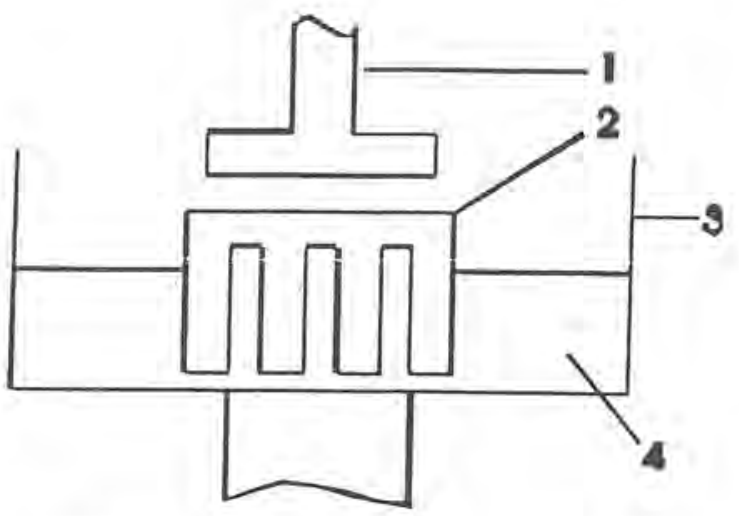

1. punch, 2. holder, 3. water container, 4. water

Fig I Measuring part of swelling force equipment

necessary to apply a lubricant as well (magnesium stearate, Ph.Eur. $3^{\text {rd }}$ ). These materials do not swell in aqueous medium.

\section{Methods}

Sedimentation: A $2.00 \mathrm{~g}$ sample was suspended in 200 $\mathrm{ml}$ boiled distilled water. $100 \mathrm{ml}$ of this suspension was poured into a cylinder. The volume of the sediment was read off after 24 hours.

Mixture: After sieving (0.8 $\mathrm{mm}$ wire distance), the components were blended at $50 \mathrm{rpm}$ for $10 \mathrm{~min}$ in a Turbula mixer (Willy A. Bachofen Maschinenfabrik, Switzerland).

The moisture contenl of powder mixtures was determined gravimetrically, through water removal with an IR lamp mounted on a quick dryer (Organic Chemistry Co., Budapest, Hungary). The moisture content was in every case $0.3-0.4 \%$.

Compression: Pressing was carried out with a Korsch EKO eccentric tablet machine (E. Korsch Maschinenfabrik, Germany) mounted with strain gauges. and a displacement transducer was applied:

punches:

pressure force:

mass of tablet:

simple, $10 \mathrm{~mm}$ in diameter

$40 \%$

air temperature: $\quad 23{ }^{\circ} \mathrm{C}$

rate of pressing: 36 tablets/min
Table 2 Compositions of tablets

\begin{tabular}{c|rc} 
Materials & \multicolumn{2}{|c}{ Mass } \\
& $(\mathrm{g})$ & \multicolumn{1}{c}{4} \\
\hline SSG $(1-6)$ & 4.8 & 95.5 \\
Parmcompress & 114.6 & 0.5 \\
Magnesium stearate & 0.6 & 100.0
\end{tabular}

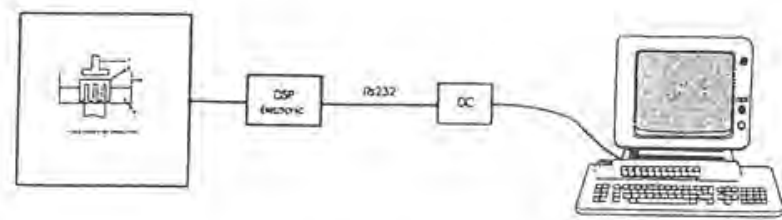

Fig.2 Scheme of measurement

\section{Swelling force measurement}

The equipment used to measure the swelling force (SF) was prepared on the basis of the principle of the List apparatus [5].

The measurement is performed with a balance (Sartorius microbalance) with electronic compensation, which is built in the equipment. The tablet-holder is a copper cylinder $10 \mathrm{~mm}$ in diameter with slits in the side. In this cylinder, a copper punch with the same diameter is fitted. The tablet-holder is in a copper cup. The tablet is placed in the holder and $5 \mathrm{ml}$ distilled water is injected at the start of the measurement. The water penetrates into the tablet through the slits. The force that builds up inside the comprimate as it absorbs the water is transmitted vertically and is detected by the balance (Fig. I).

The equipment is linked with a PC by a RS232 cable (Fig.2). Software has been developed for data acquisition, evaluation and demonstration of the swelling process. The monitor displays the SF vs. time curve with the important parameters (SF, time characteristic swelling time $\left(\mathrm{t}_{63.2 \%}\right)$ ).

Mirroring the close logical or functional relationship between them, the SF functions are arrayed in separate groups (Acquisition, Settings, Analysis). Under the Acquisition menu point, it is possible to receive data from the serial port. During acquisition, the monitor shows the current SF and baseline values. At the end of the acquisition, the software saves the data on disk. With the Settings menu point, it is possible to configure the system (e.g. serial communication, acquisition file name, etc.). With the Analysis menu point, it is possible to evaluate the saved data. The screen depicts the SF vs. time curves (a maximum of 5) with the important parameters (time, SF, baseline, $t_{63.2 \%}$ ) and $\mathrm{dF} / \mathrm{dt}$ ). The user can evaluate curves manually with the cursor, create reports, or print screen shots to the bitmap or to the printer

The characteristic swelling time and shape parameter were calculated from the following form: 
Table 3 Results of the swelling test

\begin{tabular}{|c|c|c|c|c|}
\hline & $\begin{array}{l}\text { Pressure } \\
\text { force } \\
(\mathrm{kN})\end{array}$ & $\begin{array}{l}\text { Swelling force } \\
\text { (N) }\end{array}$ & $\beta$ & $\begin{array}{l}163.277 \\
(5)\end{array}$ \\
\hline \multirow{3}{*}{ SSG1 } & 5 & $\begin{array}{c}8.56 \\
R S D=5.57\end{array}$ & 0.830 & 119.13 \\
\hline & 10 & $\begin{array}{c}10.09 \\
R S D=9.95\end{array}$ & 0.836 & 108.82 \\
\hline & 15 & $\begin{array}{c}12.49 \\
R S D=5.46\end{array}$ & 0.858 & 125.87 \\
\hline \multirow{3}{*}{ SSG2 } & 5 & $\begin{array}{c}5.45 \\
R S D=11.56\end{array}$ & 0.858 & 66.35 \\
\hline & 10 & $\begin{array}{c}7.16 \\
R S D=8.74\end{array}$ & 0.832 & 61.67 \\
\hline & 15 & $\begin{array}{c}14.23 \\
\text { RSD }=11.09\end{array}$ & 0.830 & 78.99 \\
\hline \multirow{3}{*}{ SSG3 } & 5 & $\begin{array}{c}6.96 \\
R S D=6.44\end{array}$ & 0.816 & 48.55 \\
\hline & 10 & $\begin{array}{c}8.18 \\
R S D=7.62\end{array}$ & 0.814 & 47.48 \\
\hline & 15 & $\begin{array}{c}18.33 \\
R S D=3.80\end{array}$ & 0.830 & 95,03 \\
\hline \multirow{3}{*}{ SSG4 } & 5 & $\begin{array}{c}6.92 \\
R S D=6.21\end{array}$ & 0.864 & 53.36 \\
\hline & 10 & $\begin{array}{c}8.14 \\
R S D=9.74\end{array}$ & 0.808 & 30.10 \\
\hline & 15 & $\begin{array}{c}9.59 \\
R S D=11.09\end{array}$ & 0.832 & 33.10 \\
\hline \multirow{3}{*}{ SSG5 } & 5 & $\begin{array}{c}9.94 \\
R S D=7.36\end{array}$ & 0.832 & 89.24 \\
\hline & 10 & $\begin{array}{c}13.81 \\
R S D=8.58\end{array}$ & 0.819 & 82.33 \\
\hline & 15 & $\begin{array}{c}13.49 \\
R S D=3,1]\end{array}$ & 0.831 & 40.71 \\
\hline \multirow{3}{*}{ SSG6 } & 5 & $\begin{array}{c}8.59 \\
R S D=0.37\end{array}$ & 0.825 & 40.38 \\
\hline & 10 & $\begin{array}{c}11.25 \\
R S D=4.22\end{array}$ & 0.813 & 48.88 \\
\hline & 15 & $\begin{array}{c}11.87 \\
R S D=2.85\end{array}$ & 0.816 & 38.74 \\
\hline
\end{tabular}

$$
M(t)=M_{\max }\left\{1-\exp \left(-\left[\frac{t-t_{0}}{\tau}\right]^{\beta}\right)\right\}
$$

where $\tau$ is the time parameter. $\beta$ is the shape parameter, $M_{\max }$ is the maximum value of the swelling, $M$ is the swelling at time $t$, and $t_{0}$ is the start time. It is possible to calculate the characteristic swelling time. $\beta=1$ implies first-order kinetics in the swelling process; $\beta<1$ impliest fast swelling at the beginning of the process, followed by a slower swelling; $\beta>1$ implies a sigmoid curve: slow swelling is followed by a faster swelling process.

In the literature, these parameters are generally calculated by means of the Weibull distribution equation rearranged in linearized form [8]. Another way to solve this equation is nonlinear fitting. In the present paper, this method was used with GLOBAL software (http://www.jate.u-szeged.hu\#csendes.htm) (Fig.3).

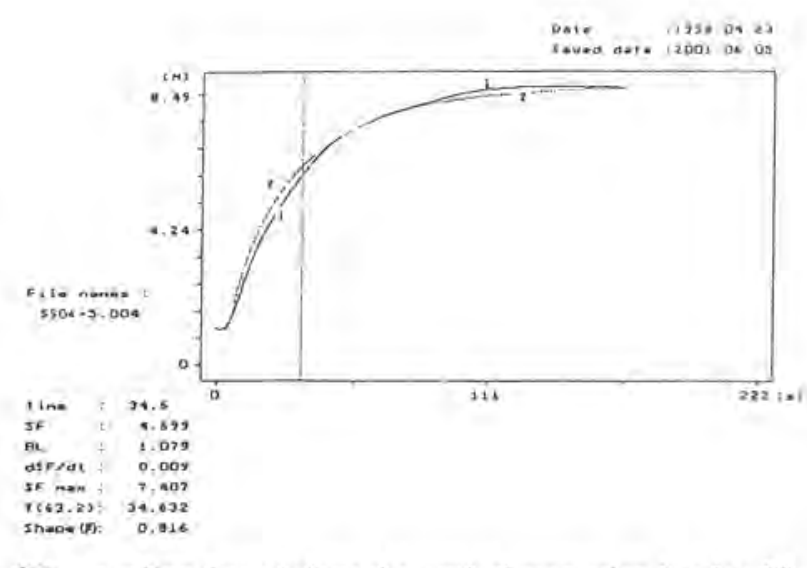

$\mathrm{SF}=$ swelling force (where the vertical measuring line is); $\mathrm{BL}$ $=$ basic line; SFmax $=$ maximum value in swelling force; $\mathrm{T}(63.2)=$ characteristic swelling time; $\mathrm{dsF} / \mathrm{dt}=$ the speed of changing of force (where the vertical measuring line is)

Fig.3 Swelling force profile (1) and nonlinear futting according to RRSBW equation (Pressure force: $5 \mathrm{kN}$ )

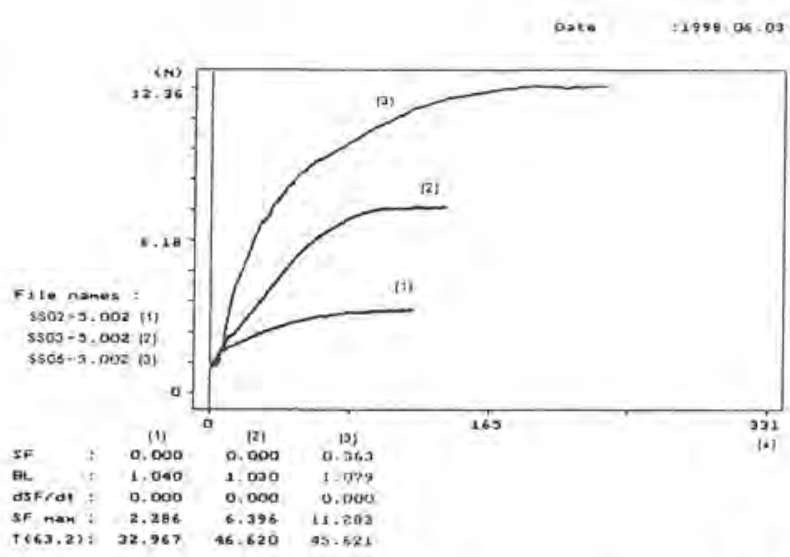

$\mathrm{SF}=$ swelling force (where the vertical measuring line is); $\mathrm{BL}$ $=$ basic line; $\mathrm{SFmax}=$ maximum value in swelling force; $\mathrm{T}(63.2)=$ characteristic swelling time; $\mathrm{dsF} / \mathrm{dt}=$ the speed of changing of force (where the vertical measuring line is)

Fig.4a Swelling process of SSG2, SSG3 and SSG5 comprimates (Pressure force: $5 \mathrm{kN}$ )

\section{Results and Discussion}

Results are shown in Table 3 . It can be seen that at $5 \mathrm{kN}$ the SSG5 comprimates exhibited the highest, and the SSG2 comprimates the smallest SF (Table 3, Figs.4/a and $4 / \mathrm{b})$. The SSG1 and SSG6 comprimates $(5 \mathrm{kN})$ had almost the same SF maximum, but there was a considerable difference in the $t_{63.2 \%}$ values.

The SF increased at higher pressure force, but to different degrees. The reason lies in the texture of the comprimates and in the properties of the materials. Increase of the pressure force generally resulted in a decrease in the porosity. The texture of the comprimates is more compact. This has an important role in the disintegration. If the character of the composition is 


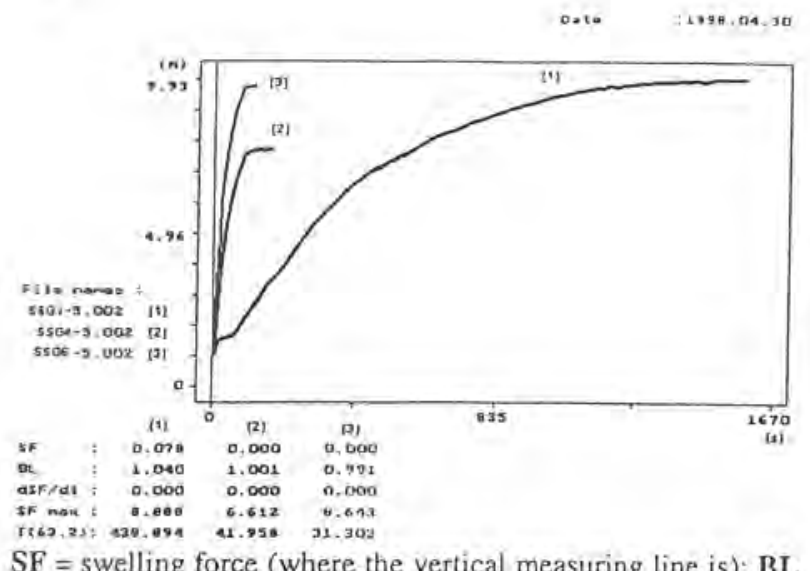

$\mathrm{SF}=$ swelling force (where the vertical measuring line is); BL $=$ basic line; $S F m a x=$ maximum value in swelling force; $\mathrm{T}(63.2)=$ characteristic swelling time; $\mathrm{dsF} / \mathrm{dt}=$ the speed of changing of force (where the vertical measuring line is)

Fig. $4 b$ Swelling process of SSG1, SSG4 and SSG6 comprimates (Pressure force: $5 \mathrm{kN}$ )

hydrophilic, the SF (disintegration force) can be better mediated by the water and the disintegration process will be rapid. The degree of the increase in the SF depends on the properties and the swelling ability of the disintegrants. By changing the disintegrant at the same composition, it is possible to study the influence of the pressure force on the SF.

The data allow the samples to be arranged in sequence.

\section{For the SF:}

$5 \mathrm{kN}: \operatorname{SSG} 5>\operatorname{SSG} 6=\operatorname{SSG} 1>\operatorname{SSG} 4=\operatorname{SSG} 3>\operatorname{SSG} 2$

$10 \mathrm{kN}: \operatorname{SSG} 5>\operatorname{SSG} 6>\operatorname{SSG} 1>\operatorname{SSG} 4=\operatorname{SSG} 3>\operatorname{SSG} 2$

$15 \mathrm{kN}$ : SSG $3>\operatorname{SSG} 2>\operatorname{SSG} 5>\operatorname{SSG} 1>\operatorname{SSG} 6>\operatorname{SSG} 4$

\section{For $\mathrm{t}_{63.2 \%}$ :}

$5 \mathrm{kN}: \quad \operatorname{SSG} 6<\operatorname{SSG} 3<\operatorname{SSG} 4<\operatorname{SSG} 2<\operatorname{SSG} 5<\operatorname{SSG~I}$ $10 \mathrm{kN}$ : SSG $4>\operatorname{SSG} 6=\operatorname{SSG} 3<\operatorname{SSG} 2<\operatorname{SSG} 5<\operatorname{SSG} 1$ $15 \mathrm{kN}$ : SSG $4<$ SSG $6=$ SSG $5<$ SSG $2<$ SSG $3<$ SSG 1

It can be stated that increase of the degree of crosslinking and of the sodium chloride content led to a higher SF. However, this effect was observed only at pressure forces of 5 and $10 \mathrm{kN}$. The degree of crosslinking influenced the swelling ability of the SSG products. It was seen that, for the samples with a smaller degree of cross-linking (SSG1-SSG3), the SF increased in a stepwise manner with increase of the pressure force. The samples with a higher degree of crosslinking (SSG4-SSG6) demonstrated an increase in swelling only between 5 and $10 \mathrm{kN}$, but not when the pressure force was increased from 10 to $15 \mathrm{kN}$. The reason is the inflexible skeleton with a compact texture.

It can further be seen that the characteristic wateruptake time $\left(\mathrm{t}_{603.2 \%)}\right)$ is influenced primarily by the deformability of the particles and by the texture of the comprimates.
Conclusion

The results of these experiments suggest that the maximum SF and the factor $\mathrm{t}_{63.2 \%}$ may be used to compare the intrinsic capability of a disintegrant. Study of the swelling process is also important with respect to the pressure force. The porosity of the tablets depends on the deformability of the particles and the porosity has an important role in water transport into the interior of the tablets and hence in the swelling process, too.

On the basis of such results, it is possible to choose the pressure force suitable for tableting. If increase of the pressure force causes no change or only a very small change in the SF, it is unnecessary to use a high pressure force during tableting. The described equipment and the developed software are suitable for study of the swelling process and for comparison and characterization of the different disintegrants.

\section{REFERENCES}

1. Lowenthal W.: J. Pharm. Sci. 1972, 61, 1695 1711

2. KANig J. L. and RuDNiC E. M.: Pharm. Technol. I984, 8, 50-58, 61-63

3. BOLHUIS G. K, VAN KAMP H. V., LERK C. F and SESSINK F. G. M.: Acta Pharm. Technol. 1982, 28, $111-114$

4. van Kamp H. V., Bolhuis G. K., De Boer A. H., LERK C. F. and LE-A-HUEN L.: Pharm. Acta Helv. $1986,61,22-29$

5. List P. H., Muazzam U. A.: Pharm. Ind. 1979, 41, 459-464

6. Caramella C., Colombo P., Conte U. and la ManNa A.; Drug Dev. Ind. Pharm. 1986, 12, 17491766

7. Colombo P., Conte U., Caramella C and GEDDO M.: J. Pharm. Sci. 1984, 73, 701-705

8. Ferrari F., Geddo M., Gazzaniga A., Caramella C. and CONTE U.: S.T.P. Pharma, $1988,4,481-484$

9. Caramella C.: Pharm Technol, Int. 1990, Sept. 30-40, Oct, 30-37

10. Bolhuis G. K., Kamp H. V., Lerk C. F., Gielen J, W., AREnds A. W. and Stunt G. K.: Acta Pharm. Technol. 1984, 30, 24-32

11. Rudnic E. M., Kanig J. L. and Rhodes C. T.: J. Pharm. Sci. 1985. 74, 647-650

12. Graf E., Ghanem A. $\mathrm{H}$ and Mahmoud H.; Pharm. Ind. 1985, 47, 773-776

13. SAKR A., RIVERA D, and JiMENEZ W.: Pharm. Ind. $1986,48,522-525$

14. WAN L. S. C. and PRASAD P. P.. Acta Pharm TechnoI. 1988, 34, 200-203

15, JOHNSON J. R., WANG L-H., GORDON M. S, and CHOWLAN Z. T.: J, Pharm. Sci. 1991, 80, 469-471

16. Miseta M., PintYe-Hódi K., SZabó-Révész P., SZALAY L. and SÁGHI P.: Pharm. Ind. 1993, 55, $515-518$ 
IV. 


\section{Preparation of Pellets Containing Theophylline}

Zsolt Muskóa ${ }^{a}$, János Bajdika , Klára Pintye-Hódia ${ }^{a}$, Piroska Szabó-Révész ${ }^{a}$, András Kelemen ${ }^{b}$, and István Erős ${ }^{a}$

Department of Pharmaceutical Technology ${ }^{\mathrm{a}}$, and Department of Medical Informatics ${ }^{\mathrm{b}}$, University of Szeged, Szeged (Hungary)

\section{Key words}

CAS $5967-84-0$

- Centrifugal granulator

- Pellets, deformation, flow properties, particle size

E Theophylline

Pharm. Ind. 64, No. 11, 11941198 (2002)

\section{Summary}

The aim of this work was to prepare theophylline (CAS 5967-84-0) pellets by using a centrifugal granulator. Theophylline crystals have unsuitable powder rheological properties. Wet granulation was necessary and pellets with different particle sizes were prepared. The habit of the pellets was spherical, with a compact texture. The process of pellet deformation was tested by means of a modified equipment, and the force-time curve is presented.
Use of a centrifugal granulator with the parameters applied resulted in theophylline pellets with suitable parameters (shape, texture, deformation behaviour and dissolution). The particle size influenced the flow properties and the deformation parameters but it had no influence on the dissolution rate of active agent.

\section{Zusammenfassung}

\begin{tabular}{|c|c|}
\hline $\begin{array}{l}\text { Herstellung von Theophyllin-Pellets } \\
\text { Ziel der Studie war es, die Fließeigen- } \\
\text { schaften von Theophyllin-Kristallen (CAS } \\
5967-84-0) \text { zu verbessern. Dazu wurden } \\
\text { Theophyllin-Kristalle mittels Feuchtgra- } \\
\text { nulation in einem Zentrifugalgranulator } \\
\text { pelletiert. Es wurden zwei Pellet-Chargen } \\
\text { mit unterschiedlicher Teilchengrößenver- } \\
\text { teilung hergestellt und verglichen. Alle }\end{array}$ & $\begin{array}{l}\text { Die Feuchtgranulation im Zentrifugal- } \\
\text { granulator hat sich als geeignet erwiesen, } \\
\text { um Pellets von guter Qualität in bezug } \\
\text { auf äußere Form, Beschaffenheit, Defor- } \\
\text { mationsverhalten und Freisetzungsprofil } \\
\text { zu erhalten. Es konnte gezeigt werden, } \\
\text { daß die Teilchengröße die Fließeigen- } \\
\text { schaften und das Deformationsverhalten } \\
\text { beeinflußt, die Freisetzungsrate hingegen } \\
\text { nicht beeinflußt wird. }\end{array}$ \\
\hline
\end{tabular}
Pellets wiesen eine annähernd runde Form und eine kompakte Beschaffenheit auf. Das Deformationsverhalten der Pellets wurde untersucht und die erhaltenen Kraft-Zeit-Kurven werden präsentiert.

\section{Introduction}

Theophylline (CAS 5967-84-0) is a bronchodilatator agent that is widely used effectively in the therapy of serious acute asthma attacks and status asthmaticus [1]. The dose must be individualized. The large variation in metabolic rate and the narrow therapeutic window require the monitoring of plasma concentrations for effective therapy [2]. Numerous preparations are available for therapy [3] and abundant publications are to be found concerning the preparations in the literature $[4-10]$.
Before tablet-making, preformulation tests must be performed. In these, a very important role is played by the powder rheological properties of the drug and additives.

Direct compression is a possibility in tablet-making. Powder mixtures intended for direct compression should possess adequate fluidity and compressibility. These may be influenced by the flow properties of the drug. From the aspect of direct tableting, testing of the flowing of drugs is also important. 
Flowability can be defined as the ease of flow of the overall powder mass $[11]_{+}$Numerous factors affect the flow properties of powders, e.g. particle shape, size, size distribution, roughness of surface of the particles, packing properties, etc. [12].

One possibility whereby the flowability of drugs may be influenced is granulation or pellet preparation. Thus, via the method of granulation, the shape, size and surface of particles (texture) can be changed and the flowability can be increased.

Pelletizing is a procedure of agglomeration in which small particles are transformed into larger spherical units with good flowability. A pellet is therefore an agglomerate with nearly spherical symmetry and usually a diameter of $0.5-1.5 \mathrm{~mm}$, though this can vary with the production technology [13-14]. As compared to classical granules, pellets not only differ in shape, but also have a more compact texture, resulting in better flow characteristics. In the interior of grains with higher porosity and a looser structure, bridges of solid particles form point-to-point bonds, resulting in a lower mechanical stability than that of pellets.

Pellets can be produced by technologies based on moving the solid component; compacting, melting and drop formation [15].

When the solid component is moved, the powder mixture is kept in motion while the granulating fluid is sprayed onto the surface of the particles. The particles aggregate and the fluid bridges are transformed into firm binding bridges by the concurrent drying. There are many forms of equipment for the production of pellets. In this study a-centrifugal granulator was used [16, 17]. In a centrifugal granulator, three forces (centrifugal, gravitation and fluidization) act upon the product from different directions. The combined action of the three forces generates a spiral material motion and a rapid turnover rate is responsible for the high efficiency of the centrifugal equipment. The granulating fluid is constantly sprayed onto the pelletizing powder. Thus the particles will stick one to another and the fluid bridges will be transformed to solid bonds by the concurrent drying. Finally, this process converts fine powders and excipients into small, free-flowing, spherical or semispherical units.

\section{Material and methods}

\subsection{Materials}

Theophylline (ICN Pharmaceuticals, Costa Mesa, USA), Vitacel $\mathrm{A} 300^{\text {(8) }}$ (Rertenmaier \& Söhne, Faserstoff-Werke, EllwangenHolzmühle, Germany), mannite (Merck, Budapest, Hungary), sucrose (Petöházi Cukorgyár, Petőháza, Hungary), corn starch (Roquette Italia, Cassano Spinole, Italy), Kollidone VA $64^{\text {a }}$ (BASF, Ludwigshafen, Germany) and colloidal silica dioxide, hydrous (Degussa, Frankfurt/Main, Germany) were used.

\subsection{Methods}

\subsubsection{Powder mixing}

Homogenization was performed with a Turbula mixer (Willi A Bachofen Maschinenfabrik, Basel, Switzerland) (10 min/50 rpm).
Table 1: Composition of the pellets.

\begin{tabular}{l|c|c|c}
\hline \multicolumn{1}{|c|}{ Components } & $\begin{array}{c}\text { Core } \\
\text { (g) }\end{array}$ & $\begin{array}{c}\text { Granularing } \\
\text { fluid } \\
\text { (g) }\end{array}$ & $\begin{array}{c}\text { Build-up } \\
\text { powder } \\
\text { (g) }\end{array}$ \\
\hline Theophylline & 200 & - & - \\
Mannite & 300 & - & - \\
Vitacel A 300 & 500 & - & - \\
Sucrose & - & 100 & 236.5 \\
Kollidone VA 64 & - & 20 & - \\
Colloidal silica & - & 300 & 27 \\
$\quad$ dioxide, hydrous & - & 780 & 236.5 \\
Corn starch & - & & - \\
\hline
\end{tabular}

\subsubsection{Pellet preparation}

Pelletization was performed with a centrifugal granulator (CF. 360 , Freund, Tokyo, Japan).

The parameters of the pelletization were as follows:

- inlet temperature: $40^{\circ} \mathrm{C}$

- outlet temperature: $35^{\circ} \mathrm{C}$

- spraying pressure: $1.2 \mathrm{~kg} / \mathrm{cm}^{2}$

- spray air flow rate: $121 / \mathrm{min}$

- rotor speed: $160 \mathrm{rpm}$

- slit air flow rate: $130 \mathrm{l} / \mathrm{min}$

- pump speed: $20 \mathrm{rpm}(20 \mathrm{ml} / \mathrm{min})$

- nozzle: $1.0 \mathrm{~mm}$ in diameter

- build-up powder: $20 \mathrm{~g} / \mathrm{min}$ (discontinuously)

- spray nozzle distance from bottom plate: $6 \mathrm{~cm}$

The composition is presented in Table 1. The pellets were separated by sieving in two fraction $(0.8-1,2 \mathrm{~mm}$ (Pellet 1$)$ and 1.2-2.0 mm (Pellet 2)).

\subsubsection{Morphological study}

A Hitachi S2400 (Hitachi Scientific Instruments, Tokyo, Japan) scanning electron microscope (SEM) was used. A polaron sputter coating apparatus (Polaron Equipment, Greenhill, UK) was applied to induce electric conductivity on the surface of the sample. The air pressure was $1.3-13 \mathrm{mPa}$.

\subsubsection{Particle size distribution}

A Laborlux S light microscope and a Quantimet 500 (Q500MC) image processing and analysis system (Leica Cambridge, Cambridge, UK) were used. Before the tests, the theophylline crystals were dispersed in glycerine because of the tendency to aggregation.

\subsubsection{Flow properties}

A Powder Testing System PTG-1 (Pharma Test Apparatebau, Hainburg, Germany) was used for the determination of mass by volume, flow time and angle of repose.

\subsubsection{Determination of rearrangement constant}

For the determinations, a tap density volumeter (Stampfvolumeter 2003, J. Engelsmann Apparatebau, Ludwigshafen, Germany) was used according to literature [11]. The rearrangement constants were calculated by means of a mathematical statistical method (Sigmaplot 2.0, Jandel Scientific, Chicago, USA). 


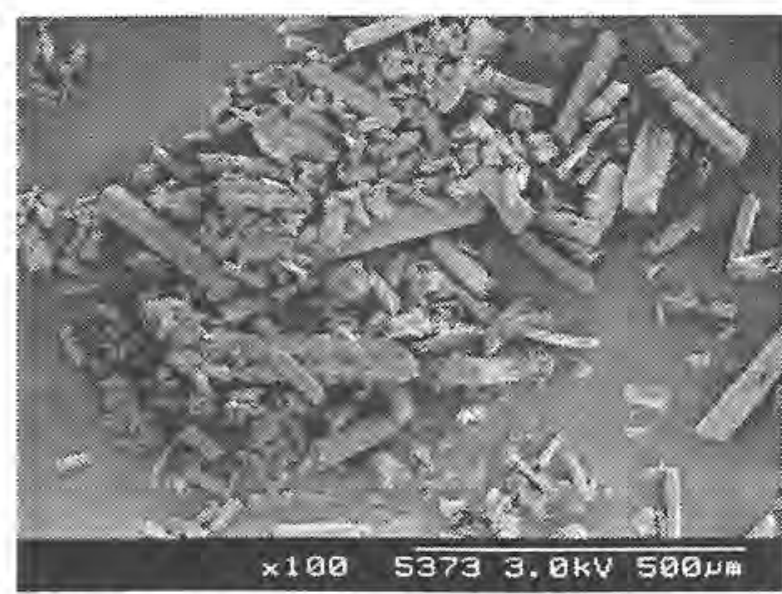

Fig. 1: Theophylline crystals (SEM).

\subsubsection{Water uptake}

The Enslin number $(\mathrm{ml} / \mathrm{g})$ was determined with a glass sieve and a pipette with $0.01 \mathrm{ml}$ accuracy [20].

\subsubsection{Breaking process of pellets}

A modified breaking hardness tester (Chinoin Chemical and Pharmaceutical Works, Budapest, Hungary) was used.

Technical parameters:

- range of measurement: $0-200 \mathrm{~N}$

- reading: $3^{1 / 2}$ digits

- rate of pressing jaw: $20 \mathrm{~mm} / \mathrm{min}$

- registering output: $0-500 \mathrm{mV}$

- sensor: Unicell load cell (MIKI) $20 \mathrm{~kg}$

- accuracy of equipment: $\pm 0.5 \pm 1$ digit

- operating voltage: $220 \mathrm{~V}$ at $50 \mathrm{~Hz}$

The electric signals emitted by the instrument were directed to the computer via an interface, The deformation curves could be analysed by means of appropriate software, yielding not only the hardness value, but also the work necessary for breaking.

\subsubsection{Dissolution of the active agent}

The rate of dissolution of theophylline was studied with a rotating basket method.

Test parameters:

- apparatus: Pharma Test PTWII (equipped with a rotating basket) (Pharma Test, Hainburg, Germany)

- basket speed: $50 \mathrm{rpm}$

- dissolution medium: $900 \mathrm{ml}$ artificial gastric juice $(\mathrm{pH}=1.2$ \pm 0.1 )

- temperature: $37 \pm 1{ }^{\circ} \mathrm{C}$

- samples taken at $5,10,20,30$ and $60 \mathrm{~min}$

- number of samples: 6

- mass of sample: $0.90 \mathrm{~g}$

- measurement: with a UV spectrophotometer at $268 \mathrm{~nm}$ (Spectromom 195D, MOM, Budapest, Hungary)

- computerized data processing: Lotus 123

\section{Results}

The habit of the crystals is shown in the SEM photo (Fig. 1). Microscopy, and especially scanning electron microscopy (SEM), has been widely used to test the shape and surface of particles. Modern SEM allows par-

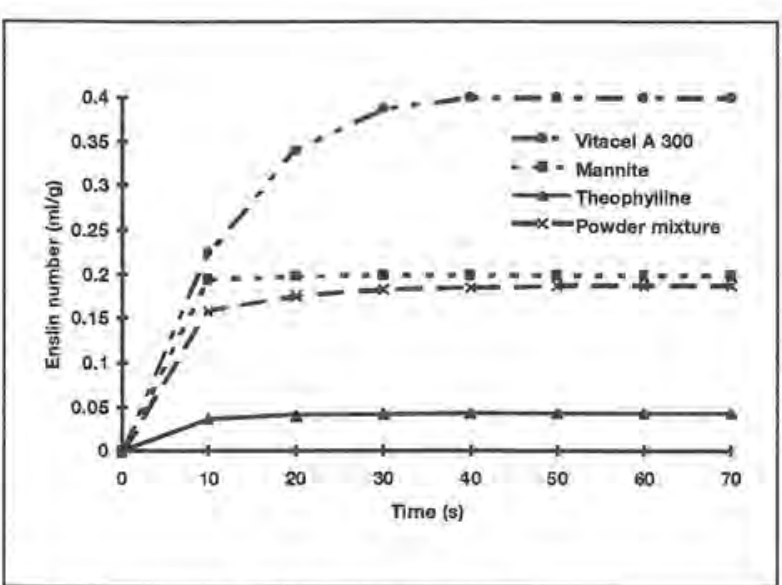

Fig. 2: Water uptake of the components.

ticles much smaller in size than a micrometer to be measured and the roughness of the surface to be observed.

Fig. 1 demonstrates, that theophylline consists of needle crystals with no circularity and it is heterodisperse. The data in Table 1 reveal that the average size of the crystals is about $75 \times 25 \mu \mathrm{m}$, but there is a rather large difference between the max. and min. values (length: max. $516 \mu \mathrm{m}$; min. $4.7 \mu \mathrm{m}$; breadth: max. 188 $\mu \mathrm{m}$; min. $1.17 \mu \mathrm{m})$. In accordance with the roundness value (Table 2), this crystal shape results in unsuitable flow properties. Roundness is a shape factor and its calculation is reported in an other paper [19]. It can also be seen that the cohesion between the crystals is too high.

In wet granulation, good moisture uptake of the powder mixture is crucial as this determines the uptake of a sufficient amount of fluid and thereby the appropriate mass consistence and the formation of binding forces.

As indicated by the Enslin number, the wetting of the agent is low. It is better for mannitol and the best for Vitacel A 300. The Enslin number of the mixture of these three components is far better than that of the agent (Fig. 2), and hence it is suitable for pelletization.

It can be seen from the data (Table 3 ) that the flow properties of theophylline are very poor. The reason lies in the morphology and particle size distribution of the drug. The results of regression analysis revealed (Table 4) that an exponential regression represents the relationship of the rearrangement [20]. The findings suggest that the direct compression of theophylline is not possible. Wet granulation (conventional or pelletization) is very important before compression.

The pellets produced are of compact texture and are nearly spherical, as demonstrated by the SEM photo in

Table 2: Particle size of theophylline crystals.

\begin{tabular}{l|c|c|c|c}
\hline & $\begin{array}{c}\text { Area } \\
\left(\mathrm{mm}^{2}\right)\end{array}$ & $\begin{array}{c}\text { Length } \\
(\mu \mathrm{m})\end{array}$ & $\begin{array}{c}\text { Breadth } \\
(\mu \mathrm{m})\end{array}$ & Roundness \\
\hline Average & 2194.5 & 75.08 & 24.88 & 2.034 \\
SD & 5047.4 & 85.60 & 23.90 & 0.744 \\
Max. & 48703.1 & 516.47 & 188.23 & 6.273 \\
Min. & 13.84 & 4.706 & 1.176 & 1.128 \\
\hline
\end{tabular}


Table 3: Flowability and compactibility parameters.

\begin{tabular}{|c|c|c|c|c|c|c|c|}
\hline Sample & $\begin{array}{l}\text { Mass by } \\
\text { volume } \\
\text { (g/100 mi) }\end{array}$ & $\begin{array}{l}\text { Flow time } \\
\text { (s) }\end{array}$ & $\begin{array}{c}\text { Angle of } \\
\text { repose } \\
\text { (0) }\end{array}$ & $\begin{array}{c}{ }^{\beta_{1}} \\
\text { (loose density) } \\
\left(\mathrm{g} / \mathrm{cm}^{3}\right)\end{array}$ & $\begin{array}{c}\rho_{\mathrm{F}} \\
\text { (tapped density) } \\
\left(\mathrm{g} / \mathrm{cm}^{3}\right)\end{array}$ & $\begin{array}{l}\text { Hausner } \\
\text { factor }\end{array}$ & $\begin{array}{l}\text { Carr's index } \\
\text { (\%) }\end{array}$ \\
\hline $\begin{array}{l}\text { Theophylline } \\
\text { Pellet } 1 \\
\text { (0.8-1.2 mm) } \\
\text { Pellet } 2 \\
(1.2-2.0 \mathrm{~mm})\end{array}$ & $\begin{array}{l}37 \\
71 \\
55\end{array}$ & $\begin{array}{r}-a) \\
8 \\
12\end{array}$ & $\begin{array}{l}55.01 \\
35.54 \\
38.66\end{array}$ & $\begin{array}{l}0.415 \\
0.701 \\
0.612\end{array}$ & $\begin{array}{l}0.587 \\
0.742 \\
0.637\end{array}$ & $\begin{array}{l}1.42 \\
1.06 \\
1.04\end{array}$ & $\begin{array}{r}29.34 \\
5.99\end{array}$ \\
\hline
\end{tabular}

Fig. 3. The flowability parameters are to be seen in Table 3. Increases may be observed in the loose and tapped volumes, and decreases in the other parameters at the both fraction of pellet (comparing with the bulk crystals). This means improvements in the flowability of the drug. The values of the Hausner factor and Carr's index are excellent. The data reveal that the particle size of the pellet influences these parameters.

Regression analysis pointed to an exponential model for the rearrangement of the pellets, but this relationship is not so strong as that for the bulk crystals (Table 4). The reason lies in the spontaneous arrangement of the pellet particles in space. The flowability and the filling of the pellets are very good, the arrangement in space being faultless because of the spherical shape of the pellet particles. This means that tablet compression may be possible from these pellets.

During compression, not only the good flow properties of the pellets are important, but also the good deformability and, in spite of this, the good mechanical hardness.

For the mechanical hardness testing of pellets, the friability test is described in the Pharmacopoeias. However, this result gives the abrasive resistance of a heap of pellets and it can not reflect the resistance of an individual pellet. Some papers relating to different forms of modified apparatus are to be found in the literature regarding this matter [21-23].

Table 4: Data of regression analysis.

\begin{tabular}{l|c|c|c}
\hline \multirow{2}{*}{ Sample } & \multicolumn{3}{|c}{ Exponential model } \\
\cline { 2 - 4 } & $\begin{array}{c}\mathrm{R}=\exp (1+\mathrm{kn}) \\
(\mathrm{p}<0.05)\end{array}$ & $\mathrm{k}$ & F-ratio \\
\hline $\begin{array}{l}\text { Theophylline } \\
\text { Pellet 1 }\end{array}$ & 0.973 & 0.0961 & 402.96 \\
$\begin{array}{c}(0.8-1.2 \mathrm{~mm}) \\
\text { Pellet 2 } \\
(1.2-2.0 \mathrm{~mm})\end{array}$ & 0.924 & 0.0829 & 72.99 \\
\hline
\end{tabular}

$\mathrm{k}=$ rearrangement constant.

Table 5: Deformation parameters of pellets.

\begin{tabular}{c|c|c|c|c|c|c}
\hline \multirow{2}{*}{ Size } & \multicolumn{2}{|c|}{ Force } & \multicolumn{2}{c|}{ Work } & \multicolumn{2}{c}{ Time } \\
\cline { 2 - 7 } & $(\mathrm{N})$ & $\mathrm{S}_{\text {rei }}$ & $(\mathrm{mI})$ & S $_{\text {ret }}$ & $(\mathrm{ms})$ & $\mathrm{s}_{\text {ret }}$ \\
\hline $0.8-1.2 \mathrm{~mm}$ & 0.712 & 3.83 & 0.038 & 13.07 & 2800 & 11.00 \\
$1.2-2.0 \mathrm{~mm}$ & 0.590 & 2.07 & 0.035 & 11.26 & 267 & 10.28 \\
\hline
\end{tabular}

In the present work the hardness of the pellets was studied with the above-mentioned breaking hardness tester. Fig. 4 depicts the pellet deformation behaviour. The initial linear section of the force-time curve (2) displays elastic deformation and then initially plastic, and later plastoelastic deformation. This demonstrates the deformation point ( $=$ the hardness), when the velocity of force changing $(\mathrm{N} / \mathrm{s})$ is zero or less than zero (negative value). The software presents the deformation work computed from the onset of loading to the completion of deformation. The slope of the linear section, the limiting hardness and the deformation work are characteristic properties of a pellet. The relative standard deviation of the hardness is within a range of $5 \%$, whilst that of the deformation work is $15-20 \%$ (Table 5 ). (The mean values were calculated from 20 measured values.) It can be seen, furthermore, that the particle size has an influence on the deformation parameters. It is very interesting that the deformation (breaking) force value of the larger pellet particles is smaller, and the difference is significant (two-sample analysis, $\mathrm{p}<0.05 ; \mathrm{r}=$ $0.9985)$. The reason is that the larger particles consists of smaller pellet particles, and in the early stages of loading the larger particles break down into these smaller particles.

Fig. 5 demonstrates the profile of theophylline dissolution from the pellets. It can be seen that $35 \%$ of the drug was released in the first $5 \mathrm{~min}$. From the 5 th minute on, the dissolution curve declined. The dissolution rate became lower and equal. The amount of agent liberated in $1 \mathrm{~h}$ was independent on the particle size.

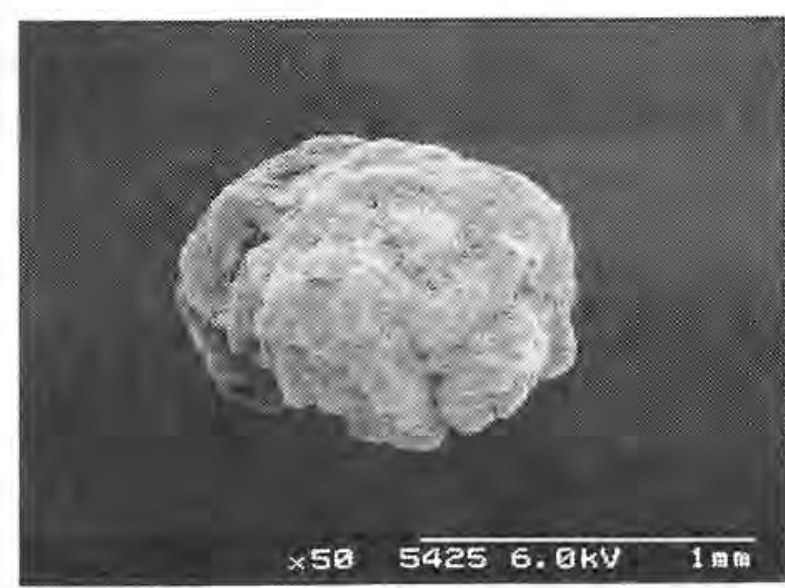

Fig. 3: Theophylline pellet (SEM). 


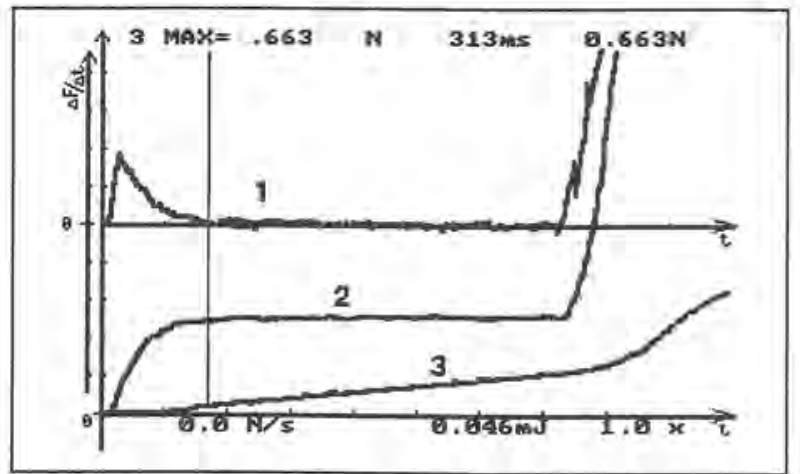

Fig. 4: Deformation process of uncoated pellet. 1: Differential curve, 2: force-time curve, 3 : integral curve.

\section{Discussion}

From the results of this work, it can be concluded that the habit of theophylline crystals indicates unsuitable flowability parameters and wet granulation is necessitated. Use of a centrifugal granulator with the applied parameters resulted in theophylline pellets with spherical shape and compact texture. The drug release into artificial gastric juice was complete in $1 \mathrm{~h}$. The modified breaking hardness equipment can be used very well for investigation of the deformation behaviour of pellets. The particle size influenced the flow properties and deformation parameters, but it had no influence on the dissolution rate of theophylline. These pelletes are suitable for tableting or for coating to prepare a sustained released dosage form.

\section{References}

[1] Mutschler, E., Derendorf, H., Drug Actions - Basic Principles and Therapeutical Aspects, p. 408. Medpharm Scientific Publishers, Stuttgart (1995)

[2] Roschlau, W. H. E., Principles of Medical Pharmacology. 4th ed., p. 454. Oxford University Press, New York (1985)

[3] Parfitt, K., Martindale, the complete drug reference, 32nd ed., p. 765. Pharmaceutical Press, London (1999)

[4] ElSayed, G., ElSaid, Y., Meshali, M, et al., Comparative bioavailability of theophylline from tablets with different sustained release kinetics, STP Pharma Sci. 6, 398 (1996)

[5] Villegas, S., Herrero-Vanrell, R., Barcia, E. et al., Kinetics and structural modification of a commercial theophylline product after storage, STP Pharma Sci. 8, 365 (1998)

[6] Fuchs, W. S., Weiss, G., Von-Nieciecki, A. et al., Pharmacokinetic characteristics of a new liquid sustained-release formulation of theophylline designed for the elderly and children: microcaps as sachet, Int. J. Clin. Pharmacol. Ther. 34, 558 (1996)

[7] Zhang, F., McGinity, W., Properties of hot-melt extruded theophylline tablets containing poly(vinyl acetate), Drug. Dev. Ind. Pharm. 26, 931 (2000)

[8] Nikolic, L., Djuric, Z., Jovanovic, Z., Influence of in vitro test conditions on release of aspirin from commercial tablets. J. Pharm. Sci. 81, 386 (1992)

[9.] Antal, I., Zelkó, R., Röczey, N. et al, Dissolution and diffuse reflectance characteristics of coated theophylline particles Int. J. Pharm. 155, 83-89 (1997)

[10] Guirgis, H., Broegman, B., Sakr, A., Hot melt granulation, 1st communication: Effect of channeling agents, Part I: Granule characteristic, Pharm. Ind. 63, 395 (2001)

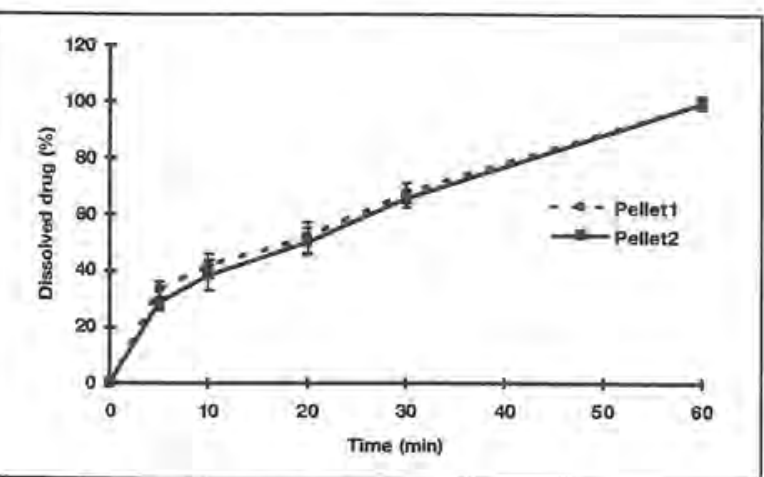

Fig. 5: Theophylline dissolution from the pellets.

[11] Carstensen, J. T., Solid Pharmaceutics: Properties and rate Phenomena, pp. 184, 188-190. Academic Press, New York-London (1980)

[12] Wray, P. E., Physics of tablet compaction revisited, Drug Dev. Ind. Pharm. 18, 627 (1992)

[13] Ghebre-Sellassie, 1., Pharmaceutical pelletization technology, pp. 1-15. Warner-Lambert Morris Plains, New Jersey (1989)

[14] Junnila, R., Heinämäki, J., Yliruusi, I, Effects of surface-active agent on the size, shape and hardness of microcrystalline cellulose/maize starch pellets prepared by an extrusion-spheronization technique, STP Pharma Sci. 8, 221 (1998)

[15] Guirgis, H., Broegman, B., Sakr, A., Hot melt granulation, 1st communication: Effect of channeling agents, Part II: Tablet characterisation, Pharm. Ind. 63, 297 (2001)

[16] Ar Rashid, H., Heinämäki, J., Antikainen, O. et al., Effects of process variables on the size, shape, and surface characteristics of microcrystalline cellulose beads prepared in a centrifugal granulator, Drug Dev. Ind. Pharm. 25, 605 (1999)

[17] Ar Rashid, H., Heinämäkd, J., Yliruusi, I., Evaluation of four microcrystalline cellulose grades for preparing spherical beads in a centrifugal granulating process, STP Pharma Sci. 8, 163 (1998)

[18] Zessin, G., Kala, H., The determination of the Enslin number, Pharmazie 39, 327 (1984)

[19] Deák, D.,Pintye-Hódi, K, Szabó-Révész, P et al., Use of different cellulose derivatives for the preparation of tablets with a high active agent content, STP Pharma Sci. 9, 525 (1999)

[20] Takieddin, M., Puisieux, F, Didry, J. R. et al., 1st Int. Conf. Powder Technology, Paris, Abstracts, Vol. 1., 1977, p. 248

[21] Pintye-Hódi, $K$, Szabó-Révész, $P_{n}$, Kása, $P$ jr. et al., Postcompressional studies of Vivacel ${ }^{\text {क }}$ comprimates, Boll, Chim, Farmaceutico 135, 170 (1996)

[22] Salako, M., Podczek, E, Newton, J. M., Investigations into the deformability and tensile strength of pellet, Int. J. Pharm. 168, 49 (1998)

[23] Nürnberg, E., Wunderlich, J., Manufacturing pellets by extrusion and spheronization (Part 1), Pharm. Technol, Eur. 11, 41 (1999)

\section{Acknowledgement}

This work was supported by Hungarian Scientific Research Fund (OTKA) T-026351 grant

\section{Correspondence:}

Dr. Klára Pintye-Hódi, Associate Professor,

Department of Pharmaceutical Technology,

University of Szeged,

Eötvös str. 6, 6720 Szeged (Hungary)

e-mail: hodi@pharma.szote.u-szeged.hu 